\title{
Trends in the Food and Sports Nutrition Industry: A Review
}

\begin{tabular}{|c|c|}
\hline Journal: & Comprehensive Reviews in Food Science and Food Safety \\
\hline Manuscript ID & CRF3-2018-0304 \\
\hline Manuscript Type: & Comprehensive Review \\
\hline $\begin{array}{r}\text { Date Submitted by the } \\
\text { Author: }\end{array}$ & 20-Dec-2018 \\
\hline Complete List of Authors: & $\begin{array}{l}\text { Arenas-Jal, Marta; University of Barcelona, Faculty of Pharmacy and } \\
\text { Food Sciences (Pharmacy and Pharmaceutical Technology Department) } \\
\text { Suñé-Negre, J.M.; University of Barcelona, Faculty of Pharmacy and Food } \\
\text { Sciences (Pharmacy and Pharmaceutical Technology Department) } \\
\text { Pérez-Lozano, Pilar; University of Barcelona, Faculty of Pharmacy and } \\
\text { Food Sciences (Pharmacy and Pharmaceutical Technology Department) } \\
\text { García-Montoya, Encarna; University of Barcelona, Faculty of Pharmacy } \\
\text { and Food Sciences (Pharmacy and Pharmaceutical Technology } \\
\text { Department) }\end{array}$ \\
\hline Keywords: & food trends, food industry, nutrition, sports nutrition, consumer \\
\hline
\end{tabular}




\section{Trends in the Food and Sports Nutrition Industry: A Review}

Names of authors: Marta Arenas-Jal; J.M. Suñé-Negre; Pilar Pérez-Lozano; Encarna García-Montoya.

Contact information for corresponding author:

Marta Arenas-Jal

University of Barcelona - Faculty of Pharmacy and Food Sciences (Pharmacy and Pharmaceutical

Technology Department), Joan XXIII, 27-31, 08028 Barcelona (Spain).

marta.arenas.jal@gmail.com.

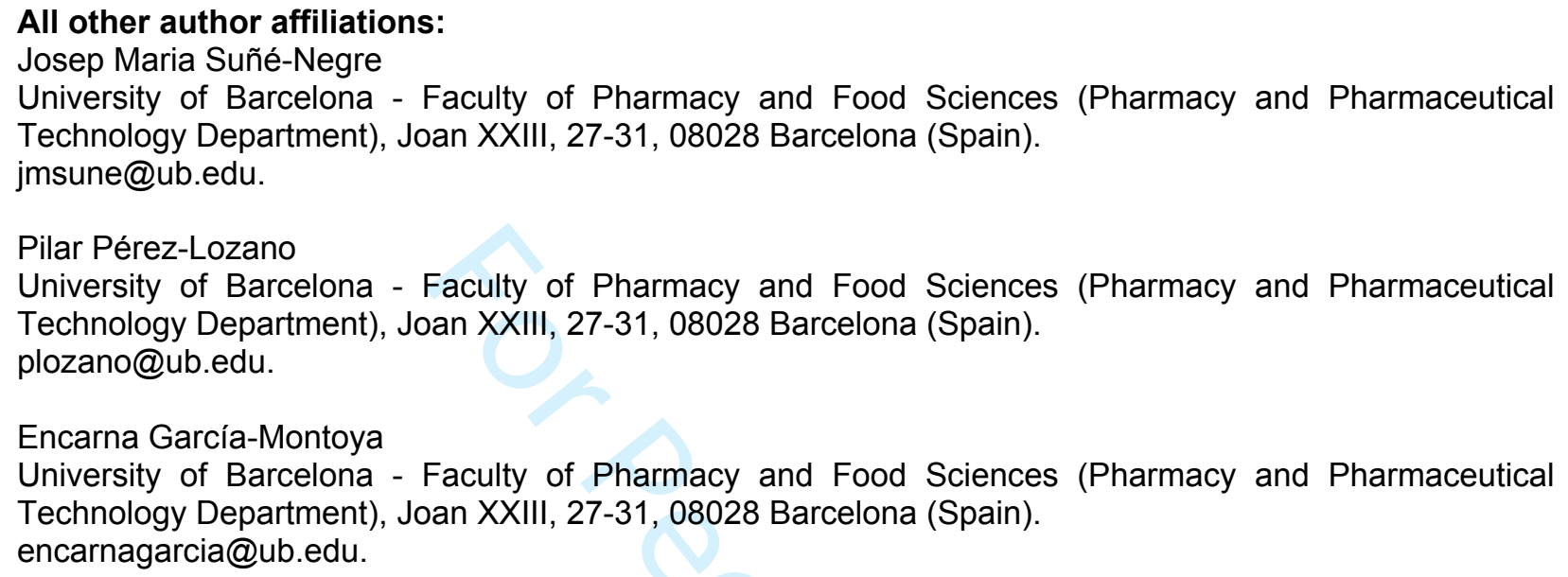

Word count of text: 11,442 words

Short version of title: Food and Sports Nutrition Trends

Choice of journal: Comprehensive Reviews in Food Science and Food Safety

\section{Author disclosures}

M. Arenas-Jal works as R\&D manager for Vitae Natural Nutrition, S.L (Industrial Doctorate). 
ABSTRACT: This revision intends to provide an overview on the major and emerging trends in food and nutrition. Food scientists and dietitians should keep an eye on the trends shaping the food industry in order to understand consumer changes in preferences, expectations and dietary patterns; and to identify those areas that should be added to the research agenda. In addition, to comprehend the major drivers of change in the food industry, global consumer trends are also reviewed in this article. Global concerns are shaping consumer attitudes, and with an easier access to information and an unprecedented consumer power through social media, the food industry should quickly adapt to meet consumer needs. In order to meet these objectives, this review is organized in three different but interrelated sections: global consumer trends, food and nutrition trends, and trends in sports foods and nutrition. This last one is also included due to its influence over food trends, and its significant relevance as a category and food trend.

Keywords: food trends, food industry, nutrition, sports nutrition, consumer.

\section{Table of contents:}

Abstract

Introduction

\section{Global consumer trends}

Clean-living and activist consumers

Personalization, a trend across all industries

Informed and connected consumers are shaping changes

Global consumer trends in brief

Food and nutrition trends

Older population growth - increased focus on health care

Connected consumers, informed decisions: going greener and healthier

- Vegetarian and vegan diets on the rise

- Organic food growth

- "Free-from" and digestive wellness

- Naturally healthy vs. fortified and functional food

Clean label, no longer a trend but the new norm

Protein is king, fat is back, and what about carbohydrates?

Beverages, snacks and indulgence foods redefined

Activist consumers against food waste

Personalization, a global trend impacting nutrition

Internet of Things shaping interaction with food

Sports nutrition is rocketing

Nutrition trends in brief

Trends in sports foods and nutrition

Sports nutrition, not just a recent trend

Sports nutrition market analysis

Sports nutrition is becoming mainstream

Proteins will not abdicate - and continue leading

- Whey protein - a sales king that is being challenged 
- Rising demand for plant-based proteins

79

- Hydrolysates are the next big thing - life is too short for slow proteins

80 What about non-protein products?

81 An overview of sports nutrition products' global sales

82 Other trends to look out for in $\mathbf{2 0 2 0}$

83 Innovation is driving the market - microencapsulation as an example

84 Considerations on regulation

85 - US regulation

$86-$ EU regulation

87 - Worldwide anti-doping regulation

$88 \quad$ Sports nutrition trends in brief

89 Conclusion

$90 \quad$ Acknowledgments

91 Author contributions

92 Abbreviations

$93 \quad$ References 


\section{Introduction}

The development of new food products is influenced by numerous factors, but among them, global dynamics stand out. Demographics, socioeconomics, culture, politics and environment have a great impact on consumer lifestyles and dietary patterns. In fact, global issues such as climate change, global population aging, child exploitation, food waste, unfair trade or animal abuse, among others, are shaping consumer attitudes towards healthy, plant-based, sustainable and socially conscious food purchases (The Nielsen Company, 2018a). It has to be noted that, thanks to the irruption of new technologies, consumers not only have an easier access to information, but also an unprecedented power to lobby for change (Euromonitor International's Head of Lifestyles Research, 2017).

In this context, and in order to adapt formulas and technologies to consumer needs, food scientists should keep an eye on the major and emerging trends shaping the food industry. Understanding consumer changes in preferences and expectations is vital when developing new products (PriceWaterhouseCoopers [PwC], 2013). Moreover, global dynamics have an influence on nutrition trends, thereby impacting dietary patterns and being potentially disruptive for the correct balancing of the diet. For this reason, not only food scientists, but also dietitians should be aware of the emerging trends that will influence food and nutrition in the coming decades.

The aim of this review is to provide an overview of the current food trends, identifying the areas that are more prone to development, and thus, that should be added to the research agenda. In addition, due to its influence over food trends, and its relevance as a category and food trend, sports foods and nutrition are also reviewed in detail (European Specialist Sports Nutrition Alliance [ESSNA], 2018), (Euromonitor, 2015b). Global consumer trends are also addressed in this review in order to understand the major drivers of change in the food industry. Finally, this review is organized in three different but interrelated sections: global consumer trends, food and nutrition trends, and trends in sports foods and nutrition. 


\section{Global Consumer Trends}

121 In 2018, with a stronger global economy, consumer expenditure is expected to grow as its strongest rate 122 since 2011 (Euromonitor International's Head of Lifestyles Research, 2017). However, shifting consumer 123 attitudes will continue shaping changes in business.

Clean-living and activist consumers

Consumers are becoming activists due to an increased awareness of global issues through Internet and social media; which at the same time give consumers an unprecedented power to lobby for change (Labrecque, vor dem Esche, Mathwick, \& Novak, 2013). Consumer opinions are far-reaching, and they feel that their spending choices can make a difference (Labrecque et al., 2013). Concerns about climate change and health are widespread among consumers, especially the younger who are adopting a clean-living

131 lifestyle. Clean lifers have strong beliefs and ideals, and they are embracing a minimalist, balanced and

132 healthier lifestyle to reduce harm to themselves, others and the environment (Euromonitor International's

133 Head of Lifestyles Research, 2017). Furthermore, they are demanding companies a greater transparency, sustainability and social responsibility (Kearney, 2010), (Kang \& Hustvedt, 2014).

\section{Personalization, a trend across all industries}

137 Besides going greener, consumers are seeking uniqueness, demanding to be involved in the production process and product personalization (Wind \& Rangaswamy, 2001). Although customization is demanded in all industries, from sneakers and furniture, to services and experiences; there is a rising interest in personalized health and beauty (Euromonitor International's Head of Lifestyles Research, 2017). Genetic

141 findings related to health, fitness and nutrition, as well as a rising interest in health, and a growing consumer curiosity about their genetics, are fueling demand for DNA testing (Subbiah, 2007), (Ferguson, 2013).

$\underline{\text { Informed and connected consumers are shaping changes }}$ are nowadays vital for everything, including shopping, sharing experiences, or health and sport tracking among others (Deloitte, 2013). Health technologies, including wearables and fitness apps, have made 
148

149

150

151

152

153

154

155

156

157

158

159

160

161

162

163

164

165

166

167

168

169

170

171

172

173

174

175

people more aware of their state of health, powering the growth of health and wellness market (L. G. Euromonitor International's Consumer Health Analyst, 2016). In fact, people tend to exercise more, with gym memberships in the United States of America (US) increasing by more than $20 \%$ for the period comprised between 2011 and 2016 (Business Development Bank of Canada [BDC], 2016).

Thanks to new technologies, consumers are more informed about their choices and reject unmeasured or uninformed spending. Ownership is under question and sharing is gaining popularity (Hamari, Sjöklint, \& Ukkonen, 2016). A new wave of apps aims to provide consumers with the opportunity to share everything, from cars to living spaces (The Economist, 2013). Consumers prefer spending their money on experiences like travels, festivals and restaurants, rather than on products (Euromonitor International's Head of Lifestyles Research, 2017). Buying time, such as adopting online shopping and ordering food for delivery, is also a trend on the rise (L. G. Euromonitor International's Consumer Health Analyst, 2016). For this reason, an increased growth rate in apps and mobile optimized websites is forecasted.

\section{Global consumer trends in brief}

Thanks to the irruption of new technologies, consumers' opinion is more powerful than it has ever been. For this reason, concerns about climate change, health and social responsibility, which are widespread among consumers, may shape changes in business. Other important trends are personalization and shared economy; as well as seeking for experiences or saving time rather than buying products. Finally, millennials will lead the mobile-driven market transformation, as they expect to do everything by using their mobile phone.

\section{Food and Nutrition Trends}

Global trends have the power to transform and disrupt entire categories, such as nutrition. One of the aforementioned global trends, clean/healthy living, stands out as the most relevant trend impacting the food industry. Connected and informed consumers are going back to nature and unprocessed foods, to preserve most of the natural vitamins and minerals. For this reason, there's a growth in plant-based, organic, naturally healthy and "free-from" foods. Clean label is also a trend on the rise, and while healthy snacks and fats are 
176

177

178

179

180

181

182

183

184

185

186

187

188

189

190

191

192

193

194

195

196

197

198

199

200

201

202

203

.

coming back, sugar and certain carbohydrates are becoming the main enemies. Protein, instead, is the preferred food component. Other trends such as personalization, redefinition of indulgence foods, activist consumers, and Internet of Things (IoT), are shaping changes in consumer behaviors and therefore, in the food industry. However, the most relevant nutrition trend is the rise of sports nutrition category.

Older population growth - increased focus on health care

As both the proportion of older people and the average life expectancy increase throughout the world, the older population is growing dramatically worldwide; and therefore, the incidence of chronic diseases (Global Burden of Disease Study 2013 collaborators, 2015). In fact, in about five years' time, the number of people aged 65 or older, will outnumber children under age 5 ; representing a forecasted $16 \%$ of world's population by 2050 (World Health Organization [WHO], 2015b). Population aging is placing pressure on overall health care spending in developed countries, and for this reason, governments are interested in promoting healthy habits to reduce morbidity and cut off its associated health-care costs. In this spirit, the World Health Organization (WHO) released "Active ageing: a policy framework" in 2002 to prevent and delay chronic diseases and premature mortality, as well as their risk factors (WHO, 2015a).

In line with WHO's health action plan, and thanks to consumer connectivity and access to information, there is an increased attention on health care (Kearney, 2010). For this reason, by 2020, a double-digit growth has been predicted for health and wellness market in the US. In addition, an increasingly number of consumers are seeing food as a medicine, and as a consequence, dietary supplements and sports nutrition stand out as one of the fastest growing healthcare categories, with an expected growth of $14 \%$ over the next few years in the US (BDC, 2016).

Connected consumers, informed decisions: going greener and healthier

With an easier access to information, consumers are becoming more aware than ever of ingredients in their food and their properties. In order to make informed decisions, consumers seek transparency throughout the production process to understand what is in their food and how it was produced (Bjørndal, FernandezPolanco, Lappo, \& Lem, 2013), (Kang \& Hustvedt, 2014). Clean lifers are turning their backs on unhealthy 
habits, food waste and animal-based products. They want to feel good about their consumption choices by eating healthily, sustainably and ethically (Radnitz, Beezhold, \& DiMatteo, 2015). Nowadays, eating often carries an ideological charge similar to belonging to a political party or football club (Euromonitor, 2015a). In fact, in $2018,67 \%$ of US consumers said that they will be prioritizing healthy or socially conscious food purchases (The Nielsen Company, 2018a). Even fast food is getting greener, and there is a decrease in reliance on animal-based nutrition. The vegetarian and vegan movement are already in full-swing, and on the next years we will see a further push to eradicate or reduce animal-based products (Hancox, 2018), (Radnitz et al., 2015).

\section{- Vegetarian and vegan diets on the rise}

The proportion of individuals choosing to follow a vegan diet has increased in the recent years, with ethics and health being the main reason for such choice (Radnitz et al., 2015). As a result of consumer interest, vegan sales growth is outpacing total food and beverage sales (The Nielsen Company, 2018b). When it comes to health benefits of vegetarian eating, current scientific evidence reinforces benefits of a plantbased diet that is low in fat, added sugars, added salt, and processed foods. A healthy and well-planned vegan diet, with a high content of fruits, vegetables and wholes grains, can provide sufficient energy and an appropriate range of carbohydrate, fat and protein intakes to support performance and health (Venderley \& Campbell, 2006). In fact, many top athletes, including world champions like Venus Williams and Lewis Hamilton, are vegan, thereby contributing to a vegan consumer base expansion (Edsor, 2017).

In line with this growing consumer interest, global market for vegetarian and vegan products was worth US $\$ 51$ bn in 2016 , but it is still expanding, with a $987 \%$ increase in demand for vegetarian products (The Vegan Society, 2018). In the same year, a $3 \%$ of the US population ate a strictly vegetarian diet, and about half of those were vegan. But the biggest revelation was that $36 \%$ of consumers opted for at least some vegetarian meal on a regular basis (Vegetarian Resource Group, 2016). In the United Kingdom (UK), the number of vegans quadrupled in the years between 2014 and 2018, reaching a 1,16\% of the population (The Vegan Society, 2018). Indeed, as shown in Figure 1, vegan trend tripled in the years between 2012 and 2018 (Google Trends, 2018). In line with this rapidly growing consumer demand for vegetarian and 
232

233 234

235

vegan products, big companies such as Danone, McDonald's or Ben\&Jerry's have invested in vegan alternatives to their products (The Vegan Society, 2018).

To sum up, consumers are keener on more plant-based, natural, minimally processed, local and seasonal food. According to Euromonitor International Global consumer trends survey 2017, "all natural" is the preferred food attribute, followed by "no artificial sweeteners", "limited or no added sugar" and "does not contain Genetically Modified Organisms (GMO) ingredients". In line with these findings, the following categories are on the rise (Euromonitor, 2017a).

\section{- Organic food growth}

Consumers are moving towards products perceived as more natural and healthier, resulting in a global demand for organic products (Asioli et al., 2017). Global sales of organic food and drink expanded by about $10 \%$ to US $\$ 81,6 \mathrm{bn}$ in 2015 . The highest growth was observed in North America, which has the largest market for organic food and drink in the world. Valued at US\$43,4bn and accounting for over half of international sales, it is followed by the European market, which is valued at US\$31,1bn in 2015 . Asia, Australasia and other regions, account for just US\$7,2bn in 2015. Despite having had an enormous growth, from US $\$ 18$ to $82 \mathrm{bn}$ over 15 years, organic food drink and sales growth is expected to continue (Sahota, 2012), (FIBL and IFOAM, 2017). In fact, by 2019, 30\% growth is forecasted for organic beverages in Canada (BDC, 2016).

When it comes to the organic packaged food and beverages, in 2016 they had a global retail value RSP of US\$32,153mn and US\$3,972.7mn, respectively (Euromonitor, 2015a). And in 2018, in Latin America, organic and "free-from" packaged food, are worth US\$35bn and US\$36bn; and will have annual growth rates of about $6 \%$ and $3,5 \%$, respectively, thereby standing out as one of the food categories with a global strongest growth (Daniells, 2018). 


\section{7}

In the same year, global free-from foods were valued at US\$33bn, and have consolidated as the category with the most dynamic growth in the health and wellness market (Euromonitor, 2017b). Consumers perceive "free-from" offering as healthier, and they associate it to digestive wellness and gut health. For this reason, free-from trend has gone beyond intolerance and allergies, as consumers increasingly focus on foods that may help them to reduce feelings of gas, bloating or more severe gastrointestinal symptoms related to suspected allergies or intolerances (Mintel, 2016), (Kerry Health And Nutrition Institute [KHNI], 2018). As a consequence, "free-from" products, as well as added-benefit ingredients such as probiotics and prebiotics are on the rise. When it comes to the largest subcategory, free-from dairy is leading, due to an increased demand for dairy milk alternatives. It is followed by free-from gluten, which had the largest absolute growth over the period between 2012 and 2017 (Euromonitor, 2017b). In fact, in 2015, 12\% of new food products launched in the UK carried a gluten-free claim (Mintel, 2016). Functional foods are those containing added biologically active ingredients that may improve health or lower the risk of disease. Besides supplying macronutrients, vitamins and minerals, they may include other active ingredients like antioxidants, prebiotics, probiotics, enzymes and/or phytonutrients to deliver a specific health benefit above their basic nutritional value (Bigliardi \& Galati, 2013).

Functional food term encompasses a wide variety of products, like those enriched or fortified. Enrichment involves replacing those nutrients lost during processing. An example is bread, often enriched with iron and 
folic acid, which are removed during milling of wheat to make flour (WHO, 2018), (Overview of Food Fortification, 2003). Fortification, instead, involves adding nutrients irrespective of whether they were originally present to any great extent in the food. Fortification is mostly used to improve nutritional status of a population or to differentiate products providing a competitive advantage. For example, bread may be fortified with omega-3 fatty acids (Gökmen et al., 2011). Nutrients are also usually added to substitute products in order to achieve a similar nutritive value to that in the original product. An example is the addition of calcium to soya-based drinks, which are sold as cow's milk substitute, in an amount equal to milk's natural content (Yazici, Alvarez, Mangino, \& Hansen, 1997).

On the other hand, naturally healthy products are those that naturally contain active ingredients. An example is oatmeal, which contains a soluble fiber that can help lower cholesterol levels and heart disease risk (Othman, Moghadasian, \& Jones, 2011), (Bernstein et al., 2013). In line with the clean-living trend, more consumers like the idea of whole plant-based foods with intrinsic nutritional value, and thus, without the need for fortification. This is leading to a decrease in demand for functional foods. In fact, naturally healthy, valued at US $\$ 253 \mathrm{bn}$, has already outpaced global fortified and functional food and beverage market, which is valued at US\$247bn (M. M. Euromonitor International's Consumer Health Analyst, 2018). Despite functional food category growth slowing down, this category is still expanding and important, especially in emerging markets, where consumers are seeking functional ingredients linked to a health positioning (Kearney, 2010).

\section{Clean label, no longer a trend but the new norm}

"Clean label" concept doesn't have any commonly accepted definition, and it is more based on consumer perception rather than on scientific evidence. Clean label products are those made with ingredients that consumers recognize and trust, and that do not contain undesirable ingredients (Asioli et al., 2017), (Bizozzero, 2017). Clean labeling usually involves reducing the number of ingredients, particularly those perceived to be artificial, and those lacking any nutritional benefit. Mainly focused on removing food additives, such as synthetic colors, preservatives, stabilizers, emulsifiers and texturizers; clean labelling in its purest form also involves reducing certain food components such as fat, sugar and salt among others. 
Claims such as "all natural", "no artificial sweeteners", "limited or no added sugar", "non-GMO" and "minimally processed" are often included in clean label products (Asioli et al., 2017).

In line with the aforementioned global trends, consumers are increasingly mindful of their food and beverage choices. $69 \%$ and $52 \%$ of worldwide consumers believe, respectively, that products without artificial ingredients, and products with fewer ingredients, are healthier (The Nielsen Company, 2016). For this reason, consumers are willing to pay more for clean label products, whose global sales hit US\$165bn in 2015 and are projected to reach US $\$ 180$ bn by 2020 (Bizozzero, 2017).

Clean label products are no longer a trend but the new norm (Bizozzero, 2017). Ingredient names, and especially consumer familiarity and acceptance of them, play a central role in clean-label. Long, chemicalsounding, difficult-to-pronounce or unfamiliar names lead to perceptions of higher risk and raise questions about the reason for their use in foods (Asioli et al., 2017). Therefore, clean labeling often includes swapping chemical-sounding names for consumer-friendly ones. By way of example "tocopherol", a synonym of vitamin E, might be perceived as chemical or artificial, so it would be better to list it as vitamin E. However, going clean label is not always such an easy task (Gallagher, Gormley, \& Arendt, 2004). For this reason, the replacement of ingredients regarded as redundant, unacceptable or even harmful without any scientific justification sets up costly and sometimes unnecessary challenges. In addition, as previously mentioned, clean labeling is more about consumer perception than scientific evidence. With a constantly changing consumers' wish-list, so does the target for formulators, whom at the same time have to face functionality, quality and safety issues derived from the replacement of certain ingredients (Lamacchia et al., 2014).

\section{Protein is king, fat is back, and what about carbohydrates?}

While consumers try to avoid specific ingredients, others are on the rise. Consumers are increasingly looking for high-protein foods, since an optimal protein intake is usually associated with satiety and lean body mass gain or maintenance (Euromonitor, 2016). Protein also serves as a great replacement for sugar and fat, which are usually linked to an unhealthy diet (Lucca \& Tepper, 1994). With 55\% of US consumers considering high protein content a remarkable attribute when buying food products, protein demand is 
340 increasing (The Nielsen Company, 2017). However, it still has room to grow, especially in emergent 341 markets.

When it comes to the reasons for this protein surge, media praise and sports nutrition have a lot to do with

344 it. Protein dominates sports nutrition global sales, as it is an accessible and understandable ingredient, 345 which gives multiple health benefits (C. S. Euromonitor International's Consumer Health Analyst, 2014). It 346 appeals mainly to younger consumers aligned with fitness trends, but with an increasing evidence of 347 benefits on aging, bone and heart health, it will potentially appeal to millions more in the near future 348 (Euromonitor, 2016).

As for the sources of protein, skinless chicken, fish, egg white and lean beef are the best dietary sources 351 of low fat and high-quality protein (Hoffman \& Falvo, 2004). While traditional sources like meat, eggs and 352 dairy are consumer's primary sources of protein and still dominate sales (as illustrated in Figure 2), plantbased alternatives are experiencing a strong growth, in demand for health, sustainability and animal rights

354 (The Nielsen Company, 2017).

It should be pointed out that fat, which is usually associated to an unhealthy diet, is an essential component of all cells, and along with carbohydrates, provides the majority of energy to individuals who exercise at a low-to-moderate intensity (Melzer, 2011). "Fat is back" is a trend in agreement with the dietary recommendation that the type is more important than the amount of fat (KHNI, 2018). Certain fats such as polyunsaturated omega-3 fatty acids found in fish and other foods, have a number of reported positive health effects, like mitigating inflammation (Calder, 2010). Other examples of healthy fat's sources would be olive and avocado, which are rich in monounsaturated fatty acids (Owen et al., 2000), (Dreher \& Davenport, 2013). Finally, fats also have a technological function, serving as texturizers or as a way to add flavor. The last one is gaining relevance as a result of an increased focus on sugar reduction (KHNI, 2018). 
popularity of carb-free foods (International Food Information Council Foundation, 2018). When it comes to its source, minimally refined grains and faux grains like quinoa, amaranth or wild rice, are gaining popularity due to their nutritional profile with increased protein content and a low glycemic index (Peters, 2018). In contrast, consumers try to avoid sugars or starches, which are often referred to as "bad carbs" due to their minimal nutritional value. This is strongly linked with the plant-based food trend, as carbs derived from fruits or vegetables are considered as "good carbs", and are used instead of refined starches (KHNI, 2018).

\section{Beverages, snacks and indulgence foods redefined}

Due to the aforementioned scientific evidence against added sugars and energy drinks, beverages are in a redefinition phase. Functional beverages like kombucha and protein shakes are gaining popularity among consumers, who are keener on beverages that incorporate protein, fiber and vegetable servings, while maintaining an acceptable flavor (KHNI, 2018). In functional beverages, stevia is usually the sweetener of choice for people who want to cut down sugar or calories (Lemus-Mondaca, Vega-Gálvez, Zura-Bravo, \& Ah-Hen, 2012).

When it comes to snacks and indulgence foods, they are being reformulated so that they contain more plant-based and/or perceived as healthy ingredients. In addition, due to busier lifestyles, an increasing number of consumers prefer a snackable meal format, which is more convenient than sit-down meals. This is a growing food trend, known as "snackification" (KHNI, 2018).

\section{Activist consumers against food waste}

With half of the world's food being thrown away, there is an increased concern about food waste (McCarthy \& Liu, 2017). For this reason, consumer acceptance of "non-perfect" products will grow, and consumers will begin to consider cheap food past its best before date. A revival in use of leftovers, right-size portioning and grow-it-yourself, is also forecasted (Euromonitor, 2015a). Finally, as consumers are keener on new initiatives encouraging more sustainable production and targeting food waste, governments are also making a move. In fact, in France, a law was approved to make supermarkets give food waste to charity or as animal feed (Sénate Français, 2016). 
$397 \quad$ Personalization, a global trend impacting nutrition

398 As discussed above, personalization is one of the main global trends, which is also influencing nutrition 399 trends. A new wave of companies provides consumers with genetic and metabolomic findings related to 400 their health, fitness and nutrition (Subbiah, 2007). Additional information can be collected through wearable 401 fitness trackers, among other methods; giving an overall picture of health. Personalized training and 402 nutrition plans are offered based on findings of individual parameters such as fat burning ability or capacity 403 to metabolize caffeine, lactose or gluten, among others (Mutch, Wahli, \& Williamson, 2005), (Ferguson, 404 2013). In this context, one of the main challenges of personalization is not just customizing mass-produced 405 products, but also shaping them to individual preferences before production, in order to shift from product 406 to experience or service (Wind \& Rangaswamy, 2001), (Euromonitor International's Head of Lifestyles 407 Research, 2017).

$409 \quad$ Internet of Things shaping interaction with food

410 By the year 2020, about 24 billion internet-connected devices will be installed globally, which is the 411 equivalent of about 3 devices/person (Gubbi, Buyya, Marusic, \& Palaniswami, 2013). loT may continue 412 shaping the way we purchase, receive and interact with our food. In fact, there is a continued expansion of 413 online or online/offline hybrid subscription services, such as click and collect grocery shopping and delivery 414 of restaurant meals. Due to strong growth of these alternative businesses, it is expected that by 2021 , 415 supermarkets and hypermarkets will account for less than a half of the total consumer goods trade 416 (Euromonitor, 2018).

\section{Sports nutrition is rocketing}

419 In line with the aforementioned healthy living trend, more people are adopting an active lifestyle, which is 420 translating into a rise of sport and endurance activities (C. S. Euromonitor International's Consumer Health 421 Analyst, 2014). As scientific evidence confirms that certain ingredients can enhance athletic performance, 422 more people recognize the benefits of sports nutrition products, and therefore, are increasingly 423 complementing their work-out sessions with these products (American Dietetic Association et al., 2009), 
(Ronald J. Maughan \& Shirreffs, 2012). For a long time, sports nutrition products were primarily meant and used by the so-called core users, that is, elite athletes and bodybuilders. However, the growing health consciousness and desire for fast results has helped sports nutrition to become more appealing to mainstream consumers and thereby, to expand its consumer base over the last decade. The so-called casual users have pushed the category into the mass market (Euromonitor, 2015b). For this reason, products that were once only available in fitness shops, can now be found in pharmacies and even supermarkets, achieving greater total sales for the sports nutrition category (Spano \& Antonio, 2008).

Sports nutrition was valued at US $\$ 8,8 \mathrm{bn}$ in 2013 ; and sports foods comprising protein supplements, sports nutrition, and soft drinks including energy and sports drinks, were valued at US\$60bn in the same year (C. S. Euromonitor International's Consumer Health Analyst, 2014). Despite having experienced a steady rate growth in the last decade, several market researches continue forecasting a sustained global growth for sports nutrition category in the following years (Euromonitor, 2015b). Last but not least, although it has been reviewed as a nutrition trend, sports nutrition is also a category itself, with its own wide range of specific trends, and for this reason it will be reviewed in detail in the corresponding section below.

\section{Nutrition trends in brief}

To sum up, global trends and concerns about climate change, health and social responsibility, which are widespread among consumers, are shaping changes in nutrition. As a consequence of the clean-living trend and the older population growth, there is an increased focus on healthy nutrition and physical exercise to prevent and delay aging, chronic diseases and premature mortality, as well as their risk factors.

Consumers seek transparency, and with an easier access to information, they are becoming more aware than ever of ingredients in their food. Consumption choices are influenced by the will of eating healthy, but also ethically and socially conscious. For this reason, consumers are keener on more natural, animal-free, plant-based, minimally processed, local, and seasonal food. Besides going back to nature, with a growth in demand for organic and naturally healthy products, other categories such as "free-from" and fortified/functional foods are also on the rise. 
453 In line with the clean labelling trend, certain ingredients or categories, such as dairy, sodium, sugar or 454 carbohydrates, are being avoided or limited by an increasing number of consumers. Instead, other 455 ingredients such as proteins or healthy fats, are becoming more popular. With health as the main priority, 456 even beverages, snacks and indulgence foods, are being redefined to incorporate ingredients with 457 demonstrated health benefits.

Other global trends such as personalization, activist consumers against food waste, and loT, are shaping interaction with food and impacting nutrition. Sports nutrition is rocketing and influencing nutrition trends, possibly being the main responsible for the protein surge. For this reason, and because it is not only a nutrition trend, but also a category itself, it will be reviewed in detail in the section below.

Finally, by way of a summary, Figure 3 shows the global sales of the selected health categories in 2017, reflecting their relevance among the different health categories.

\section{Trends in Sports Foods and Nutrition}

Global trends and consumer concerns are shaping changes in nutrition, and thereby influencing the sports nutrition category as well. "Healthy living" stands out as the most relevant global trend impacting the food industry, and it is responsible for the enormous growth that sports nutrition category is experimenting. In

471 line with this increased health awareness, consumers are keener on more natural, animal-free, plant-based, minimally processed, local, and seasonal food, what is also shaping sports nutrition products.

As more consumers become aware of the importance of a well-designed diet for a good training, the use of sports nutrition products is becoming mainstream. Besides being a nutrition trend, it is an important category influencing nutrition trends, possibly being the main responsible for the protein surge. Sports nutrition is a large and quickly growing consumer health category that promotes the achievement of an optimum nutrient intake, which is having positive implications in health care costs and well-being, and for this reason it will be reviewed in detail below. 
Sports nutrition, not just a recent trend

482 Sports foods are those specialized products designed for athletes and active people to improve their nutritional intake, health, wellbeing, performance, muscle growth and/or recovery from exercise. In addition, they can also provide a convenient source of nutrients when it is impractical to consume everyday foods. Whey protein, sports gel or electrolyte replacement drinks are examples of sports foods. Among sports foods, sports nutrition encompasses food/dietary supplements aimed to contribute to an optimal performance (ESSNA, 2018). By law, sports nutrition products can only contain vitamins, minerals, food ingredients, macronutrients, herbal ingredients with a substantial history of use, and other ingredients that are generally regarded as safe (European Parliament, 2002), (United States Congress, 1994). Despite the distinction between sports foods category and sports nutrition subcategory, the two terms are often used interchangeably, also in the following text.

Although sports nutrition is one of the latest trends, it is a much older phenomenon. In the ancient Olympic Games, athletes used to eat massive quantities of meat, bread, dried fruits and honey, along with various fungi and herbs in an attempt to increase their athletic performance. But it was not until the last century when scientists found that certain substances were effective in improving athletic performance, and thereby, the first scientific-based sports nutrition products were created (ESSNA, 2018). A well-designed diet, with nutrient-dense foods, that meets energy intake requirements and incorporates proper timing of nutrients, is the foundation of a good training (Kerksick et al., 2008). However, athletes' dietary needs might be difficult to achieve through food intake alone, and for this reason, dietary supplements and sports nutrition products are often needed. When races are won by mere fractions of a second, and games may be lost due to Until recently, only bodybuilders and strength athletes were pushing for nutrient-dense, high-quality, and more convenient sources of nutrition, that could help them satisfy their unique nutritional requirements. However, as a consequence of an increasing scientific evidence on sports nutrition health and performance benefits, more athletes and coaches from other disciplines, embraced the use of these products. In the last 
508

509

510

511

512

513

514

515

516

517

518

519

520

521

522

decade, sports nutrition has expanded its consumer base to amateur athletes and active people who not only care about their muscle growth, athletic performance and recovery, but also about their health and wellbeing (Euromonitor, 2015b), (C. S. Euromonitor International's Consumer Health Analyst, 2014).

\section{Sports nutrition market analysis}

Consumers worldwide are adopting a healthy living lifestyle and gaining awareness of their needs and proactive steps that can be taken to achieve a higher wellbeing and prevent chronic diseases (Euromonitor International's Head of Lifestyles Research, 2017). Along with this trend, different categories are growing, like the Canadian wearable device market, which includes fitness trackers, and is expected to grow by $150 \%$ in 2019 . Another example would be that in 2014 , more than $41 \%$ of Canadians were interested in buying a health monitor (BDC, 2016). So, with health in focus and with the rising mantra "strong is the new skinny", sports nutrition is the fastest growing consumer health category for several years in a row, and it is expected to continue growing at a steady pace in the next years (Mitchell, 2016).

Since more people recognize the benefits of sports nutrition products, the category has seen an enormous growth, from US $\$ 6,7 \mathrm{bn}$ and US $\$ 8,9 \mathrm{bn}$ in 2010 and 2013 , respectively, to US $\$ 10,8 \mathrm{bn}$ in 2015 . Moreover, forecasts point out that it will continue growing. Sports foods, including not only sports nutrition products, but also sports and energy drinks and bars, were worth US\$60bn in 2013 (C. S. Euromonitor International's Consumer Health Analyst, 2014).

Although US is dominating the global market, accounting for over $60 \%$ of global sales, the growth is truly global. However, in terms of consumption, developed markets are leading. By way of example, Australia followed by US were leading in consumption in 2013, with an expenditure of US $\$ 55$ and 45 per household respectively; while world average consumption was around US\$5 per household. As for low-income markets, despite the barrier of relatively high prices, the global healthy living trend together with the rising disposable incomes, are supporting the increased demand and consumption of sports nutrition products. For this reason, less developed markets such as China, India and Brazil, are evolving and fast growing (C. 
535 S. Euromonitor International's Consumer Health Analyst, 2014), (C. O. Euromonitor International's 536 Consumer Health Analyst, 2017).

537

538

539

540

541

542 543

544

545

546

547

548

549

550

551

552

553

554

555

556

557

558

559

560

561

562

\section{Sports nutrition is becoming mainstream}

The main reason for the sports nutrition market steady growth is the expansion of its consumer base over the last 10 years (Euromonitor, 2015b). Consumers have an increased health awareness and are increasingly opting for sports nutrition products to complement their work-out sessions (Mordor Intelligence, 2018). As a result, the demand for sports nutrition category and its sales are rocketing.

Sports nutrition products, which are aimed to improve performance, post workout recovery and muscle maintenance and building, were originally designed for elite athletes and body builders in order to keep up with their unique nutritional demands. However, as a result of the healthy living trend, sports nutrition products have become mainstream over the past decade (C. S. Euromonitor International's Consumer Health Analyst, 2014). Besides the constantly increasing fitness clubs, which are exposing more and more recreational sports enthusiasts to sports nutrition products, other key features to support market growth have been innovation, with a growth rate of 10'4\% of global product launches between 2011 and 2016, and consumer loyalty. In contrast to what happens to other categories, when users detect a positive difference in performance, they generally stick to it. Thereby, sports nutrition products enjoy a high degree of loyalty (Mordor Intelligence, 2018).

When it comes to consumers, they are not only increasing in number, but also in diversity. As a consequence, knowledgeable and high-volume users who purchase frequently, also known as "core users", no longer dominate sports nutrition sales. In the last decade, sports nutrition products have become more appealing to a greater number of mainstream consumers, often referred to as "casual users", who are recreationally active. They prefer convenient formats and recognizable ingredients (Euromonitor, 2015b). Another group has recently emerged in developed markets, they are the "lifestyle users" who are not particularly athletic but put a greater focus on increasing their fitness levels by trying to do more exercise. Lifestyle users are mainly young and invest in fitness as a fundament aspect of a healthy lifestyle. They are 
563

564

565

566

567

568

569

570

571

572

573

574

575

576

577

578

579

580

581

582

583

584

585

586

587

588

589

590

keen on trying new products, formats and ingredients (C. S. Euromonitor International's Consumer Health Analyst, 2014), (Mordor Intelligence, 2018).

Despite the different characteristics defining each consumer type, what all of them have in common is that they seek transparency, as well as clean and open label formulations (Kang \& Hustvedt, 2014). Responding to these demands, third-party banned-substance-free certification has become a standard for major brands and producers. In addition, an increasing number of brands are opening up their proprietary blends with complete ingredient break-outs (C. S. Euromonitor International's Consumer Health Analyst, 2014). In general, a greater focus is put on the presentation of products, including appealing and interactive labelling to make it easier for the consumer to understand the ingredients, and to ensure product safety (Mordor Intelligence, 2018).

Finally, as a consequence of the consumer base expansion and segmentation, sports nutrition products are consumed for different purposes. For this reason, companies are discussing whether a better name for the industry would be lifestyle nutrition or active nutrition, which would appeal to more consumers, helping to continue broadening the consumer base (C. O. Euromonitor International's Consumer Health Analyst, 2017). In line with this last objective, major brands are penetrating mainstream distribution channels, such as gyms, pharmacies and supermarkets. For this reason, products that were once only available in dedicated fitness shops, have made their way to other retailers. In addition, sports nutrition products are also distributed by online sellers, accounting for $41,3 \%$ of sales in the US in 2017 (Mordor Intelligence, 2018).

\section{Proteins will not abdicate - and continue leading}

Proteins dominate global sales, in no small part as a consequence of being the most accessible and understandable sports nutrition ingredient. While non-protein products were worth US $\$ 1,6 \mathrm{bn}$ in 2013 , this is $17 \%$ of the total sports nutrition market; protein products, including powder, bars, ready-to-drink beverages and others, have been growing at a steady pace, reaching US $\$ 7,3 \mathrm{bn}$ in 2013 and US $\$ 9,2 \mathrm{bn}$ in 2015 , accounting for more than $83 \%$ of the total sports nutrition market. In addition, $6,5 \%$ compound annual 
growth is forecasted for protein products during the time frame between 2015 and 2020. In fact, protein market is expected to reach US $\$ 13,5 \mathrm{bn}$ in 2020 (C. S. Euromonitor International's Consumer Health Analyst, 2014), (Euromonitor, 2015b).

Protein claims related to muscle mass growth, lean muscle maintenance and recovery from resistance exercise, makes protein the most demanded product on sports nutrition category. Protein is especially appealing for younger consumers, aged 15-34. Its popularity benefits from media praise and still has room to grow, particularly in emergent markets such as China, Latin America and India. Other lesser known protein benefits are satiety, bone and heart health, and antiaging, which are perfectly aligned with global concerns about overweight, obesity, cardiovascular health and aging. Provided that these claims become mainstream, proteins will potentially appeal to millions more in the near future (Euromonitor, 2016). As a result of its reputation as a health-promoting ingredient, natural-containing protein products and protein fortified foods, are also gaining popularity among mainstream consumers.

In the sports nutrition category, protein products remain the most demanded, as they offer a convenient way of meeting increased protein requirements without excess calories, fats or sugars. When it comes to the format, protein powder accounted for $70-80 \%$ of total protein products and reached US\$5,6bn in 2013. However, convenience formats, like ready-to-drink beverages, or protein bars, are growing quickly and reached US\$ 766mn and $837 \mathrm{mn}$, respectively, in 2013 (Euromonitor, 2016).

- Whey protein - a sales king that is being challenged

Among protein powder products, which usually need to be mixed with water or milk, whey is the king of sales. Casein, egg and soy proteins are also fairly common (Euromonitor, 2015b), (Euromonitor, 2016). However, in nutritional terms, whey is one of the best quality protein sources, and it delivers a greater taste than the offered by other sources. Besides its content in essential amino acids and BCAA, whey proteins are also well-known for its easy digestion and quick absorption, which ensure a fast delivery of the building blocks required for lean muscle mass growth and recovery (Hoffman \& Falvo, 2004), (Patel, 2015). In fact, 
618 published scientific research has demonstrated that in relation to other protein sources, whey protein 619 promotes greater muscle-building activity and muscle mass gains (Hoffman \& Falvo, 2004).

621 For a long time, whey protein isolate was only popular among core users, but due to a trickle-down effect, 622 its consumer appeal is widening (C. S. Euromonitor International's Consumer Health Analyst, 2014). In 623 addition, whey protein is versatile and easy to use in product applications, so it is also popular among manufacturers (Agarwal, Beausire, Patel, \& Patel, 2015). However, as casual and less-sophisticated users increasingly opt for whey protein products, core users are shifting to sustained-release protein blends, which could also gain mass acceptance in the near future (C. S. Euromonitor International's Consumer Health Analyst, 2014). These new formulations, including mixtures of different protein sources and protein treatments (concentrate, isolate and hydrolysate), are challenging whey protein isolate as king of protein sales (Euromonitor, 2016). Other factors, such as sustainability and animal welfare, are increasing the demand for plant-based proteins and therefore, increasing the challenge for whey protein (Radnitz et al., 2015), (Hancox, 2018).

Last but not least, in line with the healthy nutrition trend, high-protein and added-protein foods, which are already in full-swing, could pose a long-term threat to specialized sports protein products; especially among casual and lifestyle users (Chittock, 2013). In addition, although scientific evidence confirms protein supplementation safety, some dietitians are questioning the need and safety of protein supplementation, posing another threat to sports protein products (Antonio et al., 2016).

With over $80 \%$ of sports nutrition sales coming from protein-based products, and a global high-protein diet trend, sports protein products will continue to lead the industry (C. O. Euromonitor International's Consumer 642 Health Analyst, 2017). However, consumers are increasingly asking for free-from, non-allergenic and plantbased products; and proteins are not the exception. With $3 \%$ of US population eating a strictly vegetarian diet, and $36 \%$ opting for at least vegetarian meals on a regular basis in 2016 , there is a growing demand 
646

647

648

649

650

651

652

653

654

655

656

657

658

659

660

661

662

663

664

665

666

667

668

669

670

671

672

673

in reliance on animal-based nutrition are driving the demand for alternatives to milk proteins (C. S. Euromonitor International's Consumer Health Analyst, 2014), (Radnitz et al., 2015), (Hancox, 2018).

Plant-based proteins from soy, pea or rice are less common than whey protein, but they are growing quickly and will continue to do so (Euromonitor, 2016). In fact, scientific evidence shows that plant-based proteins can be as effective as animal proteins for muscle maintenance, as long as the selected source, delivers all the essential amino acids needed (Mangano et al., 2017). In addition, a well-designed vegetarian or vegan diet provides sufficient energy and appropriate range of carbohydrate, fat and protein intakes to support performance and health (Venderley \& Campbell, 2006), (Lynch et al., 2016). For this reason, certain elite athletes are going vegan and beginning to consume plant-based proteins, thereby contributing to plantbased proteins consumer base expansion (Edsor, 2017).

\section{- Hydrolysates are the next big thing - life is too short for slow proteins}

Differences in protein source, amino acid profile, and processing methods, can have an influence on amino acids bioavailability. Hydrolysates are high-quality proteins that have been finely chopped or predigested so that they can be absorbed faster than conventional proteins, helping to cut muscle recovery times from days to hours (Manninen, 2009). For this reason, they play a greater role in those athletes who place higher pressure on their body due to exercise frequency and intensity, and those who have a small window for recovery. Although hydrolysates future is promising, its bitterness and astringency hinders its incorporation into beverages, bars and gels (FitzGerald \& O'Cuinn, 2006), (Liu, Jiang, \& Peterson, 2014). This is not a drawback for core users, but since casual users prefer convenience products with good taste, until now hydrolysates have had a slow expansion. However, recent advances in hydrolysates processing technology have allowed taste-masking, enabling its incorporation into various formats such as clear drinks (FitzGerald \& O'Cuinn, 2006). As a consequence, a fast growth for hydrolysates is forecasted (Euromonitor, 2015b).

\section{What about non-protein products?}

Casual users' adoption of non-protein products is growing. However, since these products are more difficult to understand by the mainstream and uninformed consumers, they mostly appeal to core users. With sales 
674

675

676

677

678

679

680

681

682

683

684

685

686

687

688

689

690

691

692

693

694

695

696

697

698

699

700

701

reaching US\$160mn in 2013, UK has a leading position in the global non-protein products market. Global sales were worth 1,6bn in 2013 and are expected to grow by nearly US $\$ 500 \mathrm{mn}$, achieving US $\$ 2$ bn in 2018 (C. S. Euromonitor International's Consumer Health Analyst, 2014).

In general, fitness-focused lifestyle, a desire for fast results, and a high demand for portable and convenient products, are the main drivers of the sports nutrition category. When it comes to convenience formats, nonprotein products have been ahead, leading the experimentation. Gels, chews, bars, sachets and shots are examples of convenience formats. With the rise of endurance sports, gels have become the most popular convenience format (Euromonitor, 2015b), (C. S. Euromonitor International's Consumer Health Analyst, 2014).

As for sports drinks, they are expected to record the highest growth rate in the following years. Sports drinks, including products sold in powder to be rehydrated in water, are highly demanded as consumers become aware of the uses and benefits of drinks rich in carbohydrates, minerals and electrolytes (Zimberoff, 2017). Active and sports people have higher carbohydrate requirements, and without an adequate intake of them, exercise performance decreases (Williams \& Rollo, 2015). Electrolyte-replacement, glucosecontaining solutions help to maintain blood glucose levels and prevent dehydration and therefore, may delay fatigue and attenuate muscle damage during endurance exercise (American Dietetic Association et al., 2009). However, the growing sugar-averse consumer base is contributing to an increased demand for low-calorie and low-carbohydrate sports drinks, especially in North America, which is the leader in sales (International Food Information Council Foundation, 2018). New sports drinks are mainly focused on optimizing hydration before, during and after physical activity. Maintaining hydration status is one of the most effective ways to maintain exercise performance, which can be significantly impaired when $2 \%$ or more of body weight, is lost through sweating (American Dietetic Association et al., 2009),(Ronald J. Maughan \& Shirreffs, 2012).

In 2013 , sports drinks and energy drinks accounted for US $\$ 18,7 \mathrm{bn}$ and US $\$ 27,6 \mathrm{bn}$, respectively. However, there is a blurring line between energy/sports drinks, and non-protein products category (C. S. Euromonitor 
International's Consumer Health Analyst, 2014). The main reason for this, is that energy/sports drinks are shifting from the so-called bad carbs to the good ones. This is translating into products with lesser amounts of ingredients with minimal other nutritional value, like sugar or starches; and with higher amounts of naturally-containing-carbohydrates fruits, vegetables and whole grains (International Food Information Council Foundation, 2018). Strongly aligned with plant-based trend, this new wave of products is blurring the line between energy/sports drinks, and other drinks or beverages in the non-protein products category.

\section{An overview of sports nutrition products' global sales}

Before moving forward with other trends to look out for in 2020, Figure 4 shows the global sales of the selected sports foods subcategories in 2013 , thus reflecting their relative relevance.

\section{Other trends to look out for in 2020}

Nutrient timing is a well-known concept for elite athletes, and casual users' awareness of its importance is increasing. Meal times and snacks should be planned in concert with training, to make sure that athletes have sufficient availability of nutrient-dense foods throughout the day. Research has shown that meal timing and composition may play a role in optimizing performance, training adaptations and preventing overtraining (Kerksick et al., 2008). By way of example, within 30 minutes of a workout, consuming highquality carbohydrate and protein is key to replenish those nutrients depleted during the workout. While carbohydrates replenish glycogen stores and therefore, support muscle recovery, protein helps in muscle building and repairing (American Dietetic Association et al., 2009).

Global trends such as transparency, clean labeling and personalization are also impacting sports nutrition. Besides those that have already been discussed before, customized workouts and meals, tailored to preferences and goals, will help optimizing physical activity. "One size fits all" will no longer exist, and appeal for personalized fitness plans and nutrition, will broaden from elite athletes to include casual users as well (German, Zivkovic, Dallas, \& Smilowitz, 2011), (Nutraingredients, 2016), (Gardiner, 2016). 
Recovery is gaining importance over rest. While resting is just the absence of training, recovery involves all techniques and activities to maximize repair: hydration, compression, nutrition, heat or cold, stretching and massaging (Menzies et al., 2010). For a long time, a lot of these techniques were only reserved for elite athletes, but casual users' adoption is increasing as they are becoming aware that a balance between rest and recovery, together with a proper nutrition is essential for anyone who exercises (Meltzer, 2018), (Mateo, 2018).

Finally, flavor is one of the most important areas for innovation in the sports nutrition industry, and it has a long way to go in terms of customers acquisition and retention (Cash, 2017). Another main driver of sports nutrition industry is convenience packaging, since consumers prefer small and portable products (Euromonitor, 2015b), (Euromonitor International's Head of Lifestyles Research, 2017).

Innovation is driving the market - microencapsulation as an example

Besides demand-driven innovation, offering technological and professional solutions to mass market consumers is a powerful driver for growth and competitive positioning of a company (PwC, 2013). In this line, technologies such as microencapsulation would allow a broader use of certain ingredients with organoleptic or stability issues, among others. Microencapsulation is a technique that involves the entrapment of a substance within a microscopic shell of encapsulating polymeric material to give microcapsules different useful properties: preventing interactions among ingredients of a formula, flavor masking, increased stability and bioavailability, improved dissolution and flowability, and sustained-release among others (Gaonkar, Vasisht, Khare, \& Sobel, 2014).

By way of example, taste-masking microcapsules allow the incorporation of caffeine into gels or chews without its characteristic bitter taste (Pimparade et al., 2015), (Mohammadi, Ehsani, \& Bakhoda, 2018). Other examples of microencapsulation applications are increased water-dispersibility and bioavailability of hydrophobic ingredients, such as coenzyme Q10 or medium chain triglycerides (Gaonkar et al., 2014). Microcapsules are also capable to increase the stability of certain sensitive ingredients, such as probiotics, when they are exposed to different environmental conditions like heat, humidity, light and oxygen (Anal \& 
Singh, 2007). Furthermore, microcapsules can act as delivery systems. Depending on the microencapsulation technique and wall material selected, the release mechanism can be triggered by different factors such as dissolution, temperature, pressure, $\mathrm{pH}$ and enzymes among others; and the release profile can also be modified to be immediate, delayed or sustained (Gaonkar et al., 2014). Finally, microcapsules are also capable to protect acid-sensitive ingredients, like probiotics or enzymes, during their pass through the highly acidic environment of the stomach, and to release them in the intestine, which has an alkaline pH (Anal \& Singh, 2007), (Cook, Tzortzis, Charalampopoulos, \& Khutoryanskiy, 2012).

Finally, as has just been reviewed, the implementation of professional solutions for mass market products, can help overcome different challenges, from technical issues like shelf-life, to consumer acceptance problems, like unpleasant taste or poor dissolution. Until now, technological advances were a business-tobusiness tool due to a lack of consumer understanding. However, consumers access to information is greater than ever, and soon they will become aware of the benefits of these techniques (Hamari et al., 2016). For this reason, technological solutions are going to be crucial to differentiate products from their competitors (PwC, 2013).

\section{Considerations on regulation}

Last but not least, the sports nutrition category is not only shaped by dietary recommendations and research, but also by regulations. Each country has its own regulation, which has an impact on the direction and growth of the sports nutrition industry. While some countries can select from a wide range of ingredients and claims, other countries may restrict or ban the same ones (R. J. Maughan, Greenhaff, \& Hespel, 2011).

The US and the European Union (EU), by their respective competent bodies, Food and Drug Administration (FDA) and European Food Safety Authority (EFSA), have its own composition and labelling requirements, which will be briefly reviewed below. It is important to remark that besides the benefits provided by supplements and sports food, safety remains the main priority (US Congress, 2011). When it comes to professional athletes competing under anti-doping codes, not only evidence and safety are important factors to consider, but also the absence of prohibited substances. For this reason, it is important to highlight 
785

786

787

788

789

790

791

792

793

794

795

796

797

798

799

800

801

802

803

804

805

806

807

808

809

810

811

812

06

a valuable information resource developed by the Australian Institute of Sport. It consists of an $A B C D$ classification system that ranks those ingredients found in sports foods and supplements, into four groups. It is based on scientific evidence and other practical considerations to stablish product safety, legality and efficacy in improving sports performance (Australian Institute of Sport, 2018).

\section{- US regulation}

In US, according to the Dietary Supplement Health and Education Act, dietary supplements are defined as products taken by mouth, which are typically sold in the form of capsules, soft gels, liquids, powders and bars, and that contain one or more dietary ingredients intended to supplement the diet. Vitamins, minerals, herbs, botanical extracts, amino acids and other substances may be considered dietary ingredients. Products sold as dietary supplements must be clearly labeled as such. FDA monitors its manufacturing processes, quality and labelling, but it grants a greater control over supplements containing new dietary ingredients. A new dietary ingredient is a dietary ingredient that was not sold in the US before 1994. FDA requires specific safety information from manufacturers intending to market food supplements containing new dietary ingredients. Safety evidence, which may include in vitro and long-term toxicity studies, and clinical studies in humans, must be provided to FDA. When it comes to health and nutrient content claims, efficacy evidence must be submitted to FDA for approval. Authorities can act against companies who make false or misleading claims; and can also remove supplements from the market if they lack sufficient scientific evidence to demonstrate product safety. In addition, companies are now required to record all adverse event complaints about their products; and must report to FDA all those serious adverse events (United States Congress, 1994), (US Food and Drug Administration, 2018).

\section{- EU regulation}

As for the regulation in Europe, according to European Parliament Directive (2002/46/EC), food supplements are defined as products intended to supplement the normal diet, consisting of concentrated sources of nutrients, like minerals and vitamins, or other substances with a nutritional or physiological effect that are marketed in a "dosage" form (e.g. pills, tablets, capsules or liquids in measured doses). Food supplements are regulated as foods, and thereby may contain vitamins, minerals, amino acids, essential 
813

814

815

816

817

818

819

820

821

822

823

824

825

826

827

828

fatty acids, fiber and various plants and herbal extracts, among others. It has to be noted that the addition of nutrients or other substances to fortify foods, does not fall within the definition of a food supplement, and is addressed by a different regulation. Food supplements are intended to correct nutritional deficiencies, maintain an adequate intake of certain nutrients, or support specific physiological functions. The responsibility for the safety of these products lies with the food business operator placing the product on the market (European Parliament, 2002).

In order to protect consumers against potential health risks, EFSA carried out a comprehensive assessment of substances that could be intended for food supplements manufacture in the EU. Based on EFSA's work, the European Commission established a harmonized list of substances that may be used in the manufacture of food supplements, their tolerable upper intake levels, labelling requirements and approved health claims (European Parliament, 2006b), (European Food Safety Authority, 2006), (European Parliament, 2011), (European Parliament, 2006a). There is also a list of those substances that are known or suspected to have adverse effects on health, and the use of which is therefore controlled. As for those substances intended to be used in food supplements, and that do not have a history of safe use in the EU before 1997, which are known as "novel foods", EFSA is requested to provide a scientific opinion on its safety (European Parliament, 2015).

Finally, the EU register provides information on the permitted nutrition and health claims made on foods, and their conditions of use and applicable restrictions, as well as non-authorized health claims and the reason for their non-authorization (European Commission, 2018).

\section{- Worldwide anti-doping regulation}

The World Anti-Doping Agency (WADA) is an international independent agency with scientific research, education, development of anti-doping capacities, and monitoring of the world anti-doping code, as key activities. Its mission is to lead a collaborative worldwide movement for doping-free sport, bringing consistency to anti-doping policies and regulations within sport organizations and governments across the world (World Anti-Doping Agency [WADA], 2018a). The list of prohibited substances and methods, which 
841 is updated annually, is a cornerstone of the WADA. It lists substances prohibited at all times, just in842 competition or in particular sports. Some examples of prohibited substances are non-approved 843 pharmacological substances, anabolic agents, beta-2 agonists and diuretics, as well as masking agents. 844 Examples of prohibited methods are manipulation of blood, chemical manipulation of samples collected 845 during doping control and gene doping (WADA, 2018b).

According to world anti-doping code, athletes are responsible for all products ingested and any subsequent legal, health or safety consequence (WADA, 2015). For this reason, they should pay special attention when choosing a supplement, since some of them have been reported to have an accidental or deliberate content of banned substances (R. Maughan, 2005). A research of stimulants and anabolic steroids in dietary supplements revealed that the number of mislabeled supplements represented $18 \%$ of the 103 products analyzed (Baume, Mahler, Kamber, Mangin, \& Saugy, 2006). For this reason, some manufacturers order commercial third-party auditing programs, as an independent screening for banned and restricted substances that could be accidentally found in their dietary supplements. These certifications provide a greater assurance of supplement purity for those athletes competing under antidoping codes (Bishop, 2010). Non-intentional doping poses a threat to athlete's career, since anti-doping rule violation, regardless it was intentional or unintentional, may result in bans of up to four years (WADA, 2015).

\section{Sports nutrition trends in brief}

860 In line with the healthy living global trend, as consumers are increasingly focusing on health and fitness 861 goals, different categories, like wearable devices, are growing. Sports nutrition is the fastest growing 862 consumer health category for several years in a row, and it is expected to continue growing at a steady pace in the following years. An expanding and more diverse consumer base is boosting the demand for sports nutrition, which has become a mainstream category. For this reason, products that were once only available in dedicated fitness shops, have made their way to other retailers.

867 As for the sports nutrition king ingredient, proteins dominate global sales accounting for more than $83 \%$ of 
category, further growth is forecasted for the next five years. Among protein powders, whey isolate is the preferred source, due to its taste, amino acid composition and quick absorption. However, new formulations including different sources and treatments of proteins, are challenging whey protein isolate as king of sales. The main threats for whey protein isolate are a rising demand for plant-based proteins, and hydrolysates of different protein sources.

On contrast, non-protein products are more difficult to understand by the mainstream and uninformed consumers, and account for just $17 \%$ of total sports nutrition market. Despite not leading in sales, nonprotein products are way ahead of convenience formats experimentation. As for sports drinks, they are expected to record the highest growth rate in the following years. Electrolyte-replacement, glucosecontaining solutions help to maintain blood glucose levels and prevent dehydration, and therefore, may delay fatigue and attenuate muscle damage during endurance exercise. However, since there is an increasing demand for low-calorie and low-carbohydrate sports drinks, new products are mainly focused on optimizing hydration.

Besides global trends like clean labeling and personalization, which are impacting sports nutrition, other emerging trends to look out for in 2020 are nutrient timing, recovery gaining importance over rest, convenience packaging, and flavor as one of the main areas for innovation. Finally, offering professional solutions to mass market is key for disruptive innovation. Application of technologies such as microencapsulation in the sports nutrition field, would allow a broader use of certain ingredients with organoleptic or stability issues. In addition, preventing interactions, improving dissolution and achieving a sustained-release profile by means of microencapsulation, could also drive the sports nutrition category.

Last but not least, when it comes to the direction and growth of the sports nutrition industry, it is shaped by different factors. One of the most relevant but frequently forgotten factors is regulation, which can be different in each country. Competent authorities can restrict or ban ingredients to ensure safety and can also regulate to avoid false or misleading claims. Professional athletes who compete under anti-doping 
896

897

898

899

900

901

902

903

904

905

906

907

908

909

910

codes, may only consider certain manufacturers which provide a third-party certificate ensuring that no banned or restricted substance is present.

\section{Conclusion}

Global dynamics are shaping consumer attitudes and thereby, promoting changes across industries. Clean and healthy living stands out as the most relevant trend impacting the food industry. Consumers are making informed decisions to prioritize healthy, plant-based, sustainable and socially-conscious food purchases, a trend which is also affecting beverages, snacks, indulgence foods and even fast food. Aligned with this trend, governments are promoting healthy habits to reduce morbidity and cut off its associated costs. In this context, not only vegetarian and vegan product sales are growing quickly, but also organic and free-from products. In addition, since consumers prefer foods with an intrinsic nutritional value, functional foods have been outpaced by naturally healthy products.

Due to media praise and sports nutrition, a category where protein is the king of sales, consumers are increasingly looking for high-protein products. Carbohydrates, instead, have been targeted as a strategy to reduce overall calorie intake, resulting in a decreased popularity. However, the source matters, and "good carbs" are used instead of "bad carbs". In this line, as consumers increasingly avoid certain food ingredients, clean label products are no longer a trend, but the new norm. Nonetheless, the replacement of certain ingredients may set up costly and sometimes unnecessary challenges for food scientists. Other relevant trends shaping interaction with foods are personalization, loT, and food waste reduction. However, one of the main trends is sports nutrition, which is a large and quickly growing consumer health category.

Sports nutrition sales are no longer dominated by core users, instead, they have become more appealing to mainstream consumers, and as a result, sports foods have made their way to mainstream distribution channels. Proteins are leading the sports nutrition category, but whey protein isolate, which is the king of sales among protein powder products, is being challenged by the rise of high-protein foods and the rising demand for plant-based proteins. When it comes to protein processing methods, isolates are being replaced by hydrolysates, which are expected to be the next big trend among protein powders. As for non-protein 
924

925

926

927

928

929

930

931

932

933

934

935

936

937

938

939

940

941

942

943

944

945

946

947

948

949

950

951

products, despite experiencing a slower growth, they are leading the experimentation in convenience formats. Regarding new sports drinks products, they are mainly focused on optimizing hydration, and shifting from the so-called bad carbs to the good ones. As a consequence, there is a blurring line between energy/sports drinks, and other non-protein drinks or beverages.

Other trends to look out for in 2020 in the sports food industry are nutrient timing, personalization, recovery gaining importance over rest, and flavor as one of the most important areas for innovation. Different professional technologies can be applied to mass market products, as a driver for growth and competitive positioning. In this context, microencapsulation stands out as one of these technologies with a wide variety of applications and a promising future. Finally, besides innovation, dietary recommendations and research, the sports nutrition category is shaped by regulations; among which stand US and EU regulation, and World Anti-Doping Code.

To conclude, global dynamics have an influence on nutrition trends, being potentially disruptive for the correct balancing of the diet. However, as it has been reviewed, along with the healthy living trend, more people are adopting an active lifestyle, embracing a healthier dietary pattern and recognizing the benefits of sports foods, which is having positive implications in health, well-being and healthcare-associated costs. This review has also provided an overview of the areas that are more prone to development, and that should be added to the research agenda to adapt formulas and technologies to consumer needs.

\section{Acknowledgments}

This research was financially supported by the Industrial Doctorate Program of the Agency for Management of University and Research Grants (AGAUR), with the following grant number: 2015DI021.

\section{Author Contributions}

Conception, literature research and writing were performed by M. Arenas-Jal. Field experience, planning and critical review of the manuscript were performed by J.M. Suñé-Negre, P. Pérez-Lozano, and E. GarcíaMontoya. 
952

\section{Abbreviations}

954 AGAUR: Agency for Management of University and Research Grants

955 bn: billion

956 EFSA: European Food Safety Authority

957 EU: European Union

958 FDA: Food and Drug Administration

959 GMO: Genetically Modified Organism

960 loT: Internet of Things

961 mn: million

962 UK: United Kingdom

963 US: United States of America

964 WADA: World Anti-Doping Agency

965 WHO: World Health Organization 
966

967

968

969

970

971

972

973

974

975

976

977

978

979

980

981

982

983

984

985

986

987

988

989

990

991

992

993

\section{References}

Agarwal, S., Beausire, R. L. W., Patel, S., \& Patel, H. (2015). Innovative Uses of Milk Protein Concentrates in Product Development. Journal of Food Science, 80(S1), A23-A29. https://doi.org/10.1111/17503841.12807

American Dietetic Association, Dietitians of Canada, American College of Sports Medicine, Rodriguez, N. R., Di Marco, N. M., \& Langley, S. (2009). American College of Sports Medicine position stand. Nutrition and Athletic Performance. Medicine \& Science in Sports \& Exercise, 41(3), 709-731. https://doi.org/10.1249/MSS.0b013e31890eb86

Anal, A. K., \& Singh, H. (2007). Recent advances in microencapsulation of probiotics for industrial applications and targeted delivery. Trends in Food Science \& Technology, 18(5), 240-251. https://doi.org/10.1016/J.TIFS.2007.01.004

Antonio, J., Ellerbroek, A., Silver, T., Vargas, L., Tamayo, A., Buehn, R., \& Peacock, C. A. (2016). A High Protein Diet Has No Harmful Effects: A One-Year Crossover Study in Resistance-Trained Males. Journal of Nutrition and Metabolism, 2016, 9104792. https://doi.org/10.1155/2016/9104792

Asioli, D., Aschemann-Witzel, J., Caputo, V., Vecchio, R., Annunziata, A., Næs, T., \& Varela, P. (2017). Making sense of the "clean label" trends: A review of consumer food choice behavior and discussion of industry implications. Food Research International, 99, 58-71. https://doi.org/10.1016/J.FOODRES.2017.07.022

Australian Institute of Sport. (2018). ABCD Classification system for sports foods and supplements ingredients.

Baume, N., Mahler, N., Kamber, M., Mangin, P., \& Saugy, M. (2006). Research of stimulants and anabolic steroids in dietary supplements. Scandinavian Journal of Medicine and Science in Sports, 16(1), 4148. https://doi.org/10.1111/j.1600-0838.2005.00442.x

Bernstein, A., Titgemeier, B., Kirkpatrick, K., Golubic, M., Roizen, M., Bernstein, A. M., ... Roizen, M. F. (2013). Major Cereal Grain Fibers and Psyllium in Relation to Cardiovascular Health. Nutrients, 5(5), 1471-1487. https://doi.org/10.3390/nu5051471

Bigliardi, B., \& Galati, F. (2013). Innovation trends in the food industry: The case of functional foods. Trends in Food Science \& Technology, 31(2), 118-129. https://doi.org/10.1016/J.TIFS.2013.03.006 
994

995

996

997

998

999

1000

1001

1002

1003

1004

1005

1006

1007

1008

1009

1010

1011

1012

1013

1014

1015

1016

1017

1018

1019

1020

1021

Bishop, D. (2010). Dietary Supplements and Team-Sport Performance. Sports Medicine, 40(12), 9951017. https://doi.org/10.2165/11536870-000000000-00000

Bizozzero, J. (2017). 75\% of Consumers Will Pay Extra For Clean Label Ingredients. Food Insider Journal. Retrieved from https://www.foodinsiderjournal.com/clean-label/75-consumers-will-pay-extra-cleanlabel-ingredients

Bjørndal, T., Fernandez-Polanco, J., Lappo, A., \& Lem, A. (2013). Consumer trends and prefences in the demand for food. Retrieved from www.kopinor.no

Business Development Bank of Canada. (2016). Five Game-Changing Consumer Trends. Retrieved from https://www.bdc.ca/EN/Documents/analysis_research/Consumer_Trends_Report_EN.pdf

Calder, P. C. (2010). Omega-3 Fatty Acids and Inflammatory Processes. Nutrients, 2(3), 355-374. https://doi.org/10.3390/nu2030355

Cash, E. J. (2017). What's new for the European market of sports nutrition? Nutraingredients. Retrieved from https://www.nutraingredients.com/Article/2017/06/27/What-s-new-for-the-European-market-ofsports-nutrition\#

Chittock, M. (2013). Protein-enhanced food: the latest health craze. The Guardian. Retrieved from https://www.theguardian.com/lifeandstyle/wordofmouth/2013/sep/02/protein-enhanced-food-healthcraze

Cook, M. T., Tzortzis, G., Charalampopoulos, D., \& Khutoryanskiy, V. V. (2012). Microencapsulation of probiotics for gastrointestinal delivery. Journal of Controlled Release, 162(1), 56-67. https://doi.org/10.1016/J.JCONREL.2012.06.003

Daniells, S. (2018). 'Free-from is the most promising trend in LATAM': Euromonitor. Retrieved from https://www.foodnavigator-latam.com/Article/2018/06/14/Free-from-is-the-most-promising-trend-inLATAM-Euromonitor

Deloitte. (2013). The dawn of mobile influence. Discovering the value of mobile in retail. Retrieved from https://www2.deloitte.com/content/dam/Deloitte/uk/Documents/consumer-business/deloitte-uk-thedawn-of-mobile-influence-final.pdf

Dreher, M. L., \& Davenport, A. J. (2013). Hass Avocado Composition and Potential Health Effects. Critical $\begin{array}{llll}\text { Reviews in } \quad \text { Food } & \text { Science } & \text { 738-750. }\end{array}$ 
1022

1023

1024

1025

1026

1027

1028

1029

1030

1031

1032

1033

1034

1035

1036

1037

1038

1039

1040

1041

1042

1043

1044

1045

1046

1047

1048

1049

https://doi.org/10.1080/10408398.2011.556759

Edsor, B. (2017). Elite athletes who are vegan and what made them switch their diet. Business Insider. Retrieved from http://uk.businessinsider.com/elite-athletes-who-are-vegan-and-what-made-themswitch-their-diet-2017-10?IR=T/\#hannah-teter-snowboarder-7

Euromonitor, a market research provider. (2015a). Eco Worriers: Global Green Behaviour and Market Impact. Retrieved from https://www.euromonitor.com/eco-worriers-global-green-behaviour-andmarket-impact/report

Euromonitor, a market research provider. (2015b). Trends and Developments in Sports Nutrition. Retrieved from https://www.euromonitor.com/trends-and-developments-in-sports-nutrition/report

Euromonitor, a market research provider. (2016). Global Trends in Protein. Retrieved from https://www.euromonitor.com/global-trends-in-protein/report

Euromonitor, a market research provider. (2017a). Consumer Lifestyles in 2017: Global Survey Results. Retrieved from https://go.euromonitor.com/white-paper-survey-2017-lifestyles.html

Euromonitor, a market research provider. (2017b). “Free From” Food Movement: Driving Growth in Health and Wellness Space. Retrieved from https://www.euromonitor.com/-free-from-food-movementdriving-growth-in-health-and-wellness-space/report

Euromonitor, a market research provider. (2018). 8 Food Trends for 2018. Retrieved from https://www.euromonitor.com/8-food-trends-for-2018/report

Euromonitor International's Consumer Health Analyst, C. O. (2017). Sports Nutrition: Healthy Living and Fitness Trends Provide Great Prospects. Retrieved from https://blog.euromonitor.com/sportsnutrition-healthy-living-fitness-trends-provide-prospects/

Euromonitor International's Consumer Health Analyst, C. S. (2014). Trends in major sports nutrition markets and demographics - understanding the consumer market. In Bénéfiq. Quebec, Canada.

Euromonitor International's Consumer Health Analyst, L. G. (2016). New Lifestyles System Data: 2016 Global Consumer Trends Survey Results. Retrieved from https://blog.euromonitor.com/new-lifestylessystem-data-2016-global-consumer-trends-survey-results/

Euromonitor International's Consumer Health Analyst, M. M. (2018). New Health and Wellness Data: A Look into Latest Trends. Retrieved from https://blog.euromonitor.com/new-health-wellness-data-look- 
latest-trends/

1051

1052

1053

1054

1055

1056

1057

1058

1059

1060

1061

1062

1063

1064

1065

1066

1067

1068

1069

1070

1071

1072

1073

1074

1075

1076

1077

Euromonitor International's Head of Lifestyles Research, A. A. (2017). Top 10 Global Consumer Trends for 2018. Emerging forces shaping consumer behaviour. Retrieved from https://go.euromonitor.com/white-paper-economies-consumers-2018-global-consumer-trendsEN.html\#download-link

European Commission. (2018). EU Register of Nutrition and Health Claims. Retrieved from http://ec.europa.eu/food/safety/labelling_nutrition/claims/register/public/?event=register.home

European Food Safety Authority. (2006). Tolerable upper intake levels for vitamins and minerals. Retrieved from http://www.efsa.eu.int

European Parliament. (2002). Directive 2002/46/EC on the approximation of the laws of the Member States relating to food supplements. Retrieved from https://eur-lex.europa.eu/eli/dir/2002/46/oj

European Parliament. (2006a). Regulation (EC) No 1924/2006 on nutrition and health claims made on foods. Retrieved from https://eur-lex.europa.eu/legalcontent/EN/TXT/PDF/?uri=CELEX:02006R1924-20141213

European Parliament. (2006b). Regulation (EC) No 1925/2006 on the addition of vitamins and minerals and of certain other substances to foods. Retrieved from https://eur-lex.europa.eu/eli/reg/2006/1925/oj

European Parliament. (2011). Regulation (EU) No 1169/2011 on the provision of food information to consumers. Retrieved from https://eur-lex.europa.eu/eli/reg/2011/1169/oj

European Parliament. (2015). Regulation (EU) 2015/2283 on novel foods. Retrieved from https://eurlex.europa.eu/eli/reg/2015/2283/oj

European Specialist Sports Nutrition Alliance. (2018). Sports Nutrition. Retrieved November 13, 2018, from http://www.essna.com/sports-nutrition/

Ferguson, L. (2013). Nutrigenomics and Nutrigenetics in Functional Foods and Personalized Nutrition. CRC Press. https://doi.org/10.1201/b15369

FIBL and IFOAM, O. I. (2017). The world of organic agriculture - statistics and emerging trends 2017. (H. Willer \& J. Lernoud, Eds.). Bonn: IFOAM - Organics International. Retrieved from https://shop.fibl.org/CHde/mwdownloads/download/link/id/785/?ref=1

FitzGerald, R. J., \& O'Cuinn, G. (2006). Enzymatic debittering of food protein hydrolysates. Biotechnology 

Advances, 24(2), 234-237. https://doi.org/10.1016/J.BIOTECHADV.2005.11.002

Gallagher, E., Gormley, T. ., \& Arendt, E. . (2004). Recent advances in the formulation of gluten-free cerealbased products. Trends in Food Science \& Technology, 15(3-4), 143-152. https://doi.org/10.1016/J.TIFS.2003.09.012

Gaonkar, A. G., Vasisht, N., Khare, A. R., \& Sobel, R. (2014). Microencapsulation in the food industry : a practical implementation guide. Elsevier Science.

Gardiner, H. (2016). The Rise of the Personalized Nutrition Trend. Nutrition Insight. Retrieved from https://www.nutritioninsight.com/news/SPECIAL-REPORT-The-Rise-of-the-Personalized-NutritionTrend?frompage=Index\&tracking=Slider Menu\&NewTracking=SpecialReport

German, J. B., Zivkovic, A. M., Dallas, D. C., \& Smilowitz, J. T. (2011). Nutrigenomics and personalized diets: What will they mean for food? Annual Review of Food Science and Technology, 2, 97-123. https://doi.org/10.1146/annurev.food.102308.124147

Global Burden of Disease Study 2013 collaborators. (2015). Global, regional, and national incidence, prevalence, and years lived with disability for 301 acute and chronic diseases and injuries in 188 countries, 1990-2013: a systematic analysis for the Global Burden of Disease Study 2013. Lancet (London, England), 386(9995), 743-800. https://doi.org/10.1016/S0140-6736(15)60692-4

Gökmen, V., Mogol, B. A., Lumaga, R. B., Fogliano, V., Kaplun, Z., \& Shimoni, E. (2011). Development of functional bread containing nanoencapsulated omega-3 fatty acids. Journal of Food Engineering, 105(4), 585-591. https://doi.org/10.1016/J.JFOODENG.2011.03.021

Google Trends. (2018). Vegetarian and vegan search terms. Retrieved November 13, 2018, from https://trends.google.com/trends/explore?date=2012-01-01 2018-01-01\&q=vegetarian, vegan

Gubbi, J., Buyya, R., Marusic, S., \& Palaniswami, M. (2013). Internet of Things: A vision, architectural elements, and future directions. Future Generation Computer Systems, 29(7), 1645-1660. https://doi.org/10.1016/J.FUTURE.2013.01.010

Hamari, J., Sjöklint, M., \& Ukkonen, A. (2016). The sharing economy: Why people participate in collaborative consumption. Journal of the Association for Information Science and Technology, 67(9), 2047-2059. https://doi.org/10.1002/asi.23552

Hancox, D. (2018). The unstoppable rise of veganism: how a fringe movement went mainstream. The 
1106

1107

1108

1109

1110

1111

1112

1113

1114

1115

1116

1117

1118

1119

1120

1121

1122

1123

1124

1125

1126

1127

1128

1129

1130

1131

1132

1133

Guardian. Retrieved from https://www.theguardian.com/lifeandstyle/2018/apr/01/vegans-are-comingmillennials-health-climate-change-animal-welfare

Hoffman, J. R., \& Falvo, M. J. (2004). Protein - Which is Best? Journal of Sports Science \& Medicine, 3(3), 118-130. Retrieved from http://www.ncbi.nlm.nih.gov/pubmed/24482589

International Food Information Council Foundation. (2018). 2018 Food and health survey. Retrieved from https://www.foodinsight.org/2018-FHS-Report-FINAL.pdf

Kang, J., \& Hustvedt, G. (2014). Building Trust Between Consumers and Corporations: The Role of Consumer Perceptions of Transparency and Social Responsibility. Journal of Business Ethics, 125(2), 253-265. https://doi.org/10.1007/s10551-013-1916-7

Kearney, J. (2010). Food consumption trends and drivers. Philosophical Transactions of the Royal Society of London. Series B, Biological Sciences, 365(1554), 2793-2807. https://doi.org/10.1098/rstb.2010.0149

Kerksick, C., Harvey, T., Stout, J., Campbell, B., Wilborn, C., Kreider, R., ... Antonio, J. (2008). International Society of Sports Nutrition position stand: Nutrient timing. Journal of the International Society of Sports Nutrition, 5(1), 17. https://doi.org/10.1186/1550-2783-5-17

Kerry Health And Nutrition Institute. (2018). Ten Key Health and Nutrition Trends 2018. Retrieved November 13, 2018, from https://khni.kerry.com/trends-and-insights/ten-key-health-and-nutritiontrends-2018/

Labrecque, L. I., vor dem Esche, J., Mathwick, C., \& Novak, T. P. (2013). Consumer Power: Evolution in the Digital Age. Journal of Interactive Marketing, 27(4), 257-269. https://doi.org/10.1016/J.INTMAR.2013.09.002

Lamacchia, C., Camarca, A., Picascia, S., Di Luccia, A., Gianfrani, C., Lamacchia, C., ... Gianfrani, C. (2014). Cereal-Based Gluten-Free Food: How to Reconcile Nutritional and Technological Properties of Wheat Proteins with Safety for Celiac Disease Patients. Nutrients, 6(2), 575-590. https://doi.org/10.3390/nu6020575

Lemus-Mondaca, R., Vega-Gálvez, A., Zura-Bravo, L., \& Ah-Hen, K. (2012). Stevia rebaudiana Bertoni, source of a high-potency natural sweetener: A comprehensive review on the biochemical, nutritional and functional aspects. Food Chemistry, 132(3), 1121-1132. 
1135 Liu, X., Jiang, D., \& Peterson, D. G. (2014). Identification of Bitter Peptides in Whey Protein Hydrolysate.

1136 Journal of Agricultural and Food Chemistry, 62(25), 5719-5725. https://doi.org/10.1021/jf4019728

1137 Lucca, P. A., \& Tepper, B. J. (1994). Fat replacers and the functionality of fat in foods. Trends in Food 1138 Science \& Technology, 5(1), 12-19. https://doi.org/10.1016/0924-2244(94)90043-4

1139 Lynch, H., Wharton, C., Johnston, C., Lynch, H. M., Wharton, C. M., \& Johnston, C. S. (2016). 1140 Cardiorespiratory Fitness and Peak Torque Differences between Vegetarian and Omnivore $\begin{array}{lllll}\text { Endurance Athletes: A } & \text { Cross-Sectional Study. Nutrients, }\end{array}$ https://doi.org/10.3390/nu8110726

1143 Mangano, K. M., Sahni, S., Kiel, D. P., Tucker, K. L., Dufour, A. B., \& Hannan, M. T. (2017). Dietary protein 1144 is associated with musculoskeletal health independently of dietary pattern: the Framingham Third 1145 Generation Study. The American Journal of Clinical Nutrition, 105(3), 714-722. $1146 \quad$ https://doi.org/10.3945/ajcn.116.136762

1147 Manninen, A. H. (2009). Protein hydrolysates in sports nutrition. Nutrition \& Metabolism, 6(1), 38. https://doi.org/10.1186/1743-7075-6-38

1149 Mateo, A. (2018). Recovery Is the Latest Workout Trend. The Cut. Retrieved from https://www.thecut.com/2018/05/recovery-is-the-latest-workout-trend.html

1151 Maughan, R. (2005). Contamination of dietary supplements and positive drug tests in sport. Journal of $1152 \quad$ Sports Sciences, 23(9), 883-889. https://doi.org/10.1080/02640410400023258

1153 Maughan, R. J., Greenhaff, P. L., \& Hespel, P. (2011). Dietary supplements for athletes: Emerging trends 1154 and recurring themes. Journal of Sports Sciences, 29(sup1), S57-S66. https://doi.org/10.1080/02640414.2011.587446

Maughan, R. J., \& Shirreffs, S. M. (2012). Nutrition for sports performance: issues and opportunities. Proceedings of the Nutrition Society, 71(01), 112-119. https://doi.org/10.1017/S0029665111003211

1158 McCarthy, B., \& Liu, H. B. (2017). Food waste and the 'green' consumer. Australasian Marketing Journal (AMJ), 25(2), 126-132. https://doi.org/10.1016/J.AUSMJ.2017.04.007 https://www.nytimes.com/2018/07/09/style/fitness-workout-recovery.html 
1162 Melzer, K. (2011). Carbohydrate and fat utilization during rest and physical activity. European E-Journal of Clinical Nutrition and Metabolism. https://doi.org/10.1016/j.eclnm.2011.01.005

1164

1165

1166

1167

1168

1169

1170

1171

1172

1173

1174

1175

1176

1177

1178

1179

1180

1181

1182

1183

1184

1185

1186

1187

1188

1189

Menzies, P., Menzies, C., Mclntyre, L., Paterson, P., Wilson, J., \& Kemi, O. J. (2010). Blood lactate clearance during active recovery after an intense running bout depends on the intensity of the active recovery. Journal of Sports Sciences, $\quad 28(9), \quad 975-982$. https://doi.org/10.1080/02640414.2010.481721

Mintel. (2016). Free-from gains momentum: Sales of free-from food products forecast to surpass half a billion in the UK in 2016. Retrieved from http://www.mintel.com/press-centre/food-and-drink/free-fromgains-momentum-sales-of-free-from-food-products-forecast-to-surpass-half-a-billion-in-the-uk-in2016

Mitchell, A. K. (2016). Why Strong Is the New Skinny and Why That's a Good Thing. Retrieved November 13, 2018, from https://www.huffpost.com/entry/why-strong-is-the-new-skinny-and-why-thats-a-goodthing_b_8467376

Mohammadi, N., Ehsani, M. R., \& Bakhoda, H. (2018). Development of caffeine-encapsulated alginatebased matrix combined with different natural biopolymers, and evaluation of release in simulated mouth conditions. Flavour and Fragrance Journal, 33(5), 357-366. https://doi.org/10.1002/ffj.3452

Mordor Intelligence. (2018). Sports Nutrition Market: Growth, Trends and Forecasts (2018-2023). Retrieved from https://www.mordorintelligence.com/industry-reports/sports-nutrition-market

Mutch, D. M., Wahli, W., \& Williamson, G. (2005). Nutrigenomics and nutrigenetics: the emerging faces of nutrition. The FASEB Journal, 19(12), 1602-1616. https://doi.org/10.1096/fj.05-3911rev

Nutraingredients. (2016). Personalized nutrition: The path from niche service to mass appeal. Retrieved from https://www.nutraingredients-usa.com/News/Promotional-Features/Personalized-nutrition-Thepath-from-niche-service-to-mass-appeal

Othman, R. A., Moghadasian, M. H., \& Jones, P. J. (2011). Cholesterol-lowering effects of oat $\beta$-glucan. Nutrition Reviews, 69(6), 299-309. https://doi.org/10.1111/j.1753-4887.2011.00401.x

Overview of Food Fortification in the United States and Canada. (2003). In Dietary reference intakes: Guiding principles for nutrition labelling and fortification. National Academies Press (US). Retrieved from https://www.ncbi.nlm.nih.gov/books/NBK208880/ 
1190 Owen, R. W., Giacosa, A., Hull, W. E., Haubner, R., Würtele, G., Spiegelhalder, B., \& Bartsch, H. (2000).

1191 Olive-oil consumption and health: the possible role of antioxidants. The Lancet Oncology, 1(2), 107112. https://doi.org/10.1016/S1470-2045(00)00015-2

Patel, S. (2015). Functional food relevance of whey protein: A review of recent findings and scopes ahead. Journal of Functional Foods, 19, 308-319. https://doi.org/10.1016/J.JFF.2015.09.040

Peters, J. (2018). What nutrition trends can we expect to see in 2018? That Sugar Movement. Retrieved from https://thatsugarmovement.com/what-nutrition-trends-can-we-expect-to-see-in-2018/

Pimparade, M. B., Morott, J. T., Park, J.-B., Kulkarni, V. I., Majumdar, S., Murthy, S. N., .. Repka, M. A. (2015). Development of taste masked caffeine citrate formulations utilizing hot melt extrusion technology and in vitro-in vivo evaluations. International Journal of Pharmaceutics, 487(1-2), 167176. https://doi.org/10.1016/j.ijpharm.2015.04.030

1202

innovation and growth. Retrieved from www.pwc.com/innovationsurvey

Radnitz, C., Beezhold, B., \& DiMatteo, J. (2015). Investigation of lifestyle choices of individuals following a vegan diet for health and https://doi.org/10.1016/J.APPET.2015.02.026

Sahota, A. (2012). The Global Market for Organic Food and Drink. In Sustainable Foods Summit. Amsterdam, Netherlands. Retrieved from www.organicmonitor.com

Sénate Français. (2016). Proposition de loi relative à la lutte contre le gaspillage alimentaire. Retrieved from http://www.senat.fr/leg/tas15-080.html

Spano, M., \& Antonio, J. (2008). Future Trends: Nutritional Supplements in Sports and Exercise. In Nutritional Supplements in Sports and Exercise (pp. 491-508). Totowa, NJ: Humana Press. https://doi.org/10.1007/978-1-59745-231-1_14

Subbiah, M. T. R. (2007). Nutrigenetics and nutraceuticals: the next wave riding on personalized medicine.

1215 The Economist. (2013). The rise of the sharing economy. Retrieved from https://www.economist.com/leaders/2013/03/09/the-rise-of-the-sharing-economy

1217 The Nielsen Company. (2016). What's in our food and on our mind: Ingredients and dining-out trends 
around the world. Retrieved from https://www.nielsen.com/content/dam/nielsenglobal/kr/docs/globalreport/2016/global_ingredient_and_Out_of_home_dining_trends_report.pdf

1220 The Nielsen Company. (2017). US Homescan Panel Protein Survey.

1221 The Nielsen Company. (2018a). Fad or Fundamental? What's Next for Health and Wellness in 2018.

1222 Retrieved from https://www.nielsen.com/us/en/insights/news/2018/fad-or-fundamental-whats-next-

1223 for-health-wellness-in-2018.html

1224 The Nielsen Company. (2018b). Plant-Based Food Options Are Sprouting Growth for Retailers. Retrieved from https://www.nielsen.com/us/en/insights/news/2018/plant-based-food-options-are-sproutinggrowth-for-retailers.html

The Vegan Society.

(2018).

Statistics.

Retrieved November

13, 2018, from https://www.vegansociety.com/news/media/statistics

1229

1230

1231

1232

1233

1234

1235

1236

1237

1238

1239

1240

1241

1242

1243

1244

1245

United States Congress. (1994). Dietary Supplement Health and Education Act of 1994. Retrieved from https://ods.od.nih.gov/About/DSHEA_Wording.aspx

US Congress. (2011). FDA Food Safety Modernization Act. Retrieved from https://www.gpo.gov/fdsys/pkg/PLAW-111publ353/pdf/PLAW-111publ353.pdf

US Food and Drug Administration. (2018). Dietary Supplements. Retrieved November 13, 2018, from https://www.fda.gov/Food/DietarySupplements/default.htm

Vegetarian Resource Group. (2016). Harris Poll. Vegetarian Journal, (4). Retrieved from https://www.vrg.org/journal/vj2016issue4/2016_issue4_harris_poll.php

Venderley, A. M., \& Campbell, W. W. (2006). Vegetarian diets: nutritional considerations for athletes. Sports Medicine, 36(4), 293-305. https://doi.org/10.2165/00007256-200636040-00002

Williams, C., \& Rollo, I. (2015). Carbohydrate Nutrition and Team Sport Performance. Sports Medicine (Auckland, N.Z.), 45 Suppl 1(Suppl 1), S13-22. https://doi.org/10.1007/s40279-015-0399-3

Wind, J., \& Rangaswamy, A. (2001). Customerization: The next revolution in mass customization. Journal of Interactive Marketing, 15(1), 13-32. https://doi.org/10.1002/1520-6653(200124)15:1<13::AIDDIR1001>3.0.CO;2-\#

World Anti-Doping Agency. (2015). World Anti-Doping Code - 2015 with 2018 amendments. Retrieved from www.wada-ama.org 
1246 World Anti-Doping Agency. (2018a). Prohibited List. Retrieved from https://www.wada-ama.org

1247 World Anti-Doping Agency. (2018b). Retrieved November 13, 2018, from https://www.wada$1248 \quad$ ama.org/en/resources/science-medicine/prohibited-list-documents

1249 World Health Organization. (2015a). Active ageing: a policy framework. Retrieved from $1250 \quad$ https://www.who.int/ageing/publications/active_ageing/en/

1251 World Health Organization. (2015b). World report on Ageing And Health. Retrieved from www.who.int

1252 World Health Organization. (2018). Guidelines on food fortification with micronutrients. World Health $1253 \quad$ Organization.

1254 Yazici, F., Alvarez, V. B., Mangino, M. E., \& Hansen, P. M. T. (1997). Formulation and Processing of a Heat 1255 Stable Calcium-fortified Soy Milk. Journal of Food Science, 62(3), 535-538. 1256 https://doi.org/10.1111/j.1365-2621.1997.tb04424.x

1257 Zimberoff, L. (2017). Sports Drink Makers Are Waging an \$8 Billion Thirst War. Bloomberg. Retrieved from 1258 https://www.bloomberg.com/features/2017-sports-drinks-wars/ 


\section{Google trends analysis (2012-2018)}

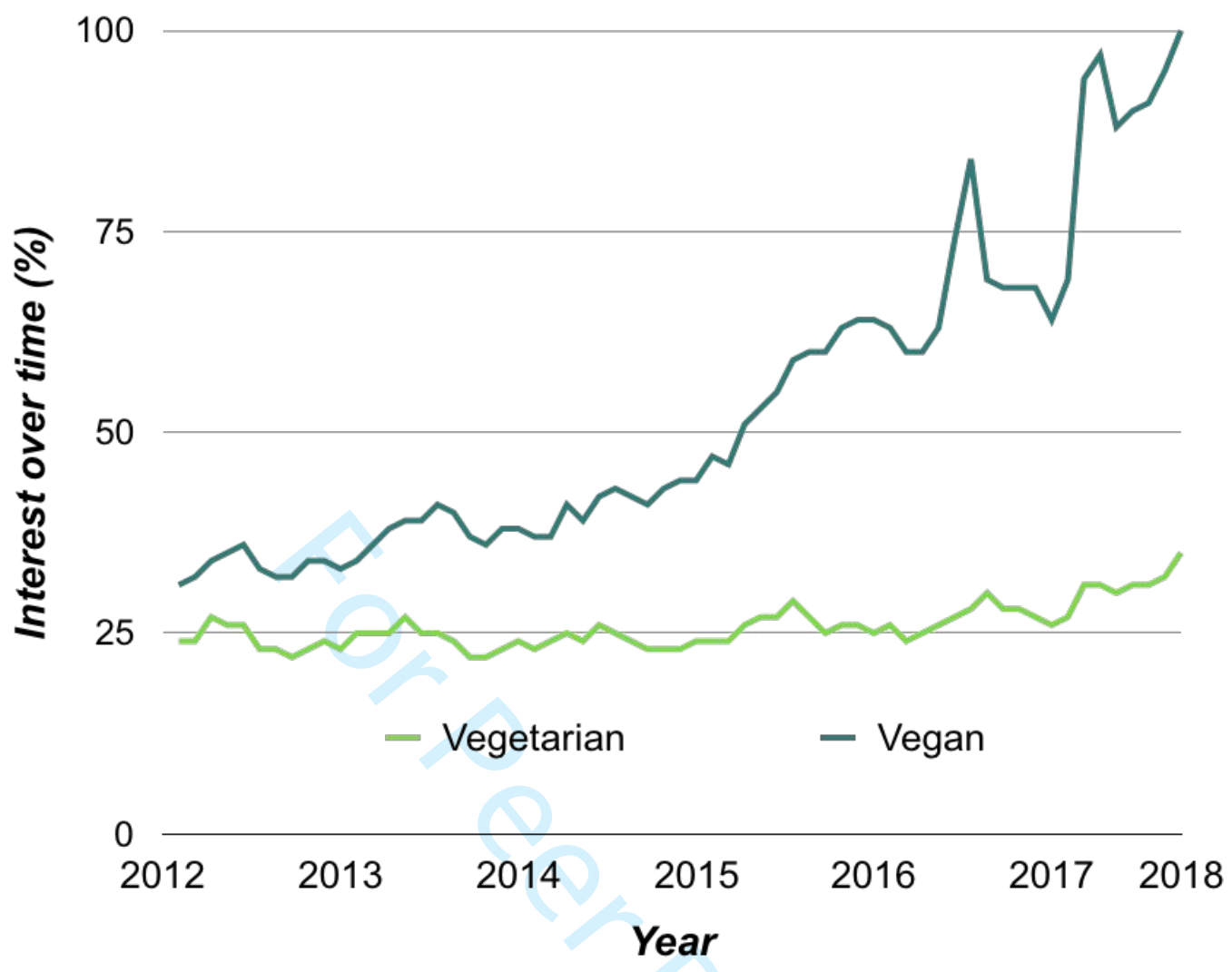




\section{Consumers' 5 primary sources of protein (2017)}

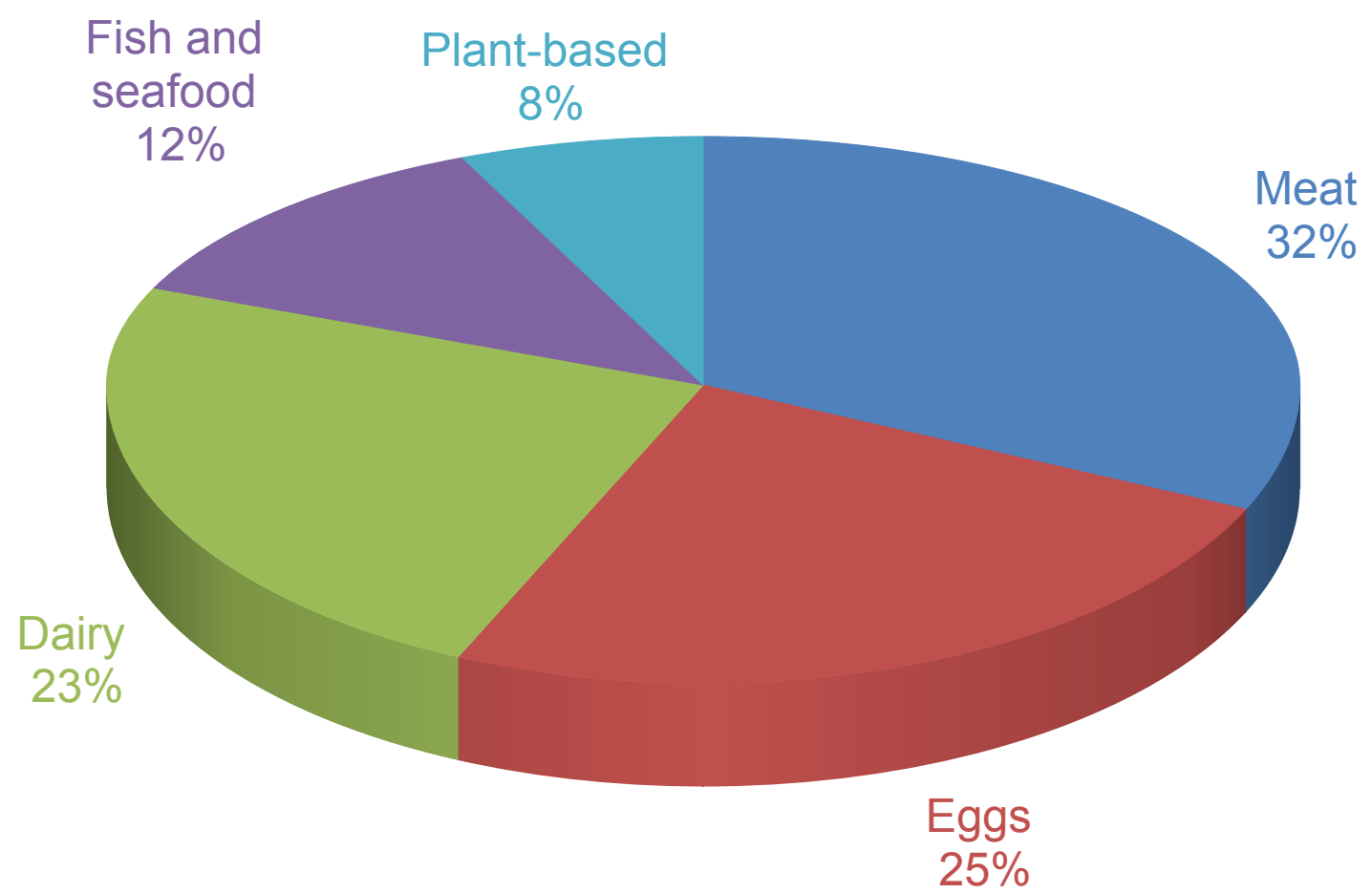

Figure 2. Top five protein sources via consumer survey (The Nielsen Company, 2017). 


\section{Global sales in selected health categories (2017)}

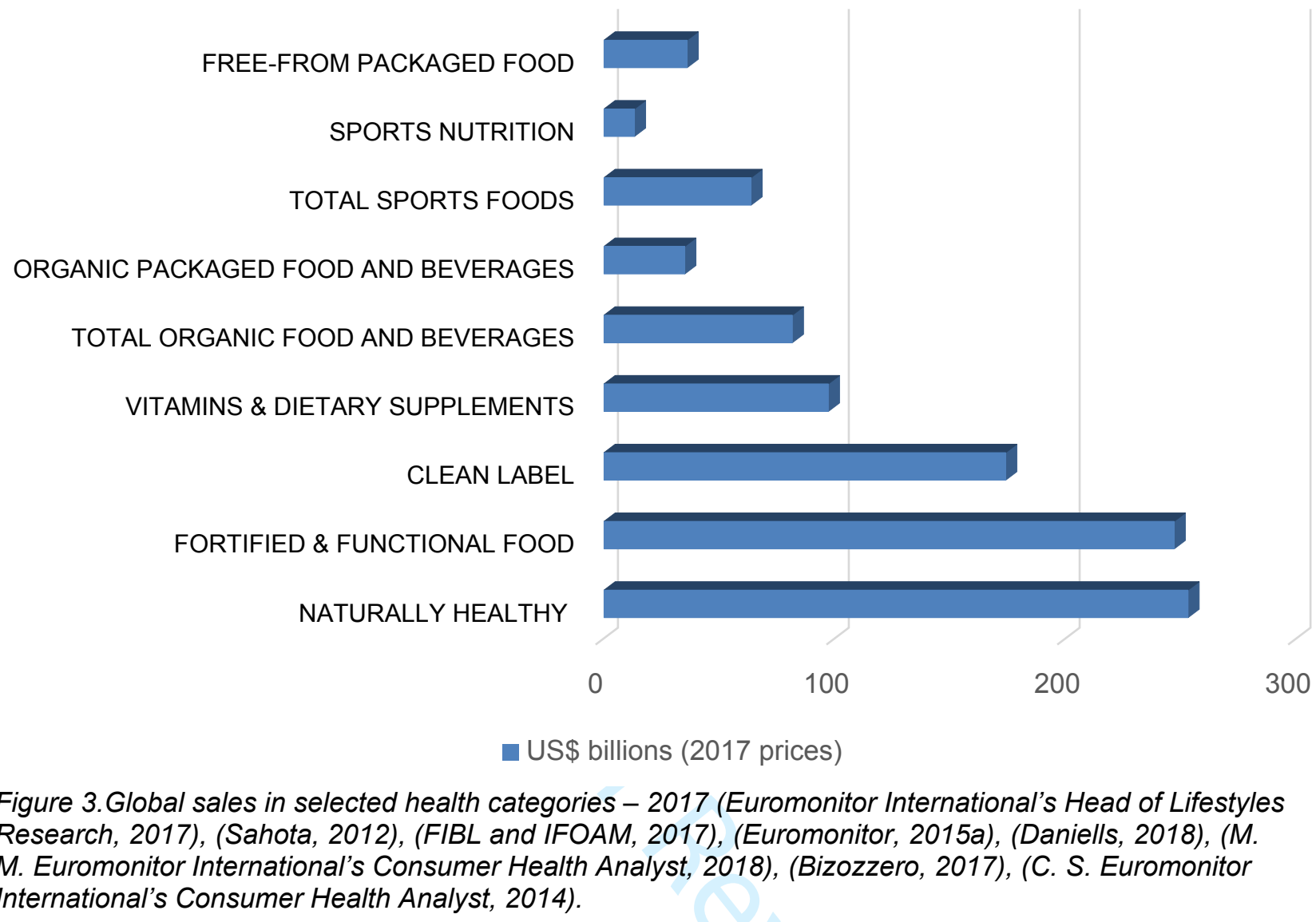

M. Euromonitor International's Consumer Health Analyst, 2018), (Bizozzero, 2017), (C. S. Euromonitor International's Consumer Health Analyst, 2014). 


\section{Global sports foods sales by categories (2016)}

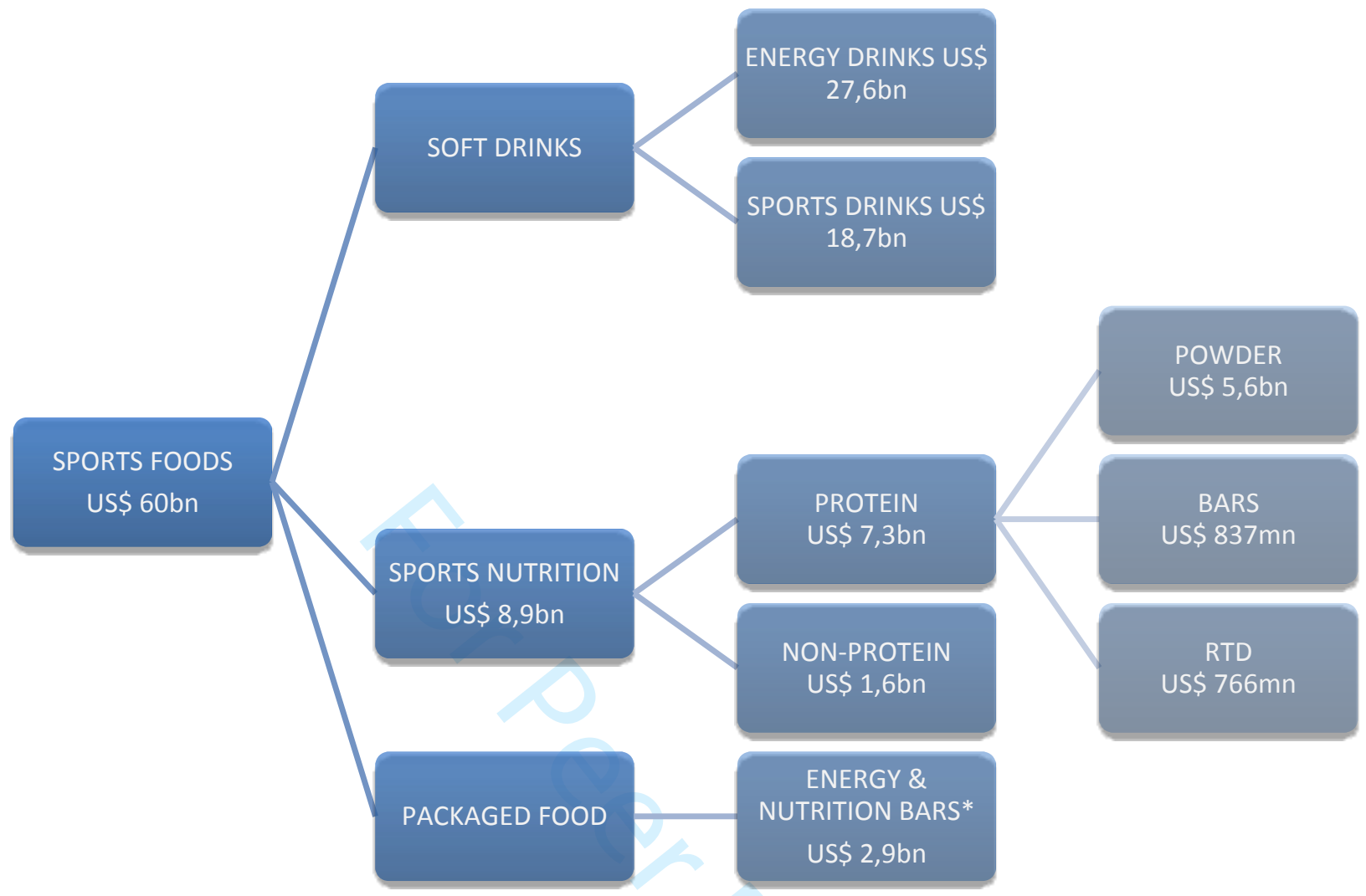

Figure 4.Global sports foods sales by categories (global retail value, US\$ bn, constant 2013 prices). (C. S. Euromonitor International's Consumer Health Analyst, 2014), (Euromonitor, 2015b), (Euromonitor, 2016). * Excluding sports nutrition protein bars. 


\section{Trends in the Food and Sports Nutrition Industry: A Review}

Names of authors: Marta Arenas-Jal; J.M. Suñé-Negre; Pilar Pérez-Lozano; Encarna García-Montoya.

Contact information for corresponding author:

Marta Arenas-Jal

University of Barcelona - Faculty of Pharmacy and Food Sciences (Pharmacy and Pharmaceutical

Technology Department), Joan XXIII, 27-31, 08028 Barcelona (Spain).

marta.arenas.jal@gmail.com.

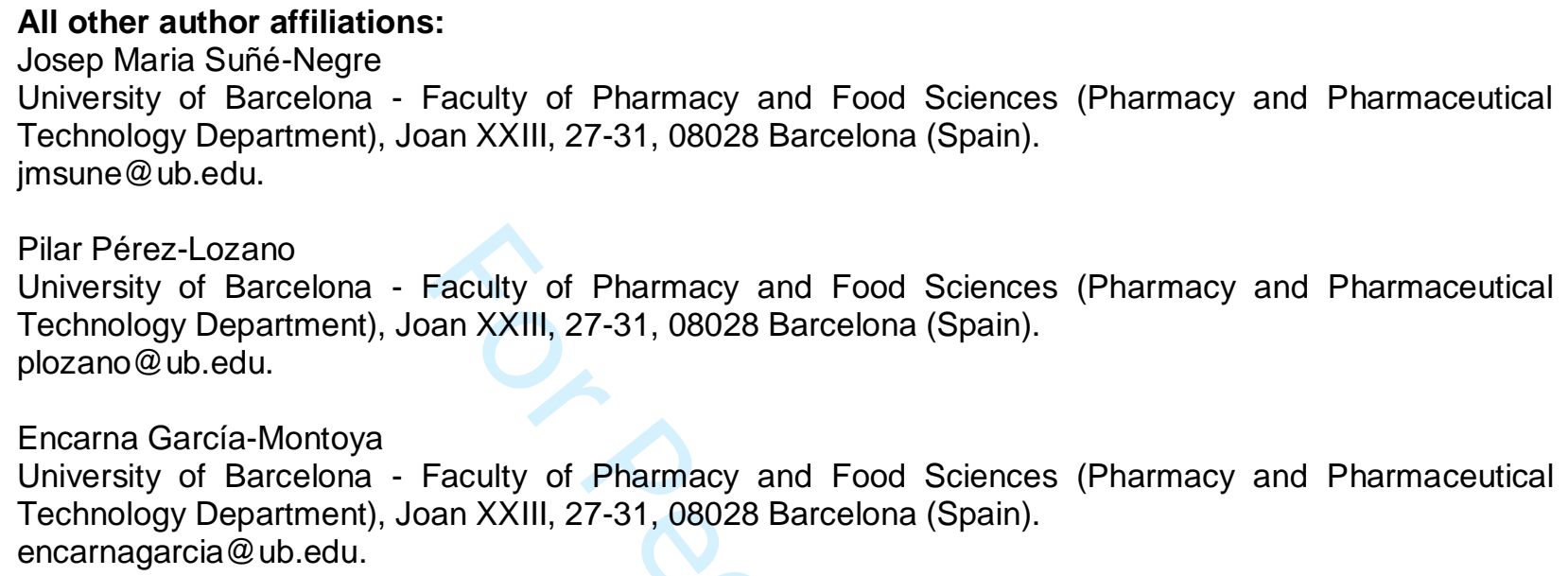

Word count of text: 11,442 words

Short version of title: Food and Sports Nutrition Trends

Choice of journal: Comprehensive Reviews in Food Science and Food Safety

\section{Author disclosures}

M. Arenas-Jal works as R\&D manager for Vitae Natural Nutrition, S.L (Industrial Doctorate). 
ABSTRACT: This revision intends to provide an overview on the major and emerging trends in food and nutrition. Food scientists and dietitians should keep an eye on the trends shaping the food industry in order to understand consumer changes in preferences, expectations and dietary patterns; and to identify those areas that should be added to the research agenda. In addition, to comprehend the major drivers of change in the food industry, global consumer trends are also reviewed in this article. Global concerns are shaping consumer attitudes, and with an easier access to information and an unprecedented consumer power through social media, the food industry should quickly adapt to meet consumer needs. In order to meet these objectives, this review is organized in three different but interrelated sections: global consumer trends, food and nutrition trends, and trends in sports foods and nutrition. This last one is also included due to its influence over food trends, and its significant relevance as a category and food trend.

Keywords: food trends, food industry, nutrition, sports nutrition, consumer.

\section{Table of contents:}

Abstract

Introduction

\section{Global consumer trends}

Clean-living and activist consumers

Personalization, a trend across all industries

Informed and connected consumers are shaping changes

Global consumer trends in brief

\section{Food and nutrition trends}

Older population growth - increased focus on health care

Connected consumers, informed decisions: going greener and healthier

- Vegetarian and vegan diets on the rise

- Organic food growth

- "Free-from" and digestive wellness

- Naturally healthy vs. fortified and functional food

Clean label, no longer a trend but the new norm

Protein is king, fat is back, and what about carbohydrates?

Beverages, snacks and indulgence foods redefined

Activist consumers against food waste

Personalization, a global trend impacting nutrition

Internet of Things shaping interaction with food

Sports nutrition is rocketing

Nutrition trends in brief

\section{Trends in sports foods and nutrition}

Sports nutrition, not just a recent trend

Sports nutrition market analysis

Sports nutrition is becoming mainstream

Proteins will not abdicate - and continue leading

- Whey protein - a sales king that is being challenged 
80 What about non-protein products?

81 An overview of sports nutrition products' global sales

82 Other trends to look out for in $\mathbf{2 0 2 0}$

83 Innovation is driving the market - microencapsulation as an example

84 Considerations on regulation

85

86

87

88

89

90

91

92

93

- US regulation

- EU regulation

- Worldwide anti-doping regulation

Sports nutrition trends in brief

Conclusion

Acknowledgments

1 Author contributions

Abbreviations

References 


\section{Introduction}

The development of new food products is influenced by numerous factors, but among them, global dynamics stand out. Demographics, socioeconomics, culture, politics and environment have a great impact on consumer lifestyles and dietary patterns. In fact, global issues such as climate change, global population aging, child exploitation, food waste, unfair trade or animal abuse, among others, are shaping consumer attitudes towards healthy, plant-based, sustainable and socially conscious food purchases (The Nielsen Company, 2018a). It has to be noted that, thanks to the irruption of new technologies, consumers not only have an easier access to information, but also an unprecedented power to lobby for change (Euromonitor International's Head of Lifestyles Research, 2017).

In this context, and in order to adapt formulas and technologies to consumer needs, food scientists should keep an eye on the major and emerging trends shaping the food industry. Understanding consumer changes in preferences and expectations is vital when developing new products (PriceWaterhouseCoopers [PwC], 2013). Moreover, global dynamics have an influence on nutrition trends, thereby impacting dietary patterns and being potentially disruptive for the correct balancing of the diet. For this reason, not only food scientists, but also dietitians should be aware of the emerging trends that will influence food and nutrition in the coming decades.

The aim of this review is to provide an overview of the current food trends, identifying the areas that are more prone to development, and thus, that should be added to the research agenda. In addition, due to its influence over food trends, and its relevance as a category and food trend, sports foods and nutrition are also reviewed in detail (European Specialist Sports Nutrition Alliance [ESSNA], 2018), (Euromonitor, 2015b). Global consumer trends are also addressed in this review in order to understand the major drivers of change in the food industry. Finally, this review is organized in three different but interrelated sections: global consumer trends, food and nutrition trends, and trends in sports foods and nutrition. 


\section{Global Consumer Trends}

In 2018, with a stronger global economy, consumer expenditure is expected to grow as its strongest rate since 2011 (Euromonitor International's Head of Lifestyles Research, 2017). However, shifting consumer attitudes will continue shaping changes in business.

\section{$\underline{\text { Clean-living and activist consumers }}$}

Consumers are becoming activists due to an increased awareness of global issues through Internet and social media; which at the same time give consumers an unprecedented power to lobby for change (Labrecque, vor dem Esche, Mathwick, \& Novak, 2013). Consumer opinions are far-reaching, and they feel that their spending choices can make a difference (Labrecque et al., 2013). Concerns about climate change and health are widespread among consumers, especially the younger who are adopting a clean-living lifestyle. Clean lifers have strong beliefs and ideals, and they are embracing a minimalist, balanced and healthier lifestyle to reduce harm to themselves, others and the environment (Euromonitor International's Head of Lifestyles Research, 2017). Furthermore, they are demanding companies a greater transparency, sustainability and social responsibility (Kearney, 2010), (Kang \& Hustvedt, 2014).

\section{Personalization, a trend across all industries}

Besides going greener, consumers are seeking uniqueness, demanding to be involved in the production process and product personalization (Wind \& Rangaswamy, 2001). Although customization is demanded in all industries, from sneakers and furniture, to services and experiences; there is a rising interest in personalized health and beauty (Euromonitor International's Head of Lifestyles Research, 2017). Genetic findings related to health, fitness and nutrition, as well as a rising interest in health, and a growing consumer curiosity about their genetics, are fueling demand for DNA testing (Subbiah, 2007), (Ferguson, 2013).

$\underline{\text { Informed and connected consumers are shaping changes }}$

Millennials, also known as "the connected generation", are driving the consumer revolution. Mobile devices are nowadays vital for everything, including shopping, sharing experiences, or health and sport tracking among others (Deloitte, 2013). Health technologies, including wearables and fitness apps, have made 
148

149

150

151

152

153

154

155

156

157

158

159

160

161

162

163

164

165

166

167

168

169

170

171

172

173

174

175

people more aware of their state of health, powering the growth of health and wellness market (L. G. Euromonitor International's Consumer Health Analyst, 2016). In fact, people tend to exercise more, with gym memberships in the United States of America (US) increasing by more than $20 \%$ for the period comprised between 2011 and 2016 (Business Development Bank of Canada [BDC], 2016).

Thanks to new technologies, consumers are more informed about their choices and reject unmeasured or uninformed spending. Ownership is under question and sharing is gaining popularity (Hamari, Sjöklint, \& Ukkonen, 2016). A new wave of apps aims to provide consumers with the opportunity to share everything, from cars to living spaces (The Economist, 2013). Consumers prefer spending their money on experiences like travels, festivals and restaurants, rather than on products (Euromonitor International's Head of Lifestyles Research, 2017). Buying time, such as adopting online shopping and ordering food for delivery, is also a trend on the rise (L. G. Euromonitor International's Consumer Health Analyst, 2016). For this reason, an increased growth rate in apps and mobile optimized websites is forecasted.

\section{Global consumer trends in brief}

Thanks to the irruption of new technologies, consumers' opinion is more powerful than it has ever been. For this reason, concerns about climate change, health and social responsibility, which are widespread among consumers, may shape changes in business. Other important trends are personalization and shared economy; as well as seeking for experiences or saving time rather than buying products. Finally, millennials will lead the mobile-driven market transformation, as they expect to do everything by using their mobile phone.

\section{Food and Nutrition Trends}

Global trends have the power to transform and disrupt entire categories, such as nutrition. One of the aforementioned global trends, clean/healthy living, stands out as the most relevant trend impacting the food industry. Connected and informed consumers are going back to nature and unprocessed foods, to preserve most of the natural vitamins and minerals. For this reason, there's a growth in plant-based, organic, naturally healthy and "free-from" foods. Clean label is also a trend on the rise, and while healthy snacks and fats are 
176

177

178

179

180

181

182

183

184

185

186

187

188

189

190

191

192

193

194

195

196

197

198

199

200

201

202

203

coming back, sugar and certain carbohydrates are becoming the main enemies. Protein, instead, is the preferred food component. Other trends such as personalization, redefinition of indulgence foods, activist consumers, and Internet of Things (IoT), are shaping changes in consumer behaviors and therefore, in the food industry. However, the most relevant nutrition trend is the rise of sports nutrition category.

Older population growth - increased focus on health care

As both the proportion of older people and the average life expectancy increase throughout the world, the older population is growing dramatically worldwide; and therefore, the incidence of chronic diseases (Global Burden of Disease Study 2013 collaborators, 2015). In fact, in about five years' time, the number of people aged 65 or older, will outnumber children under age 5; representing a forecasted $16 \%$ of world's population by 2050 (World Health Organization [WHO], 2015b). Population aging is placing pressure on overall health care spending in developed countries, and for this reason, governments are interested in promoting healthy habits to reduce morbidity and cut off its associated health-care costs. In this spirit, the World Health Organization (WHO) released "Active ageing: a policy framework" in 2002 to prevent and delay chronic diseases and premature mortality, as well as their risk factors (WHO, 2015a).

In line with WHO's health action plan, and thanks to consumer connectivity and access to information, there is an increased attention on health care (Kearney, 2010). For this reason, by 2020, a double-digit growth has been predicted for health and wellness market in the US. In addition, an increasingly number of consumers are seeing food as a medicine, and as a consequence, dietary supplements and sports nutrition stand out as one of the fastest growing healthcare categories, with an expected growth of $14 \%$ over the next few years in the US (BDC, 2016).

\section{$\underline{\text { Connected consumers, informed decisions: going greener and healthier }}$}

With an easier access to information, consumers are becoming more aware than ever of ingredients in their food and their properties. In order to make informed decisions, consumers seek transparency throughout the production process to understand what is in their food and how it was produced (Bjørndal, FernandezPolanco, Lappo, \& Lem, 2013), (Kang \& Hustvedt, 2014). Clean lifers are turning their backs on unhealthy 
habits, food waste and animal-based products. They want to feel good about their consumption choices by eating healthily, sustainably and ethically (Radnitz, Beezhold, \& DiMatteo, 2015). Nowadays, eating often carries an ideological charge similar to belonging to a political party or football club (Euromonitor, 2015a). In fact, in $2018,67 \%$ of US consumers said that they will be prioritizing healthy or socially conscious food purchases (The Nielsen Company, 2018a). Even fast food is getting greener, and there is a decrease in reliance on animal-based nutrition. The vegetarian and vegan movement are already in full-swing, and on the next years we will see a further push to eradicate or reduce animal-based products (Hancox, 2018), (Radnitz et al., 2015).

\section{- Vegetarian and vegan diets on the rise}

The proportion of individuals choosing to follow a vegan diet has increased in the recent years, with ethics and health being the main reason for such choice (Radnitz et al., 2015). As a result of consumer interest, vegan sales growth is outpacing total food and beverage sales (The Nielsen Company, 2018b). When it comes to health benefits of vegetarian eating, current scientific evidence reinforces benefits of a plantbased diet that is low in fat, added sugars, added salt, and processed foods. A healthy and well-planned vegan diet, with a high content of fruits, vegetables and wholes grains, can provide sufficient energy and an appropriate range of carbohydrate, fat and protein intakes to support performance and health (Venderley \& Campbell, 2006). In fact, many top athletes, including world champions like Venus Williams and Lewis Hamilton, are vegan, thereby contributing to a vegan consumer base expansion (Edsor, 2017).

In line with this growing consumer interest, global market for vegetarian and vegan products was worth US $\$ 51$ bn in 2016 , but it is still expanding, with a $987 \%$ increase in demand for vegetarian products (The Vegan Society, 2018). In the same year, a 3\% of the US population ate a strictly vegetarian diet, and about half of those were vegan. But the biggest revelation was that $36 \%$ of consumers opted for at least some vegetarian meal on a regular basis (Vegetarian Resource Group, 2016). In the United Kingdom (UK), the number of vegans quadrupled in the years between 2014 and 2018 , reaching a $1,16 \%$ of the population (The Vegan Society, 2018). Indeed, as shown in Figure 1, vegan trend tripled in the years between 2012 and 2018 (Google Trends, 2018). In line with this rapidly growing consumer demand for vegetarian and 
vegan products, big companies such as Danone, McDonald's or Ben\&Jerry's have invested in vegan alternatives to their products (The Vegan Society, 2018).

To sum up, consumers are keener on more plant-based, natural, minimally processed, local and seasonal food. According to Euromonitor International Global consumer trends survey 2017, "all natural" is the preferred food attribute, followed by "no artificial sweeteners", "limited or no added sugar" and "does not contain Genetically Modified Organisms (GMO) ingredients". In line with these findings, the following categories are on the rise (Euromonitor, 2017a).

\section{- Organic food growth}

Consumers are moving towards products perceived as more natural and healthier, resulting in a global demand for organic products (Asioli et al., 2017). Global sales of organic food and drink expanded by about $10 \%$ to US $\$ 81,6 \mathrm{bn}$ in 2015 . The highest growth was observed in North America, which has the largest market for organic food and drink in the world. Valued at US\$43,4bn and accounting for over half of international sales, it is followed by the European market, which is valued at US $\$ 31,1 \mathrm{bn}$ in 2015 . Asia, Australasia and other regions, account for just US\$7,2bn in 2015. Despite having had an enormous growth, from US $\$ 18$ to $82 \mathrm{bn}$ over 15 years, organic food drink and sales growth is expected to continue (Sahota, 2012), (FIBL and IFOAM, 2017). In fact, by $2019,30 \%$ growth is forecasted for organic beverages in Canada (BDC, 2016).

When it comes to the organic packaged food and beverages, in 2016 they had a global retail value RSP of US\$32,153mn and US\$3,972.7mn, respectively (Euromonitor, 2015a). And in 2018, in Latin America, organic and "free-from" packaged food, are worth US\$35bn and US\$36bn; and will have annual growth rates of about $6 \%$ and $3,5 \%$, respectively, thereby standing out as one of the food categories with a global strongest growth (Daniells, 2018). 


\section{7}

In the same year, global free-from foods were valued at US $\$ 33 \mathrm{bn}$, and have consolidated as the category with the most dynamic growth in the health and wellness market (Euromonitor, 2017b). Consumers perceive "free-from" offering as healthier, and they associate it to digestive wellness and gut health. For this reason, free-from trend has gone beyond intolerance and allergies, as consumers increasingly focus on foods that may help them to reduce feelings of gas, bloating or more severe gastrointestinal symptoms related to suspected allergies or intolerances (Mintel, 2016), (Kerry Health And Nutrition Institute [KHNI], 2018). As a consequence, "free-from" products, as well as added-benefit ingredients such as probiotics and prebiotics are on the rise. When it comes to the largest subcategory, free-from dairy is leading, due to an increased demand for dairy milk alternatives. It is followed by free-from gluten, which had the largest absolute growth over the period between 2012 and 2017 (Euromonitor, 2017b). In fact, in 2015, 12\% of new food products launched in the UK carried a gluten-free claim (Mintel, 2016). Functional foods are those containing added biologically active ingredients that may improve health or lower the risk of disease. Besides supplying macronutrients, vitamins and minerals, they may include other active ingredients like antioxidants, prebiotics, probiotics, enzymes and/or phytonutrients to deliver a specific health benefit above their basic nutritional value (Bigliardi \& Galati, 2013).

Functional food term encompasses a wide variety of products, like those enriched or fortified. Enrichment involves replacing those nutrients lost during processing. An example is bread, often enriched with iron and 
folic acid, which are removed during milling of wheat to make flour (WHO, 2018), (Overview of Food Fortification, 2003). Fortification, instead, involves adding nutrients irrespective of whether they were originally present to any great extent in the food. Fortification is mostly used to improve nutritional status of a population or to differentiate products providing a competitive advantage. For example, bread may be fortified with omega-3 fatty acids (Gökmen et al., 2011). Nutrients are also usually added to substitute products in order to achieve a similar nutritive value to that in the original product. An example is the addition of calcium to soya-based drinks, which are sold as cow's milk substitute, in an amount equal to milk's natural content (Yazici, Alvarez, Mangino, \& Hansen, 1997).

On the other hand, naturally healthy products are those that naturally contain active ingredients. An example is oatmeal, which contains a soluble fiber that can help lower cholesterol levels and heart disease risk (Othman, Moghadasian, \& Jones, 2011), (Bernstein et al., 2013). In line with the clean-living trend, more consumers like the idea of whole plant-based foods with intrinsic nutritional value, and thus, without the need for fortification. This is leading to a decrease in demand for functional foods. In fact, naturally healthy, valued at US\$253bn, has already outpaced global fortified and functional food and beverage market, which is valued at US\$247bn (M. M. Euromonitor International's Consumer Health Analyst, 2018). Despite functional food category growth slowing down, this category is still expanding and important, especially in emerging markets, where consumers are seeking functional ingredients linked to a health positioning (Kearney, 2010).

\section{Clean label, no longer a trend but the new norm}

"Clean label" concept doesn't have any commonly accepted definition, and it is more based on consumer perception rather than on scientific evidence. Clean label products are those made with ingredients that consumers recognize and trust, and that do not contain undesirable ingredients (Asioli et al., 2017), (Bizozzero, 2017). Clean labeling usually involves reducing the number of ingredients, particularly those perceived to be artificial, and those lacking any nutritional benefit. Mainly focused on removing food additives, such as synthetic colors, preservatives, stabilizers, emulsifiers and texturizers; clean labelling in its purest form also involves reducing certain food components such as fat, sugar and salt among others. 
314 Claims such as "all natural", "no artificial sweeteners", "limited or no added sugar", "non-GMO" and

315 "minimally processed" are often included in clean label products (Asioli et al., 2017).

317 In line with the aforementioned global trends, consumers are increasingly mindful of their food and beverage 318 choices. $69 \%$ and $52 \%$ of worldwide consumers believe, respectively, that products without artificial 319 ingredients, and products with fewer ingredients, are healthier (The Nielsen Company, 2016). For this 320 reason, consumers are willing to pay more for clean label products, whose global sales hit US $\$ 165 \mathrm{bn}$ in 3212015 and are projected to reach US $\$ 180$ bn by 2020 (Bizozzero, 2017).

322 Clean label products are no longer a trend but the new norm (Bizozzero, 2017). Ingredient names, and 323 especially consumer familiarity and acceptance of them, play a central role in clean-label. Long, chemical324 sounding, difficult-to-pronounce or unfamiliar names lead to perceptions of higher risk and raise questions about the reason for their use in foods (Asioli et al., 2017). Therefore, clean labeling often includes swapping chemical-sounding names for consumer-friendly ones. By way of example "tocopherol", a synonym of vitamin E, might be perceived as chemical or artificial, so it would be better to list it as vitamin E. However, going clean label is not always such an easy task (Gallagher, Gormley, \& Arendt, 2004). For this reason, the replacement of ingredients regarded as redundant, unacceptable or even harmful without any scientific

330 justification sets up costly and sometimes unnecessary challenges. In addition, as previously mentioned, 331 clean labeling is more about consumer perception than scientific evidence. With a constantly changing consumers' wish-list, so does the target for formulators, whom at the same time have to face functionality, quality and safety issues derived from the replacement of certain ingredients (Lamacchia et al., 2014).

\section{Protein is king, fat is back, and what about carbohydrates?}

335 While consumers try to avoid specific ingredients, others are on the rise. Consumers are increasingly looking for high-protein foods, since an optimal protein intake is usually associated with satiety and lean

337 body mass gain or maintenance (Euromonitor, 2016). Protein also serves as a great replacement for sugar 338 and fat, which are usually linked to an unhealthy diet (Lucca \& Tepper, 1994). With 55\% of US consumers considering high protein content a remarkable attribute when buying food products, protein demand is 
340 increasing (The Nielsen Company, 2017). However, it still has room to grow, especially in emergent 341 markets.

When it comes to the reasons for this protein surge, media praise and sports nutrition have a lot to do with it. Protein dominates sports nutrition global sales, as it is an accessible and understandable ingredient, 345 which gives multiple health benefits (C. S. Euromonitor International's Consumer Health Analyst, 2014). It 346 appeals mainly to younger consumers aligned with fitness trends, but with an increasing evidence of 347 benefits on aging, bone and heart health, it will potentially appeal to millions more in the near future 348 (Euromonitor, 2016).

As for the sources of protein, skinless chicken, fish, egg white and lean beef are the best dietary sources 351 of low fat and high-quality protein (Hoffman \& Falvo, 2004). While traditional sources like meat, eggs and 352 dairy are consumer's primary sources of protein and still dominate sales (as illustrated in Figure 2), plantbased alternatives are experiencing a strong growth, in demand for health, sustainability and animal rights

354 (The Nielsen Company, 2017).

It should be pointed out that fat, which is usually associated to an unhealthy diet, is an essential component of all cells, and along with carbohydrates, provides the majority of energy to individuals who exercise at a low-to-moderate intensity (Melzer, 2011). "Fat is back" is a trend in agreement with the dietary recommendation that the type is more important than the amount of fat (KHNI, 2018). Certain fats such as polyunsaturated omega-3 fatty acids found in fish and other foods, have a number of reported positive 361 health effects, like mitigating inflammation (Calder, 2010). Other examples of healthy fat's sources would 362 be olive and avocado, which are rich in monounsaturated fatty acids (Owen et al., 2000), (Dreher \& Davenport, 2013). Finally, fats also have a technological function, serving as texturizers or as a way to add 364 flavor. The last one is gaining relevance as a result of an increased focus on sugar reduction (KHNI, 2018). 
368

369

370

371

372

373

374

375

376

377

378

379

380

381

382

popularity of carb-free foods (International Food Information Council Foundation, 2018). When it comes to its source, minimally refined grains and faux grains like quinoa, amaranth or wild rice, are gaining popularity due to their nutritional profile with increased protein content and a low glycemic index (Peters, 2018). In contrast, consumers try to avoid sugars or starches, which are often referred to as "bad carbs" due to their minimal nutritional value. This is strongly linked with the plant-based food trend, as carbs derived from fruits or vegetables are considered as "good carbs", and are used instead of refined starches (KHNI, 2018).

\section{Beverages, snacks and indulgence foods redefined}

Due to the aforementioned scientific evidence against added sugars and energy drinks, beverages are in a redefinition phase. Functional beverages like kombucha and protein shakes are gaining popularity among consumers, who are keener on beverages that incorporate protein, fiber and vegetable servings, while maintaining an acceptable flavor (KHNI, 2018). In functional beverages, stevia is usually the sweetener of choice for people who want to cut down sugar or calories (Lemus-Mondaca, Vega-Gálvez, Zura-Bravo, \& Ah-Hen, 2012).

When it comes to snacks and indulgence foods, they are being reformulated so that they contain more plant-based and/or perceived as healthy ingredients. In addition, due to busier lifestyles, an increasing number of consumers prefer a snackable meal format, which is more convenient than sit-down meals. This is a growing food trend, known as "snackification" (KHNI, 2018).

\section{Activist consumers against food waste}

With half of the world's food being thrown away, there is an increased concern about food waste (McCarthy \& Liu, 2017). For this reason, consumer acceptance of "non-perfect" products will grow, and consumers will begin to consider cheap food past its best before date. A revival in use of leftovers, right-size portioning and grow-it-yourself, is also forecasted (Euromonitor, 2015a). Finally, as consumers are keener on new initiatives encouraging more sustainable production and targeting food waste, governments are also making a move. In fact, in France, a law was approved to make supermarkets give food waste to charity or as animal feed (Sénate Français, 2016). 
$397 \quad$ Personalization, a global trend impacting nutrition

398 As discussed above, personalization is one of the main global trends, which is also influencing nutrition 399 trends. A new wave of companies provides consumers with genetic and metabolomic findings related to 400 their health, fitness and nutrition (Subbiah, 2007). Additional information can be collected through wearable 401 fitness trackers, among other methods; giving an overall picture of health. Personalized training and 402 nutrition plans are offered based on findings of individual parameters such as fat burning ability or capacity 403 to metabolize caffeine, lactose or gluten, among others (Mutch, Wahli, \& Williamson, 2005), (Ferguson, 404 2013). In this context, one of the main challenges of personalization is not just customizing mass-produced 405 products, but also shaping them to individual preferences before production, in order to shift from product 406 to experience or service (Wind \& Rangaswamy, 2001), (Euromonitor International's Head of Lifestyles 407 Research, 2017). Internet of Things shaping interaction with food

410 By the year 2020, about 24 billion internet-connected devices will be installed globally, which is the 411 equivalent of about 3 devices/person (Gubbi, Buyya, Marusic, \& Palaniswami, 2013). loT may continue 412 shaping the way we purchase, receive and interact with our food. In fact, there is a continued expansion of 413 online or online/offline hybrid subscription services, such as click and collect grocery shopping and delivery 414 of restaurant meals. Due to strong growth of these alternative businesses, it is expected that by 2021 , 415 supermarkets and hypermarkets will account for less than a half of the total consumer goods trade 416 (Euromonitor, 2018).

\section{Sports nutrition is rocketing}

419 In line with the aforementioned healthy living trend, more people are adopting an active lifestyle, which is 420 translating into a rise of sport and endurance activities (C. S. Euromonitor International's Consumer Health 421 Analyst, 2014). As scientific evidence confirms that certain ingredients can enhance athletic performance, 422 more people recognize the benefits of sports nutrition products, and therefore, are increasingly 423 complementing their work-out sessions with these products (American Dietetic Association et al., 2009), 
(Ronald J. Maughan \& Shirreffs, 2012). For a long time, sports nutrition products were primarily meant and used by the so-called core users, that is, elite athletes and bodybuilders. However, the growing health consciousness and desire for fast results has helped sports nutrition to become more appealing to mainstream consumers and thereby, to expand its consumer base over the last decade. The so-called casual users have pushed the category into the mass market (Euromonitor, 2015b). For this reason, products that were once only available in fitness shops, can now be found in pharmacies and even supermarkets, achieving greater total sales for the sports nutrition category (Spano \& Antonio, 2008).

Sports nutrition was valued at US\$8,8bn in 2013; and sports foods comprising protein supplements, sports nutrition, and soft drinks including energy and sports drinks, were valued at US\$60bn in the same year (C. S. Euromonitor International's Consumer Health Analyst, 2014). Despite having experienced a steady rate growth in the last decade, several market researches continue forecasting a sustained global growth for sports nutrition category in the following years (Euromonitor, 2015b). Last but not least, although it has been reviewed as a nutrition trend, sports nutrition is also a category itself, with its own wide range of specific trends, and for this reason it will be reviewed in detail in the corresponding section below.

\section{Nutrition trends in brief}

To sum up, global trends and concerns about climate change, health and social responsibility, which are widespread among consumers, are shaping changes in nutrition. As a consequence of the clean-living trend and the older population growth, there is an increased focus on healthy nutrition and physical exercise to prevent and delay aging, chronic diseases and premature mortality, as well as their risk factors.

Consumers seek transparency, and with an easier access to information, they are becoming more aware than ever of ingredients in their food. Consumption choices are influenced by the will of eating healthy, but also ethically and socially conscious. For this reason, consumers are keener on more natural, animal-free, plant-based, minimally processed, local, and seasonal food. Besides going back to nature, with a growth in demand for organic and naturally healthy products, other categories such as "free-from" and fortified/functional foods are also on the rise. 
453 In line with the clean labelling trend, certain ingredients or categories, such as dairy, sodium, sugar or 454 carbohydrates, are being avoided or limited by an increasing number of consumers. Instead, other 455 ingredients such as proteins or healthy fats, are becoming more popular. With health as the main priority, 456 even beverages, snacks and indulgence foods, are being redefined to incorporate ingredients with 457 demonstrated health benefits.

458

Other global trends such as personalization, activist consumers against food waste, and loT, are shaping interaction with food and impacting nutrition. Sports nutrition is rocketing and influencing nutrition trends, possibly being the main responsible for the protein surge. For this reason, and because it is not only a nutrition trend, but also a category itself, it will be reviewed in detail in the section below.

Finally, by way of a summary, Figure 3 shows the global sales of the selected health categories in 2017, reflecting their relevance among the different health categories.

\section{Trends in Sports Foods and Nutrition}

Global trends and consumer concerns are shaping changes in nutrition, and thereby influencing the sports nutrition category as well. "Healthy living" stands out as the most relevant global trend impacting the food industry, and it is responsible for the enormous growth that sports nutrition category is experimenting. In line with this increased health awareness, consumers are keener on more natural, animal-free, plant-based, minimally processed, local, and seasonal food, what is also shaping sports nutrition products.

As more consumers become aware of the importance of a well-designed diet for a good training, the use of sports nutrition products is becoming mainstream. Besides being a nutrition trend, it is an important category influencing nutrition trends, possibly being the main responsible for the protein surge. Sports nutrition is a large and quickly growing consumer health category that promotes the achievement of an optimum nutrient intake, which is having positive implications in health care costs and well-being, and for this reason it will be reviewed in detail below. 
$\underline{\text { Sports nutrition, not just a recent trend }}$

482 Sports foods are those specialized products designed for athletes and active people to improve their nutritional intake, health, wellbeing, performance, muscle growth and/or recovery from exercise. In addition, they can also provide a convenient source of nutrients when it is impractical to consume everyday foods. Whey protein, sports gel or electrolyte replacement drinks are examples of sports foods. Among sports foods, sports nutrition encompasses food/dietary supplements aimed to contribute to an optimal performance (ESSNA, 2018). By law, sports nutrition products can only contain vitamins, minerals, food ingredients, macronutrients, herbal ingredients with a substantial history of use, and other ingredients that are generally regarded as safe (European Parliament, 2002), (United States Congress, 1994). Despite the distinction between sports foods category and sports nutrition subcategory, the two terms are often used interchangeably, also in the following text.

Although sports nutrition is one of the latest trends, it is a much older phenomenon. In the ancient Olympic Games, athletes used to eat massive quantities of meat, bread, dried fruits and honey, along with various fungi and herbs in an attempt to increase their athletic performance. But it was not until the last century when scientists found that certain substances were effective in improving athletic performance, and thereby, the first scientific-based sports nutrition products were created (ESSNA, 2018). A well-designed diet, with nutrient-dense foods, that meets energy intake requirements and incorporates proper timing of nutrients, is the foundation of a good training (Kerksick et al., 2008). However, athletes' dietary needs might be difficult to achieve through food intake alone, and for this reason, dietary supplements and sports nutrition products are often needed. When races are won by mere fractions of a second, and games may be lost due to 502 fatigue, nutrition can make the difference between an athlete and a champion (Spano \& Antonio, 2008).

504 Until recently, only bodybuilders and strength athletes were pushing for nutrient-dense, high-quality, and 505 more convenient sources of nutrition, that could help them satisfy their unique nutritional requirements. 506 However, as a consequence of an increasing scientific evidence on sports nutrition health and performance benefits, more athletes and coaches from other disciplines, embraced the use of these products. In the last 
508

509

510

511

512 Sports nutrition market analysis

513 Consumers worldwide are adopting a healthy living lifestyle and gaining awareness of their needs and 514 proactive steps that can be taken to achieve a higher wellbeing and prevent chronic diseases (Euromonitor 515

decade, sports nutrition has expanded its consumer base to amateur athletes and active people who not only care about their muscle growth, athletic performance and recovery, but also about their health and wellbeing (Euromonitor, 2015b), (C. S. Euromonitor International's Consumer Health Analyst, 2014). International's Head of Lifestyles Research, 2017). Along with this trend, different categories are growing, like the Canadian wearable device market, which includes fitness trackers, and is expected to grow by $150 \%$ in 2019 . Another example would be that in 2014 , more than $41 \%$ of Canadians were interested in buying a health monitor (BDC, 2016). So, with health in focus and with the rising mantra "strong is the new skinny", sports nutrition is the fastest growing consumer health category for several years in a row, and it is expected to continue growing at a steady pace in the next years (Mitchell, 2016).

Since more people recognize the benefits of sports nutrition products, the category has seen an enormous growth, from US $\$ 6,7 \mathrm{bn}$ and US $\$ 8,9 \mathrm{bn}$ in 2010 and 2013 , respectively, to US $\$ 10,8 \mathrm{bn}$ in 2015. Moreover, forecasts point out that it will continue growing. Sports foods, including not only sports nutrition products, but also sports and energy drinks and bars, were worth US\$60bn in 2013 (C. S. Euromonitor International's Consumer Health Analyst, 2014).

Although US is dominating the global market, accounting for over $60 \%$ of global sales, the growth is truly global. However, in terms of consumption, developed markets are leading. By way of example, Australia followed by US were leading in consumption in 2013, with an expenditure of US $\$ 55$ and 45 per household respectively; while world average consumption was around US $\$ 5$ per household. As for low-income markets, despite the barrier of relatively high prices, the global healthy living trend together with the rising disposable incomes, are supporting the increased demand and consumption of sports nutrition products. For this reason, less developed markets such as China, India and Brazil, are evolving and fast growing (C. 
S. Euromonitor International's Consumer Health Analyst, 2014), (C. O. Euromonitor International's Consumer Health Analyst, 2017).

\section{Sports nutrition is becoming mainstream}

The main reason for the sports nutrition market steady growth is the expansion of its consumer base over the last 10 years (Euromonitor, 2015b). Consumers have an increased health awareness and are increasingly opting for sports nutrition products to complement their work-out sessions (Mordor Intelligence, 2018). As a result, the demand for sports nutrition category and its sales are rocketing.

Sports nutrition products, which are aimed to improve performance, post workout recovery and muscle maintenance and building, were originally designed for elite athletes and body builders in order to keep up with their unique nutritional demands. However, as a result of the healthy living trend, sports nutrition products have become mainstream over the past decade (C. S. Euromonitor International's Consumer Health Analyst, 2014). Besides the constantly increasing fitness clubs, which are exposing more and more recreational sports enthusiasts to sports nutrition products, other key features to support market growth have been innovation, with a growth rate of 10'4\% of global product launches between 2011 and 2016, and consumer loyalty. In contrast to what happens to other categories, when users detect a positive difference in performance, they generally stick to it. Thereby, sports nutrition products enjoy a high degree of loyalty (Mordor Intelligence, 2018).

When it comes to consumers, they are not only increasing in number, but also in diversity. As a consequence, knowledgeable and high-volume users who purchase frequently, also known as "core users", no longer dominate sports nutrition sales. In the last decade, sports nutrition products have become more appealing to a greater number of mainstream consumers, often referred to as "casual users", who are recreationally active. They prefer convenient formats and recognizable ingredients (Euromonitor, 2015b). Another group has recently emerged in developed markets, they are the "lifestyle users" who are not particularly athletic but put a greater focus on increasing their fitness levels by trying to do more exercise. Lifestyle users are mainly young and invest in fitness as a fundament aspect of a healthy lifestyle. They are 
keen on trying new products, formats and ingredients (C. S. Euromonitor International's Consumer Health Analyst, 2014), (Mordor Intelligence, 2018).

Despite the different characteristics defining each consumer type, what all of them have in common is that they seek transparency, as well as clean and open label formulations (Kang \& Hustvedt, 2014). Responding to these demands, third-party banned-substance-free certification has become a standard for major brands and producers. In addition, an increasing number of brands are opening up their proprietary blends with complete ingredient break-outs (C. S. Euromonitor International's Consumer Health Analyst, 2014). In general, a greater focus is put on the presentation of products, including appealing and interactive labelling to make it easier for the consumer to understand the ingredients, and to ensure product safety (Mordor Intelligence, 2018).

Finally, as a consequence of the consumer base expansion and segmentation, sports nutrition products are consumed for different purposes. For this reason, companies are discussing whether a better name for the industry would be lifestyle nutrition or active nutrition, which would appeal to more consumers, helping to continue broadening the consumer base (C. O. Euromonitor International's Consumer Health Analyst, 2017). In line with this last objective, major brands are penetrating mainstream distribution channels, such as gyms, pharmacies and supermarkets. For this reason, products that were once only available in dedicated fitness shops, have made their way to other retailers. In addition, sports nutrition products are also distributed by online sellers, accounting for $41,3 \%$ of sales in the US in 2017 (Mordor Intelligence, 2018).

\section{Proteins will not abdicate - and continue leading}

Proteins dominate global sales, in no small part as a consequence of being the most accessible and understandable sports nutrition ingredient. While non-protein products were worth US $\$ 1,6 \mathrm{bn}$ in 2013 , this is $17 \%$ of the total sports nutrition market; protein products, including powder, bars, ready-to-drink beverages and others, have been growing at a steady pace, reaching US $\$ 7,3 b n$ in 2013 and US $\$ 9,2 b n$ in 2015 , accounting for more than $83 \%$ of the total sports nutrition market. In addition, $6,5 \%$ compound annual 
growth is forecasted for protein products during the time frame between 2015 and 2020. In fact, protein market is expected to reach US $\$ 13,5 \mathrm{bn}$ in 2020 (C. S. Euromonitor International's Consumer Health Analyst, 2014), (Euromonitor, 2015b).

Protein claims related to muscle mass growth, lean muscle maintenance and recovery from resistance exercise, makes protein the most demanded product on sports nutrition category. Protein is especially appealing for younger consumers, aged 15-34. Its popularity benefits from media praise and still has room to grow, particularly in emergent markets such as China, Latin America and India. Other lesser known protein benefits are satiety, bone and heart health, and antiaging, which are perfectly aligned with global concerns about overweight, obesity, cardiovascular health and aging. Provided that these claims become mainstream, proteins will potentially appeal to millions more in the near future (Euromonitor, 2016). As a result of its reputation as a health-promoting ingredient, natural-containing protein products and protein fortified foods, are also gaining popularity among mainstream consumers.

In the sports nutrition category, protein products remain the most demanded, as they offer a convenient way of meeting increased protein requirements without excess calories, fats or sugars. When it comes to the format, protein powder accounted for $70-80 \%$ of total protein products and reached US\$5,6bn in 2013. However, convenience formats, like ready-to-drink beverages, or protein bars, are growing quickly and reached US\$ 766mn and 837mn, respectively, in 2013 (Euromonitor, 2016).

Among protein powder products, which usually need to be mixed with water or milk, whey is the king of sales. Casein, egg and soy proteins are also fairly common (Euromonitor, 2015b), (Euromonitor, 2016). However, in nutritional terms, whey is one of the best quality protein sources, and it delivers a greater taste than the offered by other sources. Besides its content in essential amino acids and BCAA, whey proteins are also well-known for its easy digestion and quick absorption, which ensure a fast delivery of the building blocks required for lean muscle mass growth and recovery (Hoffman \& Falvo, 2004), (Patel, 2015). In fact, 
618 published scientific research has demonstrated that in relation to other protein sources, whey protein 619 promotes greater muscle-building activity and muscle mass gains (Hoffman \& Falvo, 2004).

621 For a long time, whey protein isolate was only popular among core users, but due to a trickle-down effect, 622 its consumer appeal is widening (C. S. Euromonitor International's Consumer Health Analyst, 2014). In 623 addition, whey protein is versatile and easy to use in product applications, so it is also popular among 624 manufacturers (Agarwal, Beausire, Patel, \& Patel, 2015). However, as casual and less-sophisticated users increasingly opt for whey protein products, core users are shifting to sustained-release protein blends, which could also gain mass acceptance in the near future (C. S. Euromonitor International's Consumer Health Analyst, 2014). These new formulations, including mixtures of different protein sources and protein treatments (concentrate, isolate and hydrolysate), are challenging whey protein isolate as king of protein sales (Euromonitor, 2016). Other factors, such as sustainability and animal welfare, are increasing the demand for plant-based proteins and therefore, increasing the challenge for whey protein (Radnitz et al., 2015), (Hancox, 2018).

632

Last but not least, in line with the healthy nutrition trend, high-protein and added-protein foods, which are already in full-swing, could pose a long-term threat to specialized sports protein products; especially among casual and lifestyle users (Chittock, 2013). In addition, although scientific evidence confirms protein supplementation safety, some dietitians are questioning the need and safety of protein supplementation, posing another threat to sports protein products (Antonio et al., 2016).

\section{- $\quad$ Rising demand for plant-based proteins}

With over $80 \%$ of sports nutrition sales coming from protein-based products, and a global high-protein diet

641 trend, sports protein products will continue to lead the industry (C. O. Euromonitor International's Consumer 642 Health Analyst, 2017). However, consumers are increasingly asking for free-from, non-allergenic and plant643 based products; and proteins are not the exception. With 3\% of US population eating a strictly vegetarian 644 diet, and $36 \%$ opting for at least vegetarian meals on a regular basis in 2016 , there is a growing demand 645 for plant-based proteins (Vegetarian Resource Group, 2016). Sustainability, animal welfare and a decrease 
646 in reliance on animal-based nutrition are driving the demand for alternatives to milk proteins (C. S. 647 Euromonitor International's Consumer Health Analyst, 2014), (Radnitz et al., 2015), (Hancox, 2018).

648

649

650

651

652

653

654

655

656

657

658

659

660

661

662

663

664

665

666

667

668

669

670

671

672

673

Plant-based proteins from soy, pea or rice are less common than whey protein, but they are growing quickly and will continue to do so (Euromonitor, 2016). In fact, scientific evidence shows that plant-based proteins can be as effective as animal proteins for muscle maintenance, as long as the selected source, delivers all the essential amino acids needed (Mangano et al., 2017). In addition, a well-designed vegetarian or vegan diet provides sufficient energy and appropriate range of carbohydrate, fat and protein intakes to support performance and health (Venderley \& Campbell, 2006), (Lynch et al., 2016). For this reason, certain elite athletes are going vegan and beginning to consume plant-based proteins, thereby contributing to plantbased proteins consumer base expansion (Edsor, 2017).

\section{- Hydrolysates are the next big thing - life is too short for slow proteins}

Differences in protein source, amino acid profile, and processing methods, can have an influence on amino acids bioavailability. Hydrolysates are high-quality proteins that have been finely chopped or predigested so that they can be absorbed faster than conventional proteins, helping to cut muscle recovery times from days to hours (Manninen, 2009). For this reason, they play a greater role in those athletes who place higher pressure on their body due to exercise frequency and intensity, and those who have a small window for recovery. Although hydrolysates future is promising, its bitterness and astringency hinders its incorporation into beverages, bars and gels (FitzGerald \& O'Cuinn, 2006), (Liu, Jiang, \& Peterson, 2014). This is not a drawback for core users, but since casual users prefer convenience products with good taste, until now hydrolysates have had a slow expansion. However, recent advances in hydrolysates processing technology have allowed taste-masking, enabling its incorporation into various formats such as clear drinks (FitzGerald \& O'Cuinn, 2006). As a consequence, a fast growth for hydrolysates is forecasted (Euromonitor, 2015b).

\section{What about non-protein products?}

Casual users' adoption of non-protein products is growing. However, since these products are more difficult to understand by the mainstream and uninformed consumers, they mostly appeal to core users. With sales 
674

675

676

677

678

679

680

681

682

683

684

685

686

687

688

689

690

691

692

693

694

695

696

697

698

699

700

701 reaching US\$160mn in 2013, UK has a leading position in the global non-protein products market. Global sales were worth 1,6bn in 2013 and are expected to grow by nearly US $\$ 500 \mathrm{mn}$, achieving US $\$ 2 \mathrm{bn}$ in 2018 (C. S. Euromonitor International's Consumer Health Analyst, 2014).

In general, fitness-focused lifestyle, a desire for fast results, and a high demand for portable and convenient products, are the main drivers of the sports nutrition category. When it comes to convenience formats, nonprotein products have been ahead, leading the experimentation. Gels, chews, bars, sachets and shots are examples of convenience formats. With the rise of endurance sports, gels have become the most popular convenience format (Euromonitor, 2015b), (C. S. Euromonitor International's Consumer Health Analyst, 2014).

As for sports drinks, they are expected to record the highest growth rate in the following years. Sports drinks, including products sold in powder to be rehydrated in water, are highly demanded as consumers become aware of the uses and benefits of drinks rich in carbohydrates, minerals and electrolytes (Zimberoff, 2017). Active and sports people have higher carbohydrate requirements, and without an adequate intake of them, exercise performance decreases (Williams \& Rollo, 2015). Electrolyte-replacement, glucosecontaining solutions help to maintain blood glucose levels and prevent dehydration and therefore, may delay fatigue and attenuate muscle damage during endurance exercise (American Dietetic Association et al., 2009). However, the growing sugar-averse consumer base is contributing to an increased demand for low-calorie and low-carbohydrate sports drinks, especially in North America, which is the leader in sales (International Food Information Council Foundation, 2018). New sports drinks are mainly focused on optimizing hydration before, during and after physical activity. Maintaining hydration status is one of the most effective ways to maintain exercise performance, which can be significantly impaired when $2 \%$ or more of body weight, is lost through sweating (American Dietetic Association et al., 2009),(Ronald J. Maughan \& Shirreffs, 2012).

In 2013, sports drinks and energy drinks accounted for US $\$ 18,7 \mathrm{bn}$ and US $\$ 27,6 \mathrm{bn}$, respectively. However, there is a blurring line between energy/sports drinks, and non-protein products category (C. S. Euromonitor 
702 International's Consumer Health Analyst, 2014). The main reason for this, is that energy/sports drinks are 703 shifting from the so-called bad carbs to the good ones. This is translating into products with lesser amounts 704 of ingredients with minimal other nutritional value, like sugar or starches; and with higher amounts of 705 naturally-containing-carbohydrates fruits, vegetables and whole grains (International Food Information 706 Council Foundation, 2018). Strongly aligned with plant-based trend, this new wave of products is blurring 707 the line between energy/sports drinks, and other drinks or beverages in the non-protein products category.

An overview of sports nutrition products' global sales

710 Before moving forward with other trends to look out for in 2020, Figure 4 shows the global sales of the 711 selected sports foods subcategories in 2013, thus reflecting their relative relevance.

\section{Other trends to look out for in 2020}

714 Nutrient timing is a well-known concept for elite athletes, and casual users' awareness of its importance is 715 increasing. Meal times and snacks should be planned in concert with training, to make sure that athletes have sufficient availability of nutrient-dense foods throughout the day. Research has shown that meal timing 717 and composition may play a role in optimizing performance, training adaptations and preventing overtraining (Kerksick et al., 2008). By way of example, within 30 minutes of a workout, consuming highquality carbohydrate and protein is key to replenish those nutrients depleted during the workout. While carbohydrates replenish glycogen stores and therefore, support muscle recovery, protein helps in muscle building and repairing (American Dietetic Association et al., 2009).

Global trends such as transparency, clean labeling and personalization are also impacting sports nutrition. Besides those that have already been discussed before, customized workouts and meals, tailored to preferences and goals, will help optimizing physical activity. "One size fits all" will no longer exist, and appeal for personalized fitness plans and nutrition, will broaden from elite athletes to include casual users as well (German, Zivkovic, Dallas, \& Smilowitz, 2011), (Nutraingredients, 2016), (Gardiner, 2016). 
Recovery is gaining importance over rest. While resting is just the absence of training, recovery involves all techniques and activities to maximize repair: hydration, compression, nutrition, heat or cold, stretching and massaging (Menzies et al., 2010). For a long time, a lot of these techniques were only reserved for elite athletes, but casual users' adoption is increasing as they are becoming aware that a balance between rest and recovery, together with a proper nutrition is essential for anyone who exercises (Meltzer, 2018), (Mateo, 2018).

Finally, flavor is one of the most important areas for innovation in the sports nutrition industry, and it has a long way to go in terms of customers acquisition and retention (Cash, 2017). Another main driver of sports nutrition industry is convenience packaging, since consumers prefer small and portable products (Euromonitor, 2015b), (Euromonitor International's Head of Lifestyles Research, 2017).

\section{Innovation is driving the market - microencapsulation as an example}

Besides demand-driven innovation, offering technological and professional solutions to mass market consumers is a powerful driver for growth and competitive positioning of a company (PwC, 2013). In this line, technologies such as microencapsulation would allow a broader use of certain ingredients with organoleptic or stability issues, among others. Microencapsulation is a technique that involves the entrapment of a substance within a microscopic shell of encapsulating polymeric material to give microcapsules different useful properties: preventing interactions among ingredients of a formula, flavor masking, increased stability and bioavailability, improved dissolution and flowability, and sustained-release among others (Gaonkar, Vasisht, Khare, \& Sobel, 2014).

By way of example, taste-masking microcapsules allow the incorporation of caffeine into gels or chews without its characteristic bitter taste (Pimparade et al., 2015), (Mohammadi, Ehsani, \& Bakhoda, 2018). Other examples of microencapsulation applications are increased water-dispersibility and bioavailability of hydrophobic ingredients, such as coenzyme Q10 or medium chain triglycerides (Gaonkar et al., 2014). Microcapsules are also capable to increase the stability of certain sensitive ingredients, such as probiotics, when they are exposed to different environmental conditions like heat, humidity, light and oxygen (Anal \& 
Singh, 2007). Furthermore, microcapsules can act as delivery systems. Depending on the microencapsulation technique and wall material selected, the release mechanism can be triggered by different factors such as dissolution, temperature, pressure, $\mathrm{pH}$ and enzymes among others; and the release profile can also be modified to be immediate, delayed or sustained (Gaonkar et al., 2014). Finally, microcapsules are also capable to protect acid-sensitive ingredients, like probiotics or enzymes, during their pass through the highly acidic environment of the stomach, and to release them in the intestine, which has an alkaline pH (Anal \& Singh, 2007), (Cook, Tzortzis, Charalampopoulos, \& Khutoryanskiy, 2012).

Finally, as has just been reviewed, the implementation of professional solutions for mass market products, can help overcome different challenges, from technical issues like shelf-life, to consumer acceptance problems, like unpleasant taste or poor dissolution. Until now, technological advances were a business-tobusiness tool due to a lack of consumer understanding. However, consumers access to information is greater than ever, and soon they will become aware of the benefits of these techniques (Hamari et al., 2016). For this reason, technological solutions are going to be crucial to differentiate products from their competitors (PwC, 2013).

\section{Considerations on regulation}

Last but not least, the sports nutrition category is not only shaped by dietary recommendations and research, but also by regulations. Each country has its own regulation, which has an impact on the direction and growth of the sports nutrition industry. While some countries can select from a wide range of ingredients and claims, other countries may restrict or ban the same ones (R. J. Maughan, Greenhaff, \& Hespel, 2011).

The US and the European Union (EU), by their respective competent bodies, Food and Drug Administration (FDA) and European Food Safety Authority (EFSA), have its own composition and labelling requirements, which will be briefly reviewed below. It is important to remark that besides the benefits provided by supplements and sports food, safety remains the main priority (US Congress, 2011). When it comes to professional athletes competing under anti-doping codes, not only evidence and safety are important factors to consider, but also the absence of prohibited substances. For this reason, it is important to highlight 
a valuable information resource developed by the Australian Institute of Sport. It consists of an ABCD classification system that ranks those ingredients found in sports foods and supplements, into four groups. It is based on scientific evidence and other practical considerations to stablish product safety, legality and efficacy in improving sports performance (Australian Institute of Sport, 2018).

\section{- US regulation}

In US, according to the Dietary Supplement Health and Education Act, dietary supplements are defined as products taken by mouth, which are typically sold in the form of capsules, soft gels, liquids, powders and bars, and that contain one or more dietary ingredients intended to supplement the diet. Vitamins, minerals, herbs, botanical extracts, amino acids and other substances may be considered dietary ingredients. Products sold as dietary supplements must be clearly labeled as such. FDA monitors its manufacturing processes, quality and labelling, but it grants a greater control over supplements containing new dietary ingredients. A new dietary ingredient is a dietary ingredient that was not sold in the US before 1994. FDA requires specific safety information from manufacturers intending to market food supplements containing new dietary ingredients. Safety evidence, which may include in vitro and long-term toxicity studies, and clinical studies in humans, must be provided to FDA. When it comes to health and nutrient content claims, efficacy evidence must be submitted to FDA for approval. Authorities can act against companies who make false or misleading claims; and can also remove supplements from the market if they lack sufficient scientific evidence to demonstrate product safety. In addition, companies are now required to record all adverse event complaints about their products; and must report to FDA all those serious adverse events (United States Congress, 1994), (US Food and Drug Administration, 2018).

\section{- EU regulation}

As for the regulation in Europe, according to European Parliament Directive (2002/46/EC), food supplements are defined as products intended to supplement the normal diet, consisting of concentrated sources of nutrients, like minerals and vitamins, or other substances with a nutritional or physiological effect that are marketed in a "dosage" form (e.g. pills, tablets, capsules or liquids in measured doses). Food supplements are regulated as foods, and thereby may contain vitamins, minerals, amino acids, essential 
813 fatty acids, fiber and various plants and herbal extracts, among others. It has to be noted that the addition

814 of nutrients or other substances to fortify foods, does not fall within the definition of a food supplement, and

815 is addressed by a different regulation. Food supplements are intended to correct nutritional deficiencies,

816 maintain an adequate intake of certain nutrients, or support specific physiological functions. The

817 responsibility for the safety of these products lies with the food business operator placing the product on

818 the market (European Parliament, 2002).

819

In order to protect consumers against potential health risks, EFSA carried out a comprehensive assessment

821 of substances that could be intended for food supplements manufacture in the EU. Based on EFSA's work,

822 the European Commission established a harmonized list of substances that may be used in the

823 manufacture of food supplements, their tolerable upper intake levels, labelling requirements and approved

824 health claims (European Parliament, 2006b), (European Food Safety Authority, 2006), (European

825 Parliament, 2011), (European Parliament, 2006a). There is also a list of those substances that are known

826 or suspected to have adverse effects on health, and the use of which is therefore controlled. As for those

827 substances intended to be used in food supplements, and that do not have a history of safe use in the EU

828 before 1997, which are known as "novel foods", EFSA is requested to provide a scientific opinion on its

829 safety (European Parliament, 2015).

Finally, the EU register provides information on the permitted nutrition and health claims made on foods, and their conditions of use and applicable restrictions, as well as non-authorized health claims and the reason for their non-authorization (European Commission, 2018).

The World Anti-Doping Agency (WADA) is an international independent agency with scientific research,

837 education, development of anti-doping capacities, and monitoring of the world anti-doping code, as key

838 activities. Its mission is to lead a collaborative worldwide movement for doping-free sport, bringing consistency to anti-doping policies and regulations within sport organizations and governments across the 
841 is updated annually, is a cornerstone of the WADA. It lists substances prohibited at all times, just in842 competition or in particular sports. Some examples of prohibited substances are non-approved 843 pharmacological substances, anabolic agents, beta-2 agonists and diuretics, as well as masking agents. 844 Examples of prohibited methods are manipulation of blood, chemical manipulation of samples collected during doping control and gene doping (WADA, 2018b).

According to world anti-doping code, athletes are responsible for all products ingested and any subsequent legal, health or safety consequence (WADA, 2015). For this reason, they should pay special attention when choosing a supplement, since some of them have been reported to have an accidental or deliberate content of banned substances (R. Maughan, 2005). A research of stimulants and anabolic steroids in dietary supplements revealed that the number of mislabeled supplements represented $18 \%$ of the 103 products analyzed (Baume, Mahler, Kamber, Mangin, \& Saugy, 2006). For this reason, some manufacturers order commercial third-party auditing programs, as an independent screening for banned and restricted substances that could be accidentally found in their dietary supplements. These certifications provide a greater assurance of supplement purity for those athletes competing under antidoping codes (Bishop, 2010). Non-intentional doping poses a threat to athlete's career, since anti-doping rule violation, regardless it was intentional or unintentional, may result in bans of up to four years (WADA, 2015).

\section{Sports nutrition trends in brief}

860 In line with the healthy living global trend, as consumers are increasingly focusing on health and fitness 861 goals, different categories, like wearable devices, are growing. Sports nutrition is the fastest growing 862 consumer health category for several years in a row, and it is expected to continue growing at a steady 863 pace in the following years. An expanding and more diverse consumer base is boosting the demand for 864 sports nutrition, which has become a mainstream category. For this reason, products that were once only 865 available in dedicated fitness shops, have made their way to other retailers.

867 As for the sports nutrition king ingredient, proteins dominate global sales accounting for more than $83 \%$ of 
category, further growth is forecasted for the next five years. Among protein powders, whey isolate is the preferred source, due to its taste, amino acid composition and quick absorption. However, new formulations including different sources and treatments of proteins, are challenging whey protein isolate as king of sales. The main threats for whey protein isolate are a rising demand for plant-based proteins, and hydrolysates of different protein sources.

On contrast, non-protein products are more difficult to understand by the mainstream and uninformed consumers, and account for just $17 \%$ of total sports nutrition market. Despite not leading in sales, nonprotein products are way ahead of convenience formats experimentation. As for sports drinks, they are expected to record the highest growth rate in the following years. Electrolyte-replacement, glucosecontaining solutions help to maintain blood glucose levels and prevent dehydration, and therefore, may delay fatigue and attenuate muscle damage during endurance exercise. However, since there is an increasing demand for low-calorie and low-carbohydrate sports drinks, new products are mainly focused on optimizing hydration.

Besides global trends like clean labeling and personalization, which are impacting sports nutrition, other emerging trends to look out for in 2020 are nutrient timing, recovery gaining importance over rest, convenience packaging, and flavor as one of the main areas for innovation. Finally, offering professional solutions to mass market is key for disruptive innovation. Application of technologies such as microencapsulation in the sports nutrition field, would allow a broader use of certain ingredients with organoleptic or stability issues. In addition, preventing interactions, improving dissolution and achieving a sustained-release profile by means of microencapsulation, could also drive the sports nutrition category.

Last but not least, when it comes to the direction and growth of the sports nutrition industry, it is shaped by different factors. One of the most relevant but frequently forgotten factors is regulation, which can be different in each country. Competent authorities can restrict or ban ingredients to ensure safety and can also regulate to avoid false or misleading claims. Professional athletes who compete under anti-doping 
codes, may only consider certain manufacturers which provide a third-party certificate ensuring that no banned or restricted substance is present.

\section{Conclusion}

Global dynamics are shaping consumer attitudes and thereby, promoting changes across industries. Clean and healthy living stands out as the most relevant trend impacting the food industry. Consumers are making informed decisions to prioritize healthy, plant-based, sustainable and socially-conscious food purchases, a trend which is also affecting beverages, snacks, indulgence foods and even fast food. Aligned with this trend, governments are promoting healthy habits to reduce morbidity and cut off its associated costs. In this context, not only vegetarian and vegan product sales are growing quickly, but also organic and free-from products. In addition, since consumers prefer foods with an intrinsic nutritional value, functional foods have been outpaced by naturally healthy products.

Due to media praise and sports nutrition, a category where protein is the king of sales, consumers are increasingly looking for high-protein products. Carbohydrates, instead, have been targeted as a strategy to reduce overall calorie intake, resulting in a decreased popularity. However, the source matters, and "good carbs" are used instead of "bad carbs". In this line, as consumers increasingly avoid certain food ingredients, clean label products are no longer a trend, but the new norm. Nonetheless, the replacement of certain ingredients may set up costly and sometimes unnecessary challenges for food scientists. Other relevant trends shaping interaction with foods are personalization, loT, and food waste reduction. However, one of the main trends is sports nutrition, which is a large and quickly growing consumer health category.

Sports nutrition sales are no longer dominated by core users, instead, they have become more appealing to mainstream consumers, and as a result, sports foods have made their way to mainstream distribution channels. Proteins are leading the sports nutrition category, but whey protein isolate, which is the king of sales among protein powder products, is being challenged by the rise of high-protein foods and the rising demand for plant-based proteins. When it comes to protein processing methods, isolates are being replaced by hydrolysates, which are expected to be the next big trend among protein powders. As for non-protein 
924

925

926

927

928

929

930

931

932

933

934

935

936

937

938

939

940

941

942

943

944

945

946

947

948

949

950

951

products, despite experiencing a slower growth, they are leading the experimentation in convenience formats. Regarding new sports drinks products, they are mainly focused on optimizing hydration, and shifting from the so-called bad carbs to the good ones. As a consequence, there is a blurring line between energy/sports drinks, and other non-protein drinks or beverages.

Other trends to look out for in 2020 in the sports food industry are nutrient timing, personalization, recovery gaining importance over rest, and flavor as one of the most important areas for innovation. Different professional technologies can be applied to mass market products, as a driver for growth and competitive positioning. In this context, microencapsulation stands out as one of these technologies with a wide variety of applications and a promising future. Finally, besides innovation, dietary recommendations and research, the sports nutrition category is shaped by regulations; among which stand US and EU regulation, and World Anti-Doping Code.

To conclude, global dynamics have an influence on nutrition trends, being potentially disruptive for the correct balancing of the diet. However, as it has been reviewed, along with the healthy living trend, more people are adopting an active lifestyle, embracing a healthier dietary pattern and recognizing the benefits of sports foods, which is having positive implications in health, well-being and healthcare-associated costs. This review has also provided an overview of the areas that are more prone to development, and that should be added to the research agenda to adapt formulas and technologies to consumer needs.

\section{Acknowledgments}

This research was financially supported by the Industrial Doctorate Program of the Agency for Management of University and Research Grants (AGAUR), with the following grant number: 2015DI021.

\section{Author Contributions}

Conception, literature research and writing were performed by M. Arenas-Jal. Field experience, planning and critical review of the manuscript were performed by J.M. Suñé-Negre, P. Pérez-Lozano, and E. GarcíaMontoya. 
952

953 Abbreviations

954 AGAUR: Agency for Management of University and Research Grants

955 bn: billion

956 EFSA: European Food Safety Authority

957 EU: European Union

958 FDA: Food and Drug Administration

959 GMO: Genetically Modified Organism

960 loT: Internet of Things

961 mn: million

962 UK: United Kingdom

963 US: United States of America

964 WADA: World Anti-Doping Agency

965 WHO: World Health Organization 
966

967

968

969

970

971

972

973

974

975

976

977

978

979

980

981

982

983

984

985

986

987

988

989

990

991

992

993

\section{References}

Agarwal, S., Beausire, R. L. W., Patel, S., \& Patel, H. (2015). Innovative Uses of Milk Protein Concentrates in Product Development. Journal of Food Science, 80(S1), A23-A29. https://doi.org/10.1111/17503841.12807

American Dietetic Association, Dietitians of Canada, American College of Sports Medicine, Rodriguez, N. R., Di Marco, N. M., \& Langley, S. (2009). American College of Sports Medicine position stand. Nutrition and Athletic Performance. Medicine \& Science in Sports \& Exercise, 41(3), 709-731. https://doi.org/10.1249/MSS.0b013e31890eb86

Anal, A. K., \& Singh, H. (2007). Recent advances in microencapsulation of probiotics for industrial applications and targeted delivery. Trends in Food Science \& Technology, 18(5), 240-251. https://doi.org/10.1016/J.TIFS.2007.01.004

Antonio, J., Ellerbroek, A., Silver, T., Vargas, L., Tamayo, A., Buehn, R., \& Peacock, C. A. (2016). A High Protein Diet Has No Harmful Effects: A One-Year Crossover Study in Resistance-Trained Males. Journal of Nutrition and Metabolism, 2016, 9104792. https://doi.org/10.1155/2016/9104792

Asioli, D., Aschemann-Witzel, J., Caputo, V., Vecchio, R., Annunziata, A., Næs, T., \& Varela, P. (2017). Making sense of the "clean label" trends: A review of consumer food choice behavior and discussion of industry implications. Food Research International, 99, 58-71. https://doi.org/10.1016/J.FOODRES.2017.07.022

Australian Institute of Sport. (2018). ABCD Classification system for sports foods and supplements ingredients.

Baume, N., Mahler, N., Kamber, M., Mangin, P., \& Saugy, M. (2006). Research of stimulants and anabolic steroids in dietary supplements. Scandinavian Journal of Medicine and Science in Sports, 16(1), 4148. https://doi.org/10.1111/j.1600-0838.2005.00442.x

Bernstein, A., Titgemeier, B., Kirkpatrick, K., Golubic, M., Roizen, M., Bernstein, A. M., .. Roizen, M. F. (2013). Major Cereal Grain Fibers and Psyllium in Relation to Cardiovascular Health. Nutrients, 5(5), 1471-1487. https://doi.org/10.3390/nu5051471

Bigliardi, B., \& Galati, F. (2013). Innovation trends in the food industry: The case of functional foods. Trends in Food Science \& Technology, 31(2), 118-129. https://doi.org/10.1016/J.TIFS.2013.03.006 
994

995

996

997

998

999

1000

1001

1002

1003

1004

1005

1006

1007

1008

1009

1010

1011

1012

1013

1014

1015

1016

1017

1018

1019

1020

1021

Bishop, D. (2010). Dietary Supplements and Team-Sport Performance. Sports Medicine, 40(12), 9951017. https://doi.org/10.2165/11536870-000000000-00000

Bizozzero, J. (2017). 75\% of Consumers Will Pay Extra For Clean Label Ingredients. Food Insider Journal. Retrieved from https://www.foodinsiderjournal.com/clean-label/75-consumers-will-pay-extra-cleanlabel-ingredients

Bjørndal, T., Fernandez-Polanco, J., Lappo, A., \& Lem, A. (2013). Consumer trends and prefences in the demand for food. Retrieved from www.kopinor.no

Business Development Bank of Canada. (2016). Five Game-Changing Consumer Trends. Retrieved from https://www.bdc.ca/EN/Documents/analysis_research/Consumer_Trends_Report_EN.pdf

Calder, P. C. (2010). Omega-3 Fatty Acids and Inflammatory Processes. Nutrients, 2(3), 355-374. https://doi.org/10.3390/nu2030355

Cash, E. J. (2017). What's new for the European market of sports nutrition? Nutraingredients. Retrieved from https://www.nutraingredients.com/Article/2017/06/27/What-s-new-for-the-European-market-ofsports-nutrition\#

Chittock, M. (2013). Protein-enhanced food: the latest health craze. The Guardian. Retrieved from https://www.theguardian.com/lifeandstyle/wordofmouth/2013/sep/02/protein-enhanced-food-healthcraze

Cook, M. T., Tzortzis, G., Charalampopoulos, D., \& Khutoryanskiy, V. V. (2012). Microencapsulation of probiotics for gastrointestinal delivery. Journal of Controlled Release, 162(1), 56-67. https://doi.org/10.1016/J.JCONREL.2012.06.003

Daniells, S. (2018). 'Free-from is the most promising trend in LATAM': Euromonitor. Retrieved from https://www.foodnavigator-latam.com/Article/2018/06/14/Free-from-is-the-most-promising-trend-inLATAM-Euromonitor

Deloitte. (2013). The dawn of mobile influence. Discovering the value of mobile in retail. Retrieved from https://www2.deloitte.com/content/dam/Deloitte/uk/Documents/consumer-business/deloitte-uk-thedawn-of-mobile-influence-final.pdf

Dreher, M. L., \& Davenport, A. J. (2013). Hass Avocado Composition and Potential Health Effects. Critical $\begin{array}{llll}\text { Reviews in } \quad \text { Food } & \text { Science } & \text { 738-750. }\end{array}$ 
1022

1023

1024

1025

1026

1027

1028

1029

1030

1031

1032

1033

1034

1035

1036

1037

1038

1039

1040

1041

1042

1043

1044

1045

1046

1047

1048

1049

https://doi.org/10.1080/10408398.2011.556759

Edsor, B. (2017). Elite athletes who are vegan and what made them switch their diet. Business Insider. Retrieved from http://uk.businessinsider.com/elite-athletes-who-are-vegan-and-what-made-themswitch-their-diet-2017-10?IR=T/\#hannah-teter-snowboarder-7

Euromonitor, a market research provider. (2015a). Eco Worriers: Global Green Behaviour and Market Impact. Retrieved from https://www.euromonitor.com/eco-worriers-global-green-behaviour-andmarket-impact/report

Euromonitor, a market research provider. (2015b). Trends and Developments in Sports Nutrition. Retrieved from https://www.euromonitor.com/trends-and-developments-in-sports-nutrition/report

Euromonitor, a market research provider. (2016). Global Trends in Protein. Retrieved from https://www.euromonitor.com/global-trends-in-protein/report

Euromonitor, a market research provider. (2017a). Consumer Lifestyles in 2017: Global Survey Results. Retrieved from https://go.euromonitor.com/white-paper-survey-2017-lifestyles.html

Euromonitor, a market research provider. (2017b). "Free From” Food Movement: Driving Growth in Health and Wellness Space. Retrieved from https://www.euromonitor.com/-free-from-food-movementdriving-growth-in-health-and-wellness-space/report

Euromonitor, a market research provider. (2018). 8 Food Trends for 2018. Retrieved from https://www.euromonitor.com/8-food-trends-for-2018/report

Euromonitor International's Consumer Health Analyst, C. O. (2017). Sports Nutrition: Healthy Living and Fitness Trends Provide Great Prospects. Retrieved from https://blog.euromonitor.com/sportsnutrition-healthy-living-fitness-trends-provide-prospects/

Euromonitor International's Consumer Health Analyst, C. S. (2014). Trends in major sports nutrition markets and demographics - understanding the consumer market. In Bénéfiq. Quebec, Canada.

Euromonitor International's Consumer Health Analyst, L. G. (2016). New Lifestyles System Data: 2016 Global Consumer Trends Survey Results. Retrieved from https://blog.euromonitor.com/new-lifestylessystem-data-2016-global-consumer-trends-survey-results/

Euromonitor International's Consumer Health Analyst, M. M. (2018). New Health and Wellness Data: A Look into Latest Trends. Retrieved from https://blog.euromonitor.com/new-health-wellness-data-look- 
latest-trends/

1051

1052

1053

1054

1055

1056

1057

1058

1059

1060

1061

1062

1063

1064

1065

1066

1067

1068

1069

1070

1071

1072

1073

1074

1075

1076

1077

Euromonitor International's Head of Lifestyles Research, A. A. (2017). Top 10 Global Consumer Trends for 2018. Emerging forces shaping consumer behaviour. Retrieved from https://go.euromonitor.com/white-paper-economies-consumers-2018-global-consumer-trendsEN.html\#download-link

European Commission. (2018). EU Register of Nutrition and Health Claims. Retrieved from http://ec.europa.eu/food/safety/labelling_nutrition/claims/register/public/?event=register.home

European Food Safety Authority. (2006). Tolerable upper intake levels for vitamins and minerals. Retrieved from http://www.efsa.eu.int

European Parliament. (2002). Directive 2002/46/EC on the approximation of the laws of the Member States relating to food supplements. Retrieved from https://eur-lex.europa.eu/eli/dir/2002/46/oj

European Parliament. (2006a). Regulation (EC) No 1924/2006 on nutrition and health claims made on foods. Retrieved from https://eur-lex.europa.eu/legalcontent/EN/TXT/PDF/?uri=CELEX:02006R1924-20141213

European Parliament. (2006b). Regulation (EC) No 1925/2006 on the addition of vitamins and minerals and of certain other substances to foods. Retrieved from https://eur-lex.europa.eu/eli/reg/2006/1925/oj

European Parliament. (2011). Regulation (EU) No 1169/2011 on the provision of food information to consumers. Retrieved from https://eur-lex.europa.eu/eli/reg/2011/1169/oj

European Parliament. (2015). Regulation (EU) 2015/2283 on novel foods. Retrieved from https://eurlex.europa.eu/eli/reg/2015/2283/oj

European Specialist Sports Nutrition Alliance. (2018). Sports Nutrition. Retrieved November 13, 2018, from http://www.essna.com/sports-nutrition/

Ferguson, L. (2013). Nutrigenomics and Nutrigenetics in Functional Foods and Personalized Nutrition. CRC Press. https://doi.org/10.1201/b15369

FIBL and IFOAM, O. I. (2017). The world of organic agriculture - statistics and emerging trends 2017. (H. Willer \& J. Lernoud, Eds.). Bonn: IFOAM - Organics International. Retrieved from https://shop.fibl.org/CHde/mwdownloads/download/link/id/785/?ref=1

FitzGerald, R. J., \& O'Cuinn, G. (2006). Enzymatic debittering of food protein hydrolysates. Biotechnology 
1078

1079

1080

1081

1082

1083

1084

1085

1086

1087

1088

1089

1090

1091

1092

1093

1094

1095

1096

1097

1098

1099

1100

1101

1102

1103

1104

1105

Advances, 24(2), 234-237. https://doi.org/10.1016/J.BIOTECHADV.2005.11.002

Gallagher, E., Gormley, T. ., \& Arendt, E. . (2004). Recent advances in the formulation of gluten-free cerealbased products. Trends in Food Science \& Technology, 15(3-4), 143-152. https://doi.org/10.1016/J.TIFS.2003.09.012

Gaonkar, A. G., Vasisht, N., Khare, A. R., \& Sobel, R. (2014). Microencapsulation in the food industry: a practical implementation guide. Elsevier Science.

Gardiner, H. (2016). The Rise of the Personalized Nutrition Trend. Nutrition Insight. Retrieved from https://www.nutritioninsight.com/news/SPECIAL-REPORT-The-Rise-of-the-Personalized-NutritionTrend?frompage=Index\&tracking=Slider Menu\&NewTracking=SpecialReport

German, J. B., Zivkovic, A. M., Dallas, D. C., \& Smilowitz, J. T. (2011). Nutrigenomics and personalized diets: What will they mean for food? Annual Review of Food Science and Technology, 2, 97-123. https://doi.org/10.1146/annurev.food.102308.124147

Global Burden of Disease Study 2013 collaborators. (2015). Global, regional, and national incidence, prevalence, and years lived with disability for 301 acute and chronic diseases and injuries in 188 countries, 1990-2013: a systematic analysis for the Global Burden of Disease Study 2013. Lancet (London, England), 386(9995), 743-800. https://doi.org/10.1016/S0140-6736(15)60692-4

Gökmen, V., Mogol, B. A., Lumaga, R. B., Fogliano, V., Kaplun, Z., \& Shimoni, E. (2011). Development of functional bread containing nanoencapsulated omega-3 fatty acids. Journal of Food Engineering, 105(4), 585-591. https://doi.org/10.1016/J.JFOODENG.2011.03.021

Google Trends. (2018). Vegetarian and vegan search terms. Retrieved November 13, 2018, from https://trends.google.com/trends/explore?date=2012-01-01 2018-01-01\&q=vegetarian,vegan

Gubbi, J., Buyya, R., Marusic, S., \& Palaniswami, M. (2013). Internet of Things: A vision, architectural elements, and future directions. Future Generation Computer Systems, 29(7), 1645-1660. https://doi.org/10.1016/J.FUTURE.2013.01.010

Hamari, J., Sjöklint, M., \& Ukkonen, A. (2016). The sharing economy: Why people participate in collaborative consumption. Journal of the Association for Information Science and Technology, 67(9), 2047-2059. https://doi.org/10.1002/asi.23552

Hancox, D. (2018). The unstoppable rise of veganism: how a fringe movement went mainstream. The 
1106

1107

1108

1109

1110

1111

1112

1113

1114

1115

1116

1117

1118

1119

1120

1121

1122

1123

1124

1125

1126

1127

1128

1129

1130

1131

1132

1133

Guardian. Retrieved from https://www.theguardian.com/lifeandstyle/2018/apr/01/vegans-are-comingmillennials-health-climate-change-animal-welfare

Hoffman, J. R., \& Falvo, M. J. (2004). Protein - Which is Best? Journal of Sports Science \& Medicine, 3(3), 118-130. Retrieved from http://www.ncbi.nlm.nih.gov/pubmed/24482589

International Food Information Council Foundation. (2018). 2018 Food and health survey. Retrieved from https://www.foodinsight.org/2018-FHS-Report-FINAL.pdf

Kang, J., \& Hustvedt, G. (2014). Building Trust Between Consumers and Corporations: The Role of Consumer Perceptions of Transparency and Social Responsibility. Journal of Business Ethics, 125(2), 253-265. https://doi.org/10.1007/s10551-013-1916-7

Kearney, J. (2010). Food consumption trends and drivers. Philosophical Transactions of the Royal Society of London. Series B, Biological Sciences, 365(1554), 2793-2807. https://doi.org/10.1098/rstb.2010.0149

Kerksick, C., Harvey, T., Stout, J., Campbell, B., Wilborn, C., Kreider, R., ... Antonio, J. (2008). International Society of Sports Nutrition position stand: Nutrient timing. Journal of the International Society of Sports Nutrition, 5(1), 17. https://doi.org/10.1186/1550-2783-5-17

Kerry Health And Nutrition Institute. (2018). Ten Key Health and Nutrition Trends 2018. Retrieved November 13, 2018, from https://khni.kerry.com/trends-and-insights/ten-key-health-and-nutritiontrends-2018/

Labrecque, L. I., vor dem Esche, J., Mathwick, C., \& Novak, T. P. (2013). Consumer Power: Evolution in the Digital Age. Journal of Interactive Marketing, 27(4), 257-269. https://doi.org/10.1016/J.INTMAR.2013.09.002

Lamacchia, C., Camarca, A., Picascia, S., Di Luccia, A., Gianfrani, C., Lamacchia, C., ... Gianfrani, C. (2014). Cereal-Based Gluten-Free Food: How to Reconcile Nutritional and Technological Properties of Wheat Proteins with Safety for Celiac Disease Patients. Nutrients, 6(2), 575-590. https://doi.org/10.3390/nu6020575

Lemus-Mondaca, R., Vega-Gálvez, A., Zura-Bravo, L., \& Ah-Hen, K. (2012). Stevia rebaudiana Bertoni, source of a high-potency natural sweetener: A comprehensive review on the biochemical, nutritional and functional aspects. Food Chemistry, 132(3), 1121-1132. 
1135 Liu, X., Jiang, D., \& Peterson, D. G. (2014). Identification of Bitter Peptides in Whey Protein Hydrolysate. 1136 Journal of Agricultural and Food Chemistry, 62(25), 5719-5725. https://doi.org/10.1021/jf4019728

1137 Lucca, P. A., \& Tepper, B. J. (1994). Fat replacers and the functionality of fat in foods. Trends in Food 1138 Science \& Technology, 5(1), 12-19. https://doi.org/10.1016/0924-2244(94)90043-4

1139 Lynch, H., Wharton, C., Johnston, C., Lynch, H. M., Wharton, C. M., \& Johnston, C. S. (2016). 1140 Cardiorespiratory Fitness and Peak Torque Differences between Vegetarian and Omnivore 1141 Endurance Athletes: A Cross-Sectional Study. Nutrients, 8(11), 726. https://doi.org/10.3390/nu8110726

1143 Mangano, K. M., Sahni, S., Kiel, D. P., Tucker, K. L., Dufour, A. B., \& Hannan, M. T. (2017). Dietary protein 1144 is associated with musculoskeletal health independently of dietary pattern: the Framingham Third 1145 Generation Study. The American Journal of Clinical Nutrition, 105(3), 714-722. https://doi.org/10.3945/ajcn.116.136762

1148

Manninen, A. H. (2009). Protein hydrolysates in sports nutrition. Nutrition \& Metabolism, 6(1), 38.

1149

1150

1151

1152

1153

1154

1155

1156

1157

1158

1159

1160

1161 https://doi.org/10.1186/1743-7075-6-38

Mateo, A. (2018). Recovery Is the Latest Workout Trend. The Cut. Retrieved from https://www.thecut.com/2018/05/recovery-is-the-latest-workout-trend.html

Maughan, R. (2005). Contamination of dietary supplements and positive drug tests in sport. Journal of Sports Sciences, 23(9), 883-889. https://doi.org/10.1080/02640410400023258

Maughan, R. J., Greenhaff, P. L., \& Hespel, P. (2011). Dietary supplements for athletes: Emerging trends and recurring themes. Journal of Sports Sciences, 29(sup1), S57-S66. https://doi.org/10.1080/02640414.2011.587446

Maughan, R. J., \& Shirreffs, S. M. (2012). Nutrition for sports performance: issues and opportunities. Proceedings of the Nutrition Society, 71(01), 112-119. https://doi.org/10.1017/S0029665111003211

McCarthy, B., \& Liu, H. B. (2017). Food waste and the 'green' consumer. Australasian Marketing Journal (AMJ), 25(2), 126-132. https://doi.org/10.1016/J.AUSMJ.2017.04.007

Meltzer, M. (2018). How to Recover Like an Elite Athlete. The New York TImes. Retrieved from https://www.nytimes.com/2018/07/09/style/fitness-workout-recovery.html 
1162 Melzer, K. (2011). Carbohydrate and fat utilization during rest and physical activity. European E-Journal of Clinical Nutrition and Metabolism. https://doi.org/10.1016/j.eclnm.2011.01.005

1164

1165

1166

1167

1168

1169

1170

1171

1172

1173

1174

1175

1176

1177

1178

1179

1180

1181

1182

1183

1184

1185

1186

1187

1188

1189

Menzies, P., Menzies, C., Mclntyre, L., Paterson, P., Wilson, J., \& Kemi, O. J. (2010). Blood lactate clearance during active recovery after an intense running bout depends on the intensity of the active recovery. Journal of Sports Sciences, $28(9), \quad 975-982$. https://doi.org/10.1080/02640414.2010.481721

Mintel. (2016). Free-from gains momentum: Sales of free-from food products forecast to surpass half a billion in the UK in 2016. Retrieved from http://www.mintel.com/press-centre/food-and-drink/free-fromgains-momentum-sales-of-free-from-food-products-forecast-to-surpass-half-a-billion-in-the-uk-in2016

Mitchell, A. K. (2016). Why Strong Is the New Skinny and Why That's a Good Thing. Retrieved November 13, 2018, from https://www.huffpost.com/entry/why-strong-is-the-new-skinny-and-why-thats-a-goodthing_b_8467376

Mohammadi, N., Ehsani, M. R., \& Bakhoda, H. (2018). Development of caffeine-encapsulated alginatebased matrix combined with different natural biopolymers, and evaluation of release in simulated mouth conditions. Flavour and Fragrance Journal, 33(5), 357-366. https://doi.org/10.1002/ffj.3452

Mordor Intelligence. (2018). Sports Nutrition Market: Growth, Trends and Forecasts (2018-2023). Retrieved from https://www.mordorintelligence.com/industry-reports/sports-nutrition-market

Mutch, D. M., Wahli, W., \& Williamson, G. (2005). Nutrigenomics and nutrigenetics: the emerging faces of nutrition. The FASEB Journal, 19(12), 1602-1616. https://doi.org/10.1096/fj.05-3911rev

Nutraingredients. (2016). Personalized nutrition: The path from niche service to mass appeal. Retrieved from https://www.nutraingredients-usa.com/News/Promotional-Features/Personalized-nutrition-Thepath-from-niche-service-to-mass-appeal

Othman, R. A., Moghadasian, M. H., \& Jones, P. J. (2011). Cholesterol-lowering effects of oat $\beta$-glucan. Nutrition Reviews, 69(6), 299-309. https://doi.org/10.1111/j.1753-4887.2011.00401.x

Overview of Food Fortification in the United States and Canada. (2003). In Dietary reference intakes: Guiding principles for nutrition labelling and fortification. National Academies Press (US). Retrieved from https://www.ncbi.nlm.nih.gov/books/NBK208880/ 
1190

1191

1192

1193

1194

1195

1196

1197

1198

1199

1200

1201

1202

1203

1204

1205

1206

1207

1208

1209

1210

1211

1212

1213

1214

1215 The Economist. (2013). The rise of the sharing economy. Retrieved from

1216

1217

Owen, R. W., Giacosa, A., Hull, W. E., Haubner, R., Würtele, G., Spiegelhalder, B., \& Bartsch, H. (2000). Olive-oil consumption and health: the possible role of antioxidants. The Lancet Oncology, 1(2), 107112. https://doi.org/10.1016/S1470-2045(00)00015-2

Patel, S. (2015). Functional food relevance of whey protein: A review of recent findings and scopes ahead. Journal of Functional Foods, 19, 308-319. https://doi.org/10.1016/J.JFF.2015.09.040

Peters, J. (2018). What nutrition trends can we expect to see in 2018? That Sugar Movement. Retrieved from https://thatsugarmovement.com/what-nutrition-trends-can-we-expect-to-see-in-2018/

Pimparade, M. B., Morott, J. T., Park, J.-B., Kulkarni, V. I., Majumdar, S., Murthy, S. N., ... Repka, M. A. (2015). Development of taste masked caffeine citrate formulations utilizing hot melt extrusion technology and in vitro-in vivo evaluations. International Journal of Pharmaceutics, 487(1-2), 167176. https://doi.org/10.1016/j.ijpharm.2015.04.030

PriceWaterhouseCoopers. (2013). Breakthrough innovation and growth. Retrieved from www.pwc.com/innovationsurvey

Radnitz, C., Beezhold, B., \& DiMatteo, J. (2015). Investigation of lifestyle choices of individuals following a vegan diet for health and ethical reasons. Appetite, 90, 31-36. https://doi.org/10.1016/J.APPET.2015.02.026

Sahota, A. (2012). The Global Market for Organic Food and Drink. In Sustainable Foods Summit. Amsterdam, Netherlands. Retrieved from www.organicmonitor.com

Sénate Français. (2016). Proposition de loi relative à la lutte contre le gaspillage alimentaire. Retrieved from http://www.senat.fr/leg/tas15-080.html

Spano, M., \& Antonio, J. (2008). Future Trends: Nutritional Supplements in Sports and Exercise. In Nutritional Supplements in Sports and Exercise (pp. 491-508). Totowa, NJ: Humana Press. https://doi.org/10.1007/978-1-59745-231-1_14

Subbiah, M. T. R. (2007). Nutrigenetics and nutraceuticals: the next wave riding on personalized medicine. Translational Research, 149(2), 55-61. https://doi.org/10.1016/J.TRSL.2006.09.003 https://www.economist.com/leaders/2013/03/09/the-rise-of-the-sharing-economy

The Nielsen Company. (2016). What's in our food and on our mind: Ingredients and dining-out trends 
around the world. Retrieved from https://www.nielsen.com/content/dam/nielsenglobal/kr/docs/globalreport/2016/global_ingredient_and_0ut_of_home_dining_trends_report.pdf

The Nielsen Company. (2017). US Homescan Panel Protein Survey.

1221 The Nielsen Company. (2018a). Fad or Fundamental? What's Next for Health and Wellness in 2018. Retrieved from https://www.nielsen.com/us/en/insights/news/2018/fad-or-fundamental-whats-nextfor-health-wellness-in-2018.html

The Nielsen Company. (2018b). Plant-Based Food Options Are Sprouting Growth for Retailers. Retrieved

The Vegan Society. from https://www.nielsen.com/us/en/insights/news/2018/plant-based-food-options-are-sproutinghttps://www.vegansociety.com/news/media/statistics

United States Congress. (1994). Dietary Supplement Health and Education Act of 1994. Retrieved from https://www.gpo.gov/fdsys/pkg/PLAW-111publ353/pdf/PLAW-111publ353.pdf

US Food and Drug Administration. (2018). Dietary Supplements. Retrieved November 13, 2018, from https://www.fda.gov/Food/DietarySupplements/default.htm

Vegetarian Resource Group. (2016). Harris Poll. Vegetarian Journal, (4). Retrieved from https://www.vrg.org/journal/vj2016issue4/2016_issue4_harris_poll.php

Venderley, A. M., \& Campbell, W. W. (2006). Vegetarian diets: nutritional considerations for athletes. Sports Medicine, 36(4), 293-305. https://doi.org/10.2165/00007256-200636040-00002

Wind, J., \& Rangaswamy, A. (2001). Customerization: The next revolution in mass customization. Journal of Interactive Marketing, 15(1), 13-32. https://doi.org/10.1002/1520-6653(200124)15:1<13::AIDDIR1001>3.0.CO;2-\# 
1246 World Anti-Doping Agency. (2018a). Prohibited List. Retrieved from https://www.wada-ama.org

1247 World Anti-Doping Agency. (2018b). Retrieved November 13, 2018, from https://www.wada-

$1248 \quad$ ama.org/en/resources/science-medicine/prohibited-list-documents

1249 World Health Organization. (2015a). Active ageing: a policy framework. Retrieved from $1250 \quad$ https://www.who.int/ageing/publications/active_ageing/en/

1251 World Health Organization. (2015b). World report on Ageing And Health. Retrieved from www.who.int

1252 World Health Organization. (2018). Guidelines on food fortification with micronutrients. World Health 1253 Organization.

1254 Yazici, F., Alvarez, V. B., Mangino, M. E., \& Hansen, P. M. T. (1997). Formulation and Processing of a Heat 1255 Stable Calcium-fortified Soy Milk. Journal of Food Science, 62(3), 535-538. 1256 https://doi.org/10.1111/j.1365-2621.1997.tb04424.x

1257 Zimberoff, L. (2017). Sports Drink Makers Are Waging an \$8 Billion Thirst War. Bloomberg. Retrieved from $1258 \quad$ https://www.bloomberg.com/features/2017-sports-drinks-wars/ 


\section{Google trends analysis (2012-2018)}

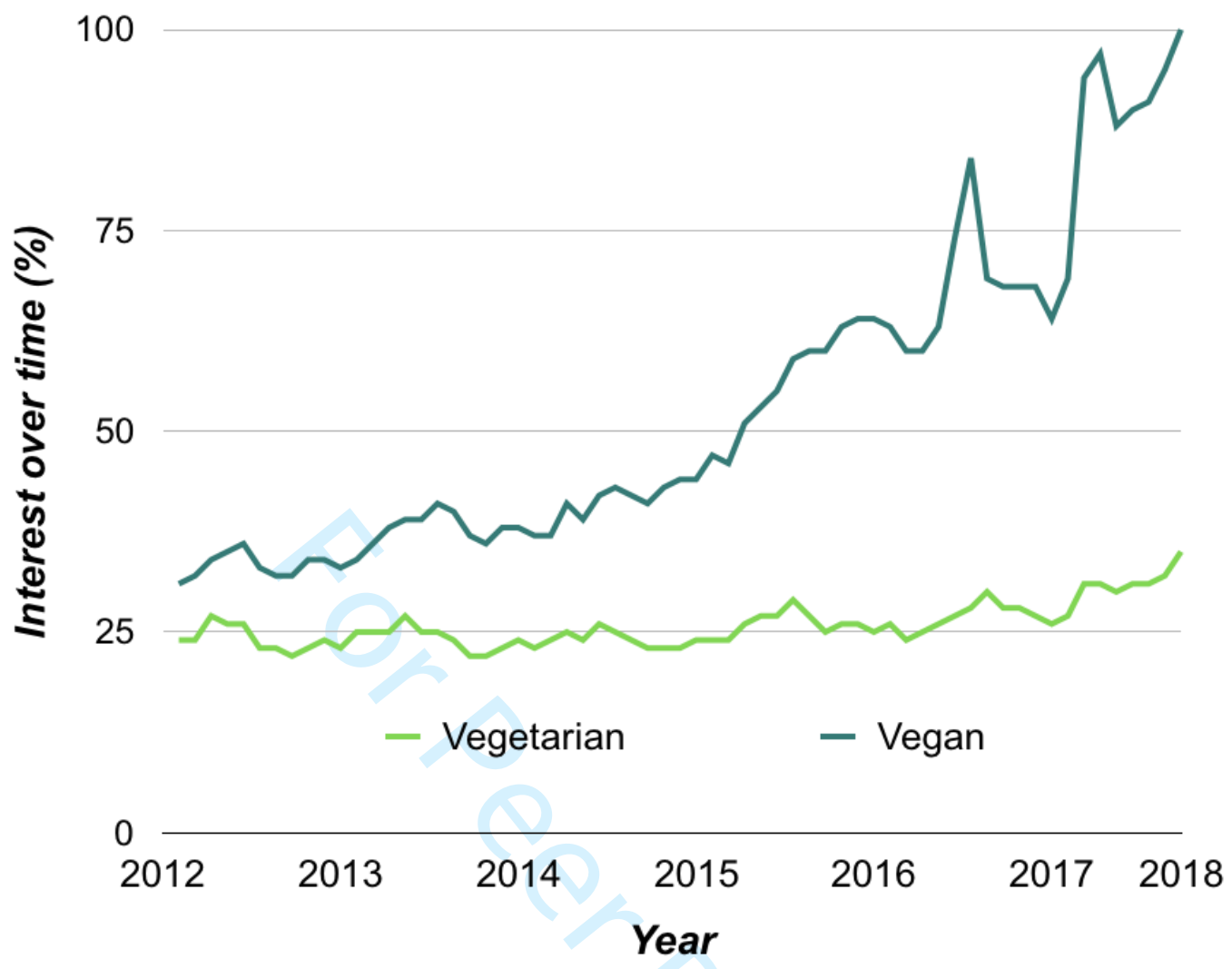




\section{Consumers' 5 primary sources of protein (2017)}

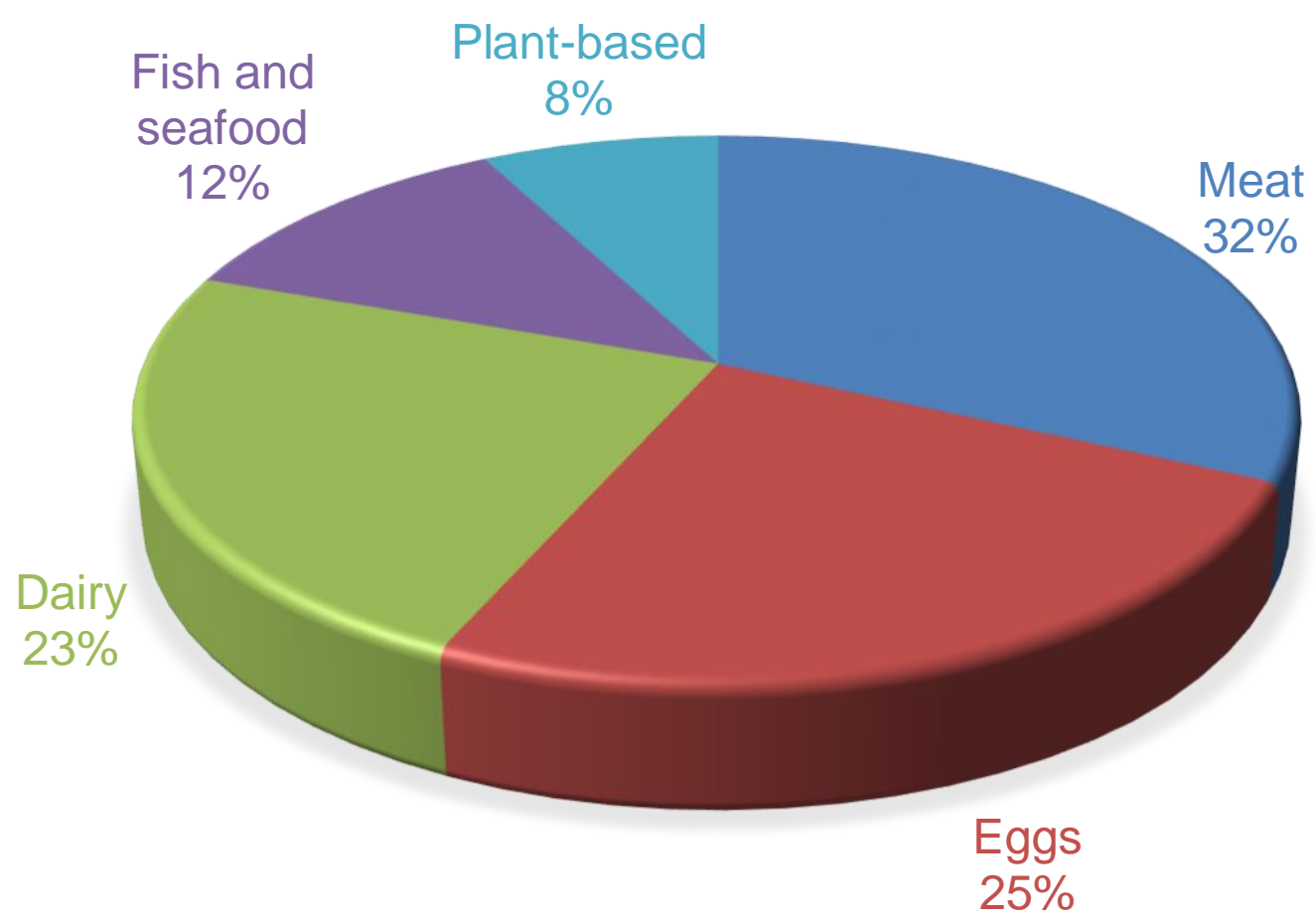

Figure 2. Top five protein sources via consumer survey (The Nielsen Company, 2017). 


\title{
Global sales in selected health categories (2017)
}

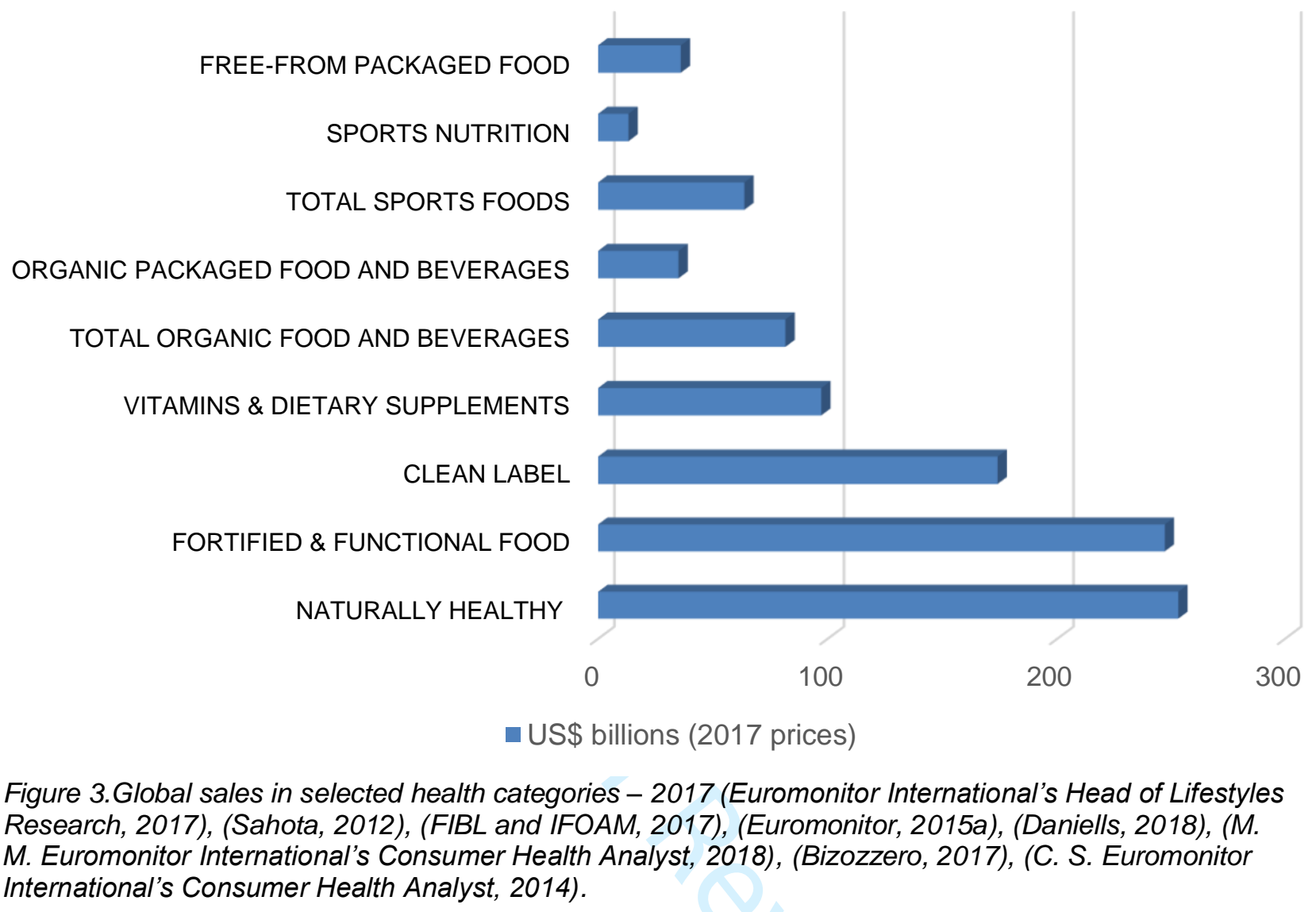

1264

1265

1266

1267

1268

\begin{abstract}
International's Consumer Health Analyst, 2014).
\end{abstract}




\section{Global sports foods sales by categories (2016)}

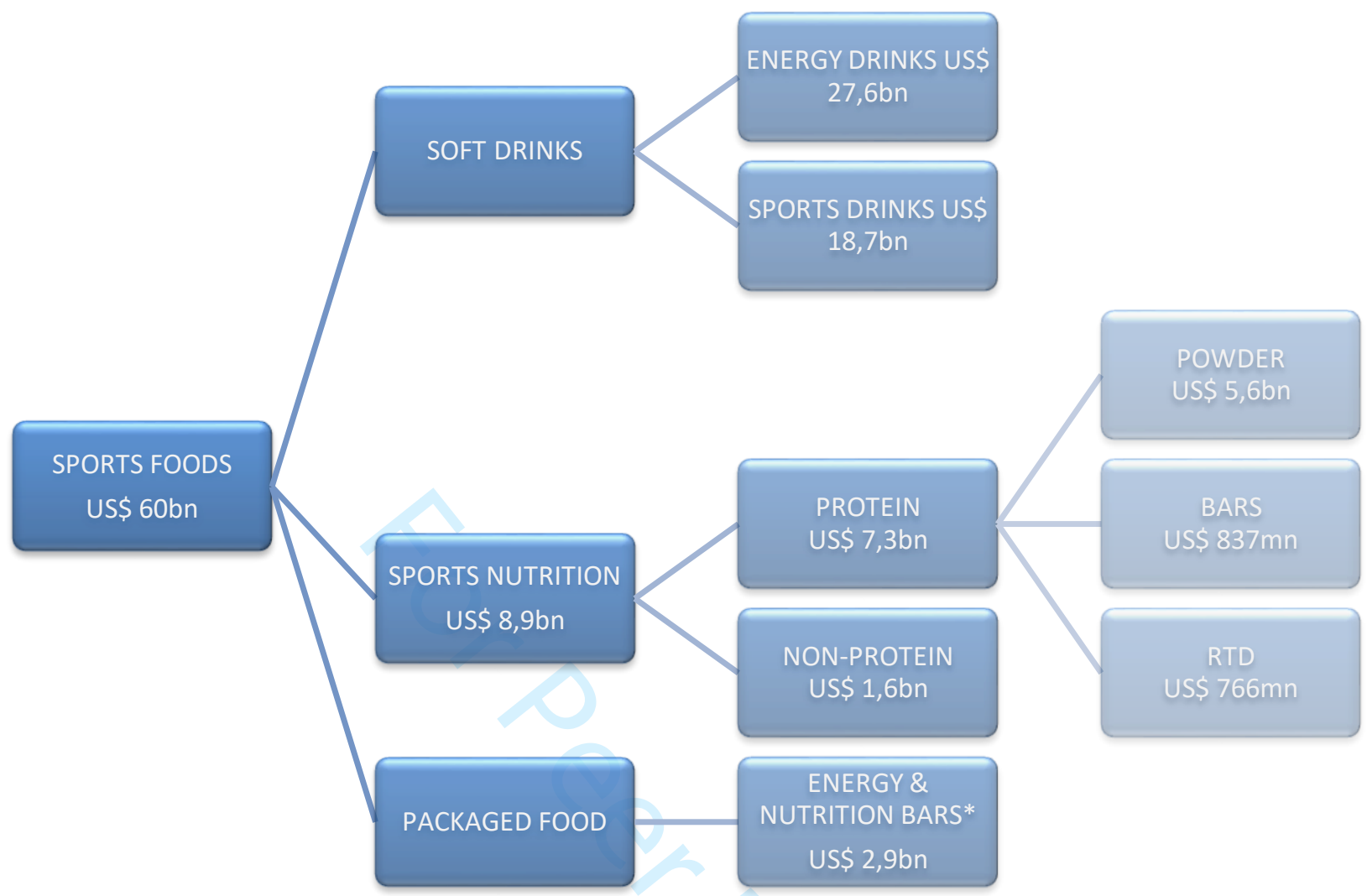

Figure 4.Global sports foods sales by categories (global retail value, US\$ bn, constant 2013 prices). (C. S. Euromonitor International's Consumer Health Analyst, 2014), (Euromonitor, 2015b), (Euromonitor, 2016). * Excluding sports nutrition protein bars. 